\author{
Universidade de São Paulo \\ Instituto de Física
}

\title{
Caracterização de Plasmons de Superfície em filmes de metais nobres através de tunelamento ótico
}

\section{Fábio Lombardi Maximino}

Orientador: Prof. Dr. Antonio Domingues dos Santos

Dissertação de mestrado apresentada ao Instituto de Física para a obtenção do título de Mestre em Ciências

Comissão examinadora:

Prof. Dr. Antonio Domingues dos Santos - IF-USP

Prof. Dr. Cid Bartolomeu de Araújo - UFPE

Prof. Dr. Koiti Araki - IQ-USP 
Dedica este trabalha a meu Mestre Dr. Celsa Charuri (in memariam) 


\section{Agradecimentos}

Gostaria de agradecer ao meu orientador Toninho pela parceria criada, por me mostrar o sentido da palavra orientar. Sou muito grato por tudo;

Ao Prof. Paulo Costa, grande amigo, que sempre esteve disposto a me ajudar em qualquer problema;

À Profa. Lucy e Profa. Marcia pelos almoços divertidos e tantas vezes esclarecedores;

Ao Sergio, Marcelo, Paulo, Renato por muitas ajudas com os equipamentos do Laboratório;

Ao pessoal do LSI e do LAMFI pelo tempo gasto com algumas medidas deste trabalho.

À Mariana, Divino, Gilderlon e Jeferson pelo companheirismo demonstrado nestes anos;

Ao Gabriel, grande amigo, que aturou todas as brincadeiras e momentos de raivas possíveis;

À CNPq pelo apoio financeiro;

Um especial agradecimento em nome de meu orientador Toninho ao Dr. Yves Souche pelas inúmeras discussões sobre o tema deste trabalho. Ele foi o primeiro idealizador deste projeto;

A todos meus AMIGOS que lutam pelos mesmos OBJETIVOS, obrigado a todos por sempre me lembrarem o CAMINHO;

A Juliana que além de namorada, é uma ótima companheira que dividiu estes anos comigo e têm tantos outros ainda a dividir.

A minha família (Valter, Rita, Nádia, Daniel, Paola e Juliana) por estarem sempre ao meu lado, mesmo nas situações mais adversas. Vocês foram por muitas vezes os braços que me carregavam. Obrigado por me ajudarem nesta caminhada;

Obrigado ao meu Mestre por ter me mostrado o CAMINHO e ter me ensinado o verdadeiro sentido da VIDA. Meu ETERNO agradecimento a você! 


\section{Resumo}

Os metais nobres são admirados desde as culturas mais antigas por sua capacidade de refletir a luz. Com os desenvolvimentos na área da nanotecnologia se pode entender um pouco mais sobre a interação entre a luz e estes metais. Devido a esta interação foi criada a Plasmônica e a partir dela começaram os estudos acerca dos plasmons de superfície (SP). Estes estudos vêem gerando inúmeros desenvolvimentos nas pesquisas de gravação magneto-ótica, microscopia, detectores moleculares biológicos entre outras. Como os SPs são ondas evanescentes, eles precisam ser observados em campo próximo. Com o intuito de observar e compreender a propagação destes SPs foi utilizado um microscópio ótico de varredura em campo próximo (SNOM). Para isto, o SNOM foi adaptado para operar em modo de transmissão.

A sonda do SNOM serviu de coletora de luz para que a partir de imagens óticas em amostras de $\mathrm{Ag}$ e $\mathrm{Au}$ pudéssemos caracterizar a propagação destes SPs na superfície do material e também a sua dependência com a distância de detecção. Os resultados mostraram que a propagação do SP é maior que $70 \mu \mathrm{m}$ e a intensidade do SP na superfície do metal depende fortemente da rugosidade da amostra e de possíveis defeitos. Foi possível ainda estimar a que distância a partir da superfície da amostra, em que o SP decai para 1/e. Este resultado está de acordo com o esperado teoricamente, que prevê para a distância de propagação do SP, o valor de 420nm. Através do SP ainda foi possível analisar defeitos existentes na amostra. E pelas imagens topográficas do SNOM também foi possível observar os grãos de Ag e Au da amostra.

Em posse destes resultados pudemos concluir que o SNOM é uma ótima ferramenta para a análise dos plasmons de superfície. 


\begin{abstract}
The noble metals are largely admired since ancient cultures because of its capability to reflect light. With the development of nanotechnology it is possible now to understand the interaction between these metals and light. Due to this strong interaction, the Plasmonic area was created and the studies on Surface Plasmons(SP) started. These studies are responsible for important new developments in magneto-optical recording, new optical microscopy apparatus, molecular biological sensors, among others. As SPs are evanescent waves, they need to be observed in near-field optics. For the observation and study of the propagation of these SPs a scanning near-field optical microscope (SNOM) was used.
\end{abstract}

The SNOM's probe was used in collection mode so that we could characterize the propagation of SPs in the material surface and the dependence with the distance of detection in air, for thin films of $\mathrm{Ag}$ and $\mathrm{Au}$. The results showed that the propagation of the SP inside the metallic film is beyon $70 \mu \mathrm{m}$. And the SP's intensity in the metal surface is strongly dependent on the roughness of the sample. It was also possible to estimate the distance from the sample's surface the SP decay to 1/e. Our measurements agree to the theoretical calculation of $420 \mathrm{~nm}$ for this distance. The SP made it possible to analyze existing defects on the sample. Furthermore, with the SNOM topographical images it was also possible to observe the grains of the policrystalline $\mathrm{Ag}$ and Au samples.

From these results we could conclude that the SNOM is a very useful tool for the analysis of surface plasmons in thin films. 


\section{Sumário}

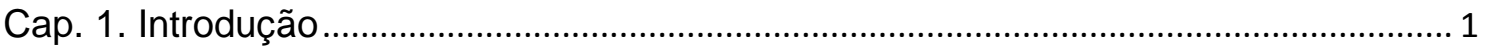

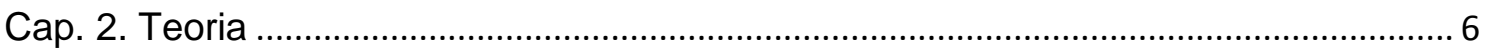

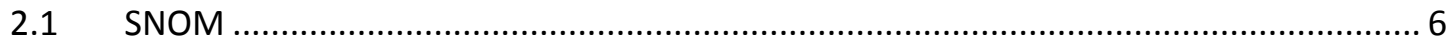

2.1.1 Critério de Rayleigh e a ótica em campo próximo ............................................. 7

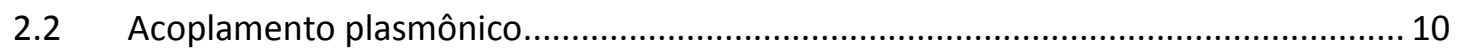

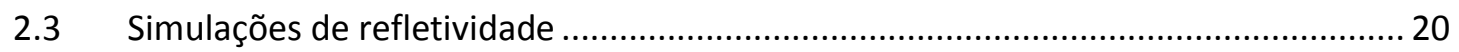

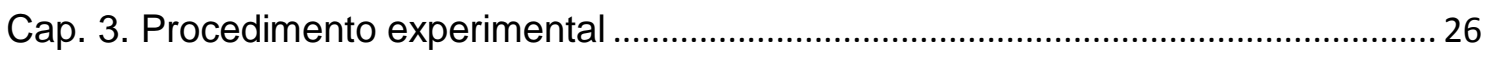

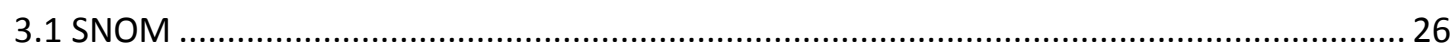

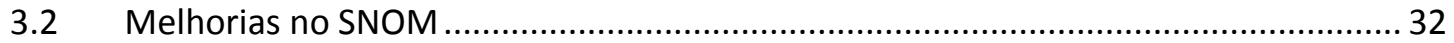

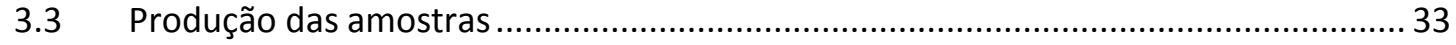

3.4 Porta-amostra para o modo PSTM do SNOM …….................................................... 35

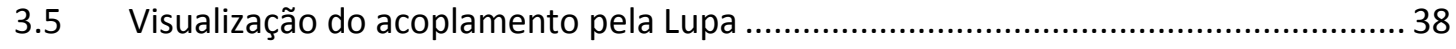

3.6 Observação do plasmon de superfície pelo SNOM ....................................................... 40

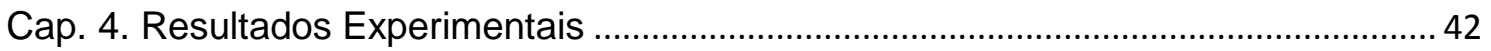

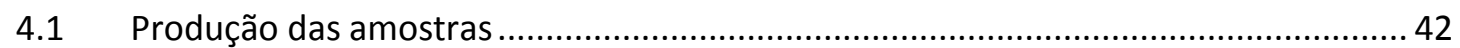

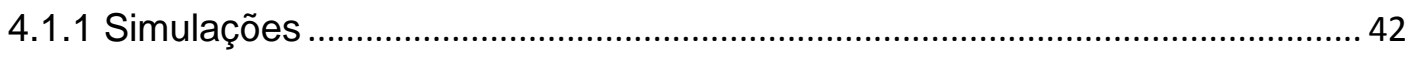

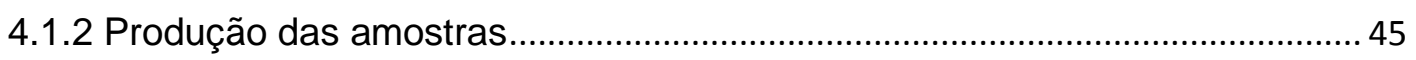

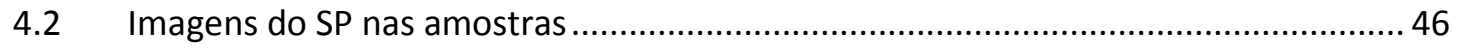

4.3 Estudos dos grãos de prata e ouro............................................................................. 55

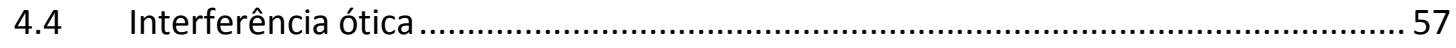

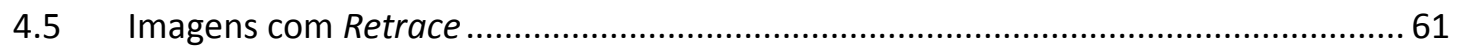

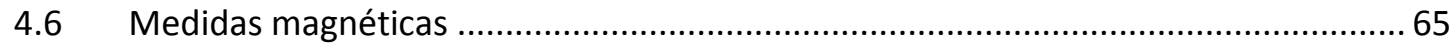

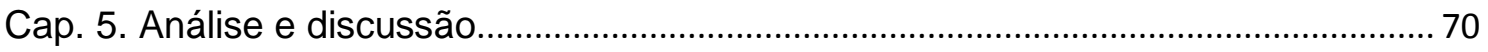

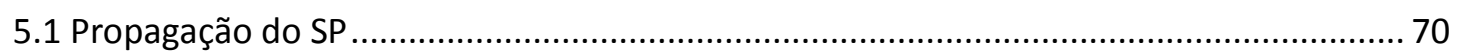

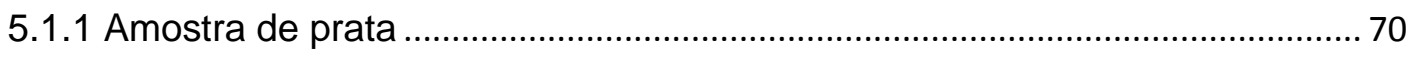

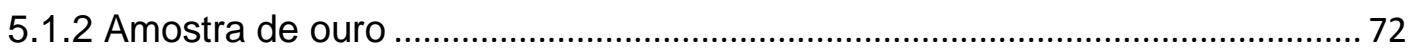

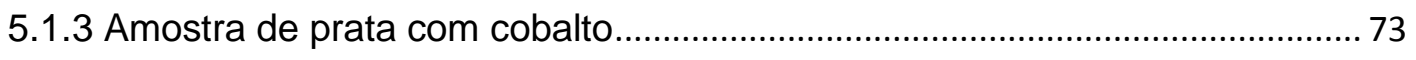

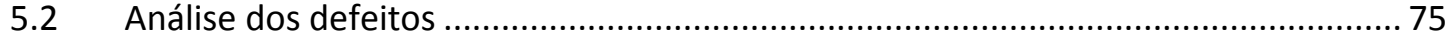

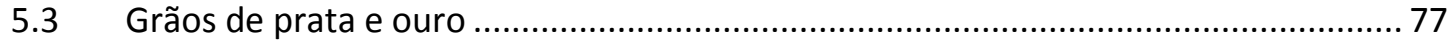

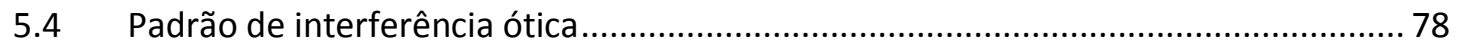

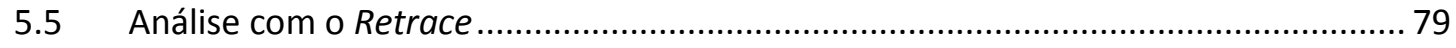

5.6 Distância de propagação ...................................................................................... 84

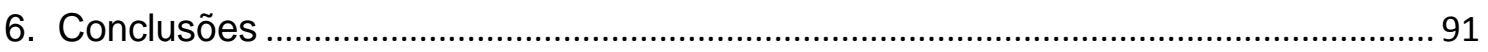


7. Perspectivas futuras .

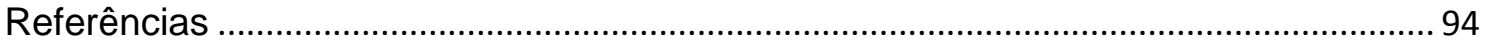

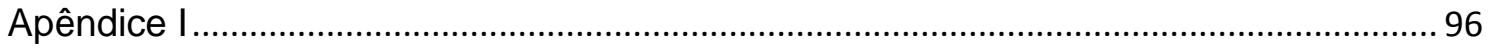




\section{Cap. 1. Introdução}

Com o crescente número das pesquisas em nanociências e nanotecnologia surgiram muitas novas áreas dentro deste grande campo, com algumas destas pesquisas visando o melhor entendendimento da interação da luz com nanopartículas e filmes finos. A partir destas pesquisas surgiu a área da plasmônica. Esta área se tornou totalmente inovadora quando começaram os estudos sobre a interação da luz com os metais nobres. Nestes estudos perceberam que os metais nobres quando excitados por uma onda de comprimento de onda específico apresentava a possibilidade de excitar uma onda evanescente que percorria sua superfície. Esta onda evanescente recebeu o nome de plasmon de superfície.

A palavra Plasmon veio da língua inglesa para representar a quantidade da oscilação do plasma ("quantum of plasma oscillation"). Os plasmons de superfície foram primeiramente notados por Michel Faraday no ano de 1857 quando ele percebeu que apesar do ouro ser amarelo, uma solução de nanopartículas de ouro apresentava a cor vermelhaesta cor variava com a dimensão das partículas do ouro. A explicação para este fato somente veio com a implementação das equações de Maxwell e em 1908 quando Gustav Mie encontrou a solução analítica para as equações de uma esfera de tamanho arbitrário, onde se pode entender porque partículas de tamanhos diferentes e de mesmo material forneciam cores diferentes, como visto por Faraday. A solução de Mie fez com que entendêssemos um pouco mais sobre a interação da luz com metais em escala nanométrica. $O$ estudo desta interação deu origem ao que hoje é chamado de plasmônica.

Plasmônica é uma das áreas da Fotônica que estuda como o campo eletromagnético pode ser confinado em dimensões de mesmos tamanhos ou menores que o comprimento de onda. O componente importante da plasmônica é o metal, pois este suporta modos de propagação de plasmons de superfície (ou Surface Plasmons, SP). Plasmons de superfície resultam do acoplamento entre a onda eletromagnética e a oscilação coletiva dos elétrons livres (ou de condução) de um metal. Quando esta oscilação é otimizada, ou seja, são escolhidos parâmetros para que ela atinja a condição 
de ressonância, chamamos este tipo de oscilação de ressonância de plasmons de superfície (Surface Plasmons Resonance, SPR).

Existem dois tipos de SPs: o primeiro é obtido quando a onda eletromagnética incide em filmes metálicos e ela fica confinada na superfície deste filme, este SP é chamado de "Surface Plasmon Polariton" (SPP). O segundo é obtido quando o acoplamento é feito com uma nanopartícula metálica com diâmetro muito menor que o comprimento de onda incidente; este é chamado de "Localized Surface Plasmon" (LSP) (Maier, 2007). Ambos os casos aceitam a condição de ressonância sendo classificados como SPPR e LSPR respectivamente. Na figura 1.1 vemos uma representação destes dois tipos de acoplamento plasmônico (Rycenga, et al., 2011).

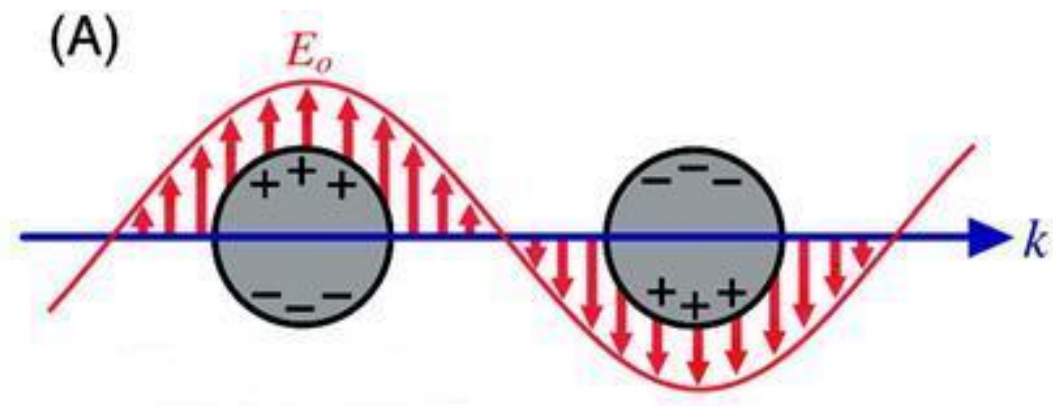

(B)

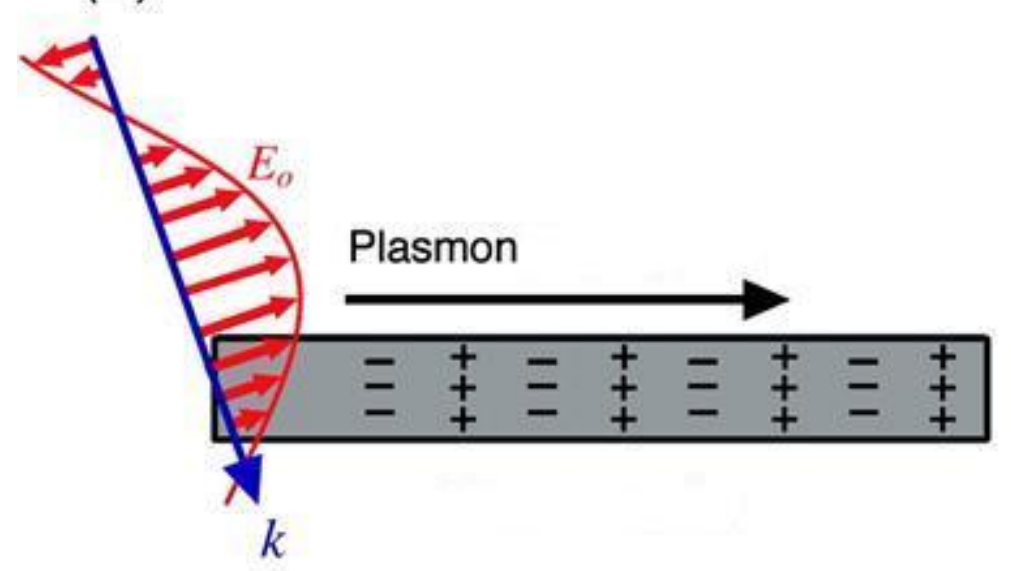

Figura 1.1 Esquema de acoplamento com o material usado. (A) LSPR- acoplamento com nanoesferas metálicas de tamanho menor que o comprimento de onda da luz. (B) SPPR- acoplamento do $k$ da onda incidente com o filme metálico.

Assim como Mie foi de essencial importância para o estudo de plasmons de superfície em nanoparticulas, R.H. Ritchie (Ritchie, 1957) foi quem introduziu o termo SPP em filmes finos metálicos na década de 50 . Os 
metais tipicamente utilizados são $\mathrm{Au}, \mathrm{Ag}$ e $\mathrm{Cu}$, porém qualquer metal serviria para gerar SP, contanto que tenham a parte real da constante dielétrica grande e negativa e a parte imaginária pequena e positiva. Como estas duas características da constante dielétrica são encontradas nos metais nobres, eles se tornam uma ótima escolha. Além disto, estes metais nobres são utilizados, pois sua ressonância ocorre em comprimentos de onda dentro do espectro visível. No gráfico visto na figura 1.2 vemos as curvas da constante dielétrica da Ag, Au e Co (Johnson, et al., 1972) (Johnson, et al., 1974) que explicitam o fato da parte real ser negativa e grande e da parte imaginária em alguns casos, ser positiva e pequena. Em preto vemos os dados para a prata, em vermelho vemos os dados para o ouro e em verde vemos os dados para o cobalto.

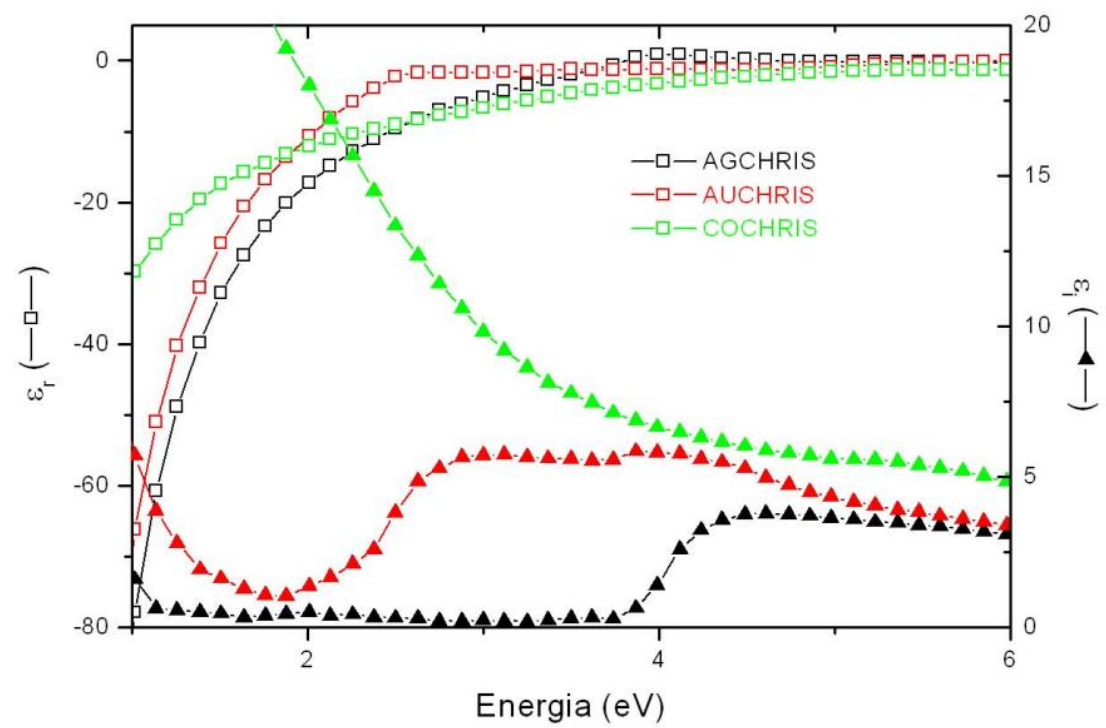

Figura 1.2 constante dielétrica real (quadrado vazio) e imaginária (triângulo cheio) para ouro, cobalto e prata.

Como podemos ver por este gráfico a parte real da constante dielétrica (quadrado vazio) tem as mesmas características para qualquer um dos três materiais. Seu valor é negativo e menor que - 10 para quase todas as energias menores que $2 \mathrm{eV}$. O que diferencia os metais nobres dos outros metais é a parte imaginária da constante dielétrica. Como pode ser observado a parte imaginária (triângulo cheio) para o cobalto é maior que cinco para qualquer energia, já para o ouro vemos um mínimo por volta de 
$2 \mathrm{eV}$ e para a prata vemos que para energias menores que $4 \mathrm{eV}$ o valor da parte imaginária é muito pequena. Por isto este material é o preferencial para o acoplamento de SP.

Se considerarmos o gráfico para a parte real $(n)$ e imaginária $(k)$ do índice de refração em função da energia, podemos ver o mesmo comportamento analisado para a constante dielétrica. Na figura 1.3 podemos ver esta relação.

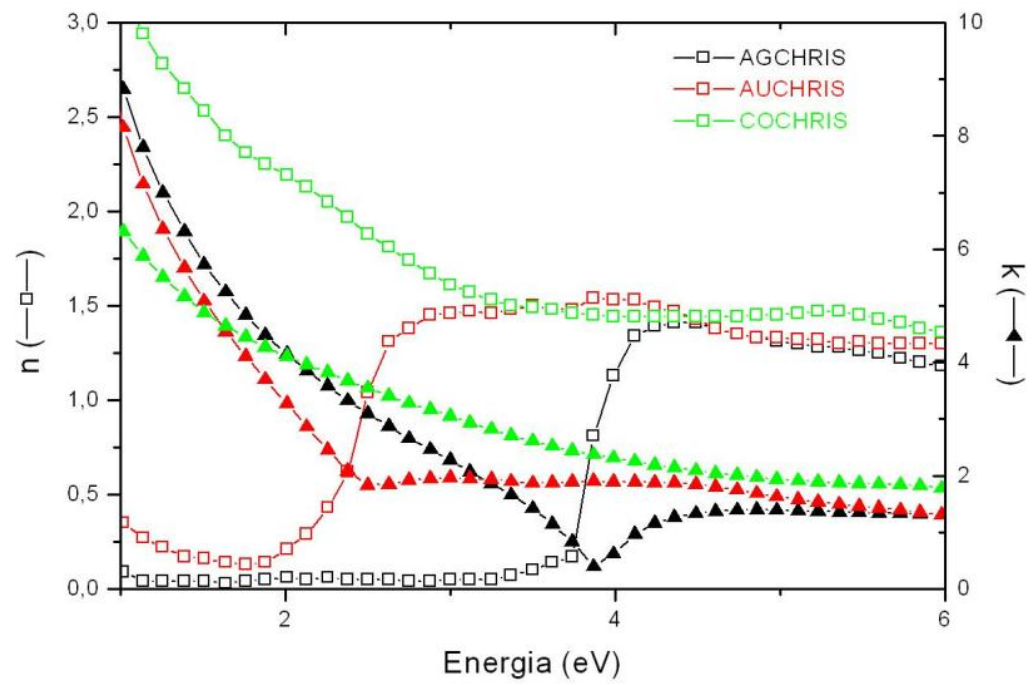

Figura 1.3 parte real (n) e parte imaginária (k) do incide de refração do material em função da energia.

A figura 1.3 mostra que a parte imaginária do índice de refração $(k)$ tem comportamento muito parecido para os três metais. Porém a parte real $(n)$ demonstra que para o cobalto o seu valor é muito alto, variando de 3 a 1,5. Para o ouro e com energias menores que $2 \mathrm{eV}$ encontramos um valor da parte real por volta de 0,3 e para a prata vemos que para energias menores que $4 \mathrm{eV}$ o valor da parte real é em torno de 0,1 . Como a luz visível varia de $3,1 \mathrm{eV}$ a $1,8 \mathrm{eV}$ podemos ver que a prata acopla SP melhor que o ouro para a espectro do visível.

Por isto o metal nobre com o qual grande parte das pesquisas estão sendo feitas é a prata. Resumindo, as vantagens da prata sobre os outros metais nobres são: 
1) $O$ acoplamento plasmônico na prata ocorre para comprimentos de onda entre $300 \mathrm{~nm}$ e $1200 \mathrm{~nm}$. Isto é muito útil, pois o acoplamento abrange todo o espectro do visível.

2) E particularmente com os lasers do nosso laboratório $(658 \mathrm{~nm}$ e $405 \mathrm{~nm}$ ) a prata tem a parte real da constante dielétrica grande e negativa e a imaginária pequena e positiva como o esperado, o que não ocorre para o ouro quando excitado com o laser violeta (405nm).

Como o SP se estende para fora do metal, na forma de uma onda evanescente, ele só poderá ser visto se observado com um detector a no máximo algumas centenas de nanômetros da amostra. Isto ocorre porque o decaimento deste tipo de onda em um meio dielétrico é muito forte. Portanto para analisar a propagação do SP é necessário detectar a onda em campo próximo. Com esta necessidade foi utilizado o SNOM (Scanning Near-field Optical Microscope). Este instrumento é um microscópio ótico de varredura em campo próximo que também tem a possibilidade de trabalhar como um AFM (Atomic Force Microscopy).

Com o SNOM vamos analisar a propagação dos SPs para diferentes materiais e com lasers de diferentes comprimentos de onda. Como é um microscópio ótico de varredura em campo próximo, ou seja, seu detector está a algumas dezenas de nanômetros da amostra vamos poder obter imagens da própria propagação do SP. 


\section{Cap. 2. Teoria}

Neste capítulo discutiremos aspectos teoricos necessários para melhor compreender o arranjo experimental utilizado e os resultados experimentais obtidos. Irei discorrer sobre o funcionamento do SNOM, sobre o acoplamento entre a luz e a amostra, e as simulações e cálculos para a otimização do acoplamento plasmônico.

\subsection{SNOM}

A microscopia vem sendo melhorada com o passar dos anos, pois existe sempre a necessidade de estudar estruturas cada vez menores. Existem muitos tipos de microscópios de alta resolução, entre eles se encontram o microscópio eletrônico de varredura (SEM) e o de transmissão (TEM) que fornecem imagens de altíssima resolução, mas com a desvantagem que exigem que as amostras estejam em vácuo; o microscópio de força atômica (AFM) que fornece imagens topográficas e o microscópio utilizado em nosso laboratório que é o Scanning Near-field Optical Microscope (SNOM) (Schoenmaker, 2005) (Mariana, 2008). Este microscópio tem muitos modos de operação:

1. Modo AFM: como modo AFM(Atomic Force Microscope) pode fornecer imagens topográficas com resolução lateral de 100nm.

2. Modo SNOM: como SNOM (Scanning Near-field Optical Microscope) é possível obter imagens óticas com resolução lateral de $100 \mathrm{~nm}$.

3. Modo MO-SNOM: como MO-SNOM (Magneto-Optical Scanning Near-field Optical Microscope) é possível obter informações magnéticas das amostras analisando o efeito Kerr magneto-ótico nas ondas evanescentes presentes na luz espalhada pela amostra (Schoenmaker J., 2003) (Schoenmaker J., 2004).

4. Modo PSTM: como PSTM (Photon Scanning Tunneling Microscope) é possível obter imagens óticas através do tunelamento de 
fótons. Este é o modo utilizado para obtenção das imagens de propagação do SP.

Por esta variedade de modos de operação o SNOM se torna um instrumento muito versátil. Ele vem sendo utilizado em muitas áreas da ciência e com fins diversos, tais como a espectroscopia Raman, a fluorescência e com os plasmons de superfície como, por exemplo, no caso de sensores (Mayer, et al., 2011), entre outros.

Por estar obtendo imagens óticas em campo próximo, ou seja, capturando as ondas evanescentes o SNOM não fica restrito ao limite clássico de resolução ótica, dado pelo critério de Rayleigh como veremos na próxima seção.

\subsubsection{Critério de Rayleigh e a ótica em campo próximo}

Segundo o critério de Rayleigh (RAYLEIGH, 1896) existe um limite para a ótica convencional e este limite é dado pela seguinte equação:

$$
r \geq \frac{1.22 \lambda}{2 n \operatorname{sen}(\theta)}
$$

onde $r$ é a distancia entre os objetos a serem observados, $\lambda$ é o comprimento de onda no vácuo da luz incidente, $n$ é o índice de refração do meio, e $\theta$ é o semi-ângulo da abertura da objetiva.

Como os valores de $n \operatorname{sen}(\theta)$ utilizados estão entre 1,3 ou 1,4 dependendo do material em que está imersa a objetiva (água ou óleo), então a equação 2.1.1 se reduz a $r \geq \lambda$ / 2. Portanto a resolução máxima, na ótica convencional, se restringe tipicamente a metade do comprimento de onda. Como para luz visível os comprimentos de onda variam entre $400 \mathrm{~nm}$ e $700 \mathrm{~nm}$, a resolução ótica fica entre $200 \mathrm{~nm}$ e $350 \mathrm{~nm}$, não podendo assim diferenciar objetos que estejam separados por menos de $200 \mathrm{~nm}$. 
Para solucionar este problema foi projetado em 1981, em Zurich, pela IBM um microscópio que eliminava o limite imposto pelo critério de Rayleigh. Este tipo de microscópio ficou conhecido por STM (Microscópio Eletrônico de Tunelamento). Somente em 1983 que a própria IBM e pesquisadores da Cornell University projetaram o primeiro SNOM. Os princípios físicos de funcionamento do STM e do SNOM são semelhantes. No STM é utilizado o tunelamento de elétrons e no SNOM é o tunelamento de fótons.

No caso da microscopia ótica tradicional as ondas captadas são as ondas propagantes, que obedecem ao critério de Rayleigh. Já no SNOM as ondas utilizadas são as ondas evanescentes e por isso o critério de Rayleigh não é um delimitador como demonstraremos a seguir.

Levando em consideração o princípio da incerteza de Heisenberg e que $\Delta p=\hbar \Delta k:$

$$
\Delta \vec{r} . \Delta \vec{k} \geq \frac{1}{2}
$$

Sabendo que o módulo de k poderá somente ser $+\mathrm{k}$ ou $-\mathrm{k}$, então a variação máxima que $\mathrm{k}$ pode ter é $2 \mathrm{k}$. Assim o princípio da incerteza de Heisenberg fica sendo:

$$
2 \vec{k} \cdot \Delta \overrightarrow{\mathbf{r}} \geq \frac{1}{2}
$$

Portanto a resolução de um microscópio tradicional fica:

$$
|\Delta \vec{r}| \geq \frac{1}{4|\vec{k}|}
$$

Considerando a propagação da onda em um meio de índice de refração n, o módulo de k é: 


$$
|\vec{k}|=\frac{2 \pi n}{\lambda}
$$

Substituindo 2.1.5 em 2.1.4 ficamos com o valor do modulo de $\Delta r$ sendo:

$$
|\Delta \overrightarrow{\mathbf{r}}| \geq \frac{\lambda}{8 \pi n}
$$

Considerando que o fóton se propaga em uma direção arbitrária, chamemos esta direção de $\mathrm{x}$. A componente do vetor $\vec{k}$ de propagação nesta direção é dado por:

$$
\boldsymbol{k}_{x}=|\vec{k}| \operatorname{sen}(\theta)
$$

Substituindo 2.1 .7 e 2.1.6 em 2.1.5 vamos obter o valor de máxima resolução de um microscópio tradicional em uma direção arbitrária:

$$
|\Delta \vec{x}|=\frac{\lambda}{8 \pi n \operatorname{sen}(\theta)}
$$

Isto demonstra que o princípio da incerteza de Heisenberg equivale a menos de uma constante, ao critério de Rayleigh.

Em um microscópio de campo próximo estas equações ainda valem, porém com a diferença que neste caso 0 vetor de onda pode ter componentes imaginárias, como no caso das ondas evanescentes. A equação para o $k_{x}$ da onda é do tipo: 


$$
\boldsymbol{k}_{x}=\sqrt{\boldsymbol{k}^{2}-\left(\boldsymbol{k}_{y}\right)^{2}-\left(\boldsymbol{k}_{z}\right)^{2}}
$$

Portanto o valor de $\mathrm{k}_{\mathrm{x}}$ compensa os valores de $\mathrm{k}_{\mathrm{y}}$ e $\mathrm{k}_{\mathrm{z}}$ já que neste caso podem ser imaginários, portanto $\circ \mathrm{k}_{\mathrm{x}}$ para ondas evanescentes pode ser maior que para ondas propagantes. Com o aumento do valor de $\mathrm{k}_{\mathrm{x}}, \Delta x$ pode assumir valores menores que os da microscopia tradicional. Assim comprovando que o microscópio de campo próximo é uma ótima alternativa para melhorar a resolução ótica das imagens.

Apesar do SNOM não ficar limitado às resoluções óticas tradicionais, existe ainda um delimitador para as medidas óticas deste microscópio. Este delimitador é o tamanho da abertura ótica da sua sonda. E como esta abertura para nossas sondas é da ordem de $100 \mathrm{~nm}$, este passará a ser o delimitador ótico do nosso SNOM. Isto nos leva a uma melhora de um fator de pelo menos dois, pois devido ao critério de Rayleigh a ótica é limitada na melhor das hipóteses a 200nm, já no nosso SNOM a limitação é de $100 \mathrm{~nm}$. Aperfeiçoamentos na técnica de preparação das aberturas óticas das sondas que utilizamos, podem nos levar a resoluções laterais ainda melhores que as atuais. Para melhorar a resolução ótica do SNOM é necessário diminuir a abertura da sonda. Então temos a expectativa de produzir a abertura das sondas do SNOM usando a técnica de FIB (Feixe de Íon Focalizado) o que pode melhorar a resolução ótica do equipamento em até uma ordem de grandeza.

$\mathrm{Na}$ próxima parte deste texto serão inseridos os conceitos teóricos necessários para a descrição do acoplamento plasmônico entre o feixe de luz incidente e a amostra.

\subsection{Acoplamento plasmônico}

O SP é uma oscilação dos elétrons livres da banda de condução de um metal quando estes são submetidos a uma onda eletromagnética. $O$ que ocorre é que os elétrons de condução do metal estão praticamente livres, 
portanto quando nestes materiais existe uma excitação eletromagnética, os elétrons por estarem livres, conseguem oscilar coerentemente com a onda. Esta oscilação é o que conhecemos como plasmon de superfície. Qualquer metal quando em contato com uma onda eletromagnética gera um acoplamento plasmônico. Porém os metais nobres têm a vantagem de ter a condição de ressonância do acoplamento plasmônico dentro do comprimento de onda da luz visível. Por isto estes metais se tornam a escolha perfeita para o acoplamento do SP.

Existem varias formas para se excitar com luz SPs nas amostras:

- A excitação usando um feixe ótico altamente focado (Bouhelier, et al., 2005),

- Usar uma grade de difração para garantir o acoplamento (Devaux, et al., 2003)

- O acoplamento usando um prisma que garanta o ângulo de incidência correto.

Estes métodos têm em comum que para acoplar o plasmon de superfície no material é necessário se acoplar o $\mathrm{k}$ da onda incidente com o $\mathrm{k}_{\mathrm{sp}}$ do SP. Para isto se utiliza configurações especiais como os casos acima citados. Iremos explicitar apenas o terceiro caso onde existe um prisma que auxilia no acoplamento entre o $\mathrm{k}_{\mathrm{sp}}$ do SP e o $\mathrm{k}$ da onda incidente.

Dentro deste caso podemos separar ainda em dois tipos de acoplamentos: o primeiro é o acoplamento com a configuração Otto (Otto, 1968) e o segundo é com a configuração Kretschmann (Krestchmann, et al., 1968) e que será a usada por nós. Os dois tipos de configurações são representados na figura 2.2.1, sendo $\varepsilon_{0}$ a constante dielétrica do prisma que vale $2,25, \varepsilon_{1}$ a constante dielétrica do metal que varia de material para material e $\varepsilon_{2}$ a constante dielétrica do ar que vale 1 .

Na configuração Kretschmann, a amostra é colada com uma de suas faces em um prisma que garante o ângulo do acoplamento plasmônico. Os plasmons de superfície irão se formar na outra face da amostra onde ela encontra o outro meio dielétrico, neste caso $\circ$ ar. Pela condição de ressonância ocorrer com um ângulo de incidência da luz maior que o ângulo 
crítico do metal utilizado não existe luz transmitida. Portanto toda a luz incidente seria refletida pela superfície do metal. Porém quando $k=k_{s p}$ a luz não é refletida pelo metal e sim absorvida por ele. Esta é a condição de ressonância do acoplamento do SP.

$\mathrm{Na}$ configuração Otto um prisma garante o ângulo do acoplamento plasmônico. Entre o prisma e o metal existe uma camada de ar e nesta interface metal/ar que irão se formar os plasmons de superfície. As mesmas condições de ressonâncias utilizadas na configuração Kretschmann valem para a configuração Otto.

a)

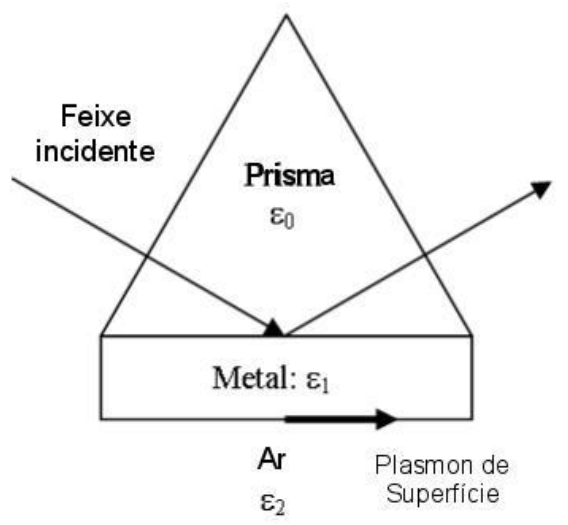

b)

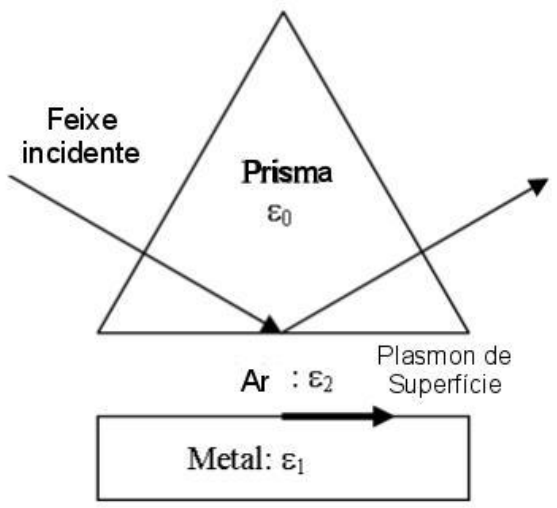

Figura 2.21 (a) configuração Kretschmann, (b) configuração Otto.

No nosso caso escolhemos a configuração Kretschmann para acoplar o SP. Isto por que como desejamos visualizar a propagação do SP com a sonda do SNOM, apenas a configuração Krestchmann nos permitia que chegassemos com a sonda onde estava o SP.

A nossa configuração difere um pouco da configuração Kretschmann tradicional, pois não usamos um prisma para acoplar a luz. Foi construído um porta-amostra que garante o ângulo de incidência da luz necessário para o acoplamento do SP. Este ângulo foi calculado através de simulações em relação à refletividade e transmissão do material como veremos no próximo tópico. Assim o SP iria se formar na face oposta da amostra tal como a 
configuração Kretschmann tradicional. Este porta-amostra será detalhado em um capítulo posterior.

Por estarmos usando a configuração Kretschmann com ângulo de incidência onde não existe transmissão da luz incidente, as imagens óticas captadas pela sonda do SNOM são obtidas por tunelamento dos fótons através da amostra. Por isto seria mais correto afirmar que o nosso microscópio funciona no modo PSTM para as imagens de SP. Porém usualmente chamaremos o equipamento de SNOM.

A partir daqui faremos duas aproximações necessárias: a primeira é que apesar de não podermos garantir que a frente de onda que chega a amostra é plana, vamos supor que a onda é plana. A segunda aproximação é que o metal é semi-infinito. Porque para um metal finito, como no nosso caso, primeiramente é necessário calcular o vetor de onda do SP com o metal sendo semi-infinito e depois se faz uma aproximação para o caso dele ser finito.

O acoplamento plasmônico é definido pelo eletromagnetismo clássico e ele advém de uma particularidade das equações de Maxwell. Partindo da equação de onda no vácuo do eletromagnetismo:

$$
\nabla^{2} \overrightarrow{\mathbf{E}}-\mathbf{k}_{\mathbf{0}}^{2} \varepsilon \overrightarrow{\mathbf{E}}=\mathbf{0}
$$

onde $k_{0}=\omega / c$ é o vetor de propagação da onda no vácuo.

Para os eixos de coordenadas vamos adotar $x$ como sendo a direção de propagação do plasmon de superfície da amostra, y como sendo a outra direção no plano da amostra e z a direção perpendicular ao plano da amostra. Levando em consideração a onda eletromagnética do tipo:

$$
\vec{E}=\overrightarrow{E_{0}^{ \pm}} \exp \left[+i\left(k_{x} x+k_{y} y \pm k_{z} z-\omega t\right)\right]
$$


com + para $z \geq 0$ (ar), e - para $z \leq 0$ (metal) e com $k_{z}$ imaginário, que causa um decaimento exponencial da componente do campo $E_{z}$. Na figura 2.2.2 temos uma representação do sistema de coordenadas utilizado, considerando que $\mathrm{z}=0$ é a interface metal/ar.

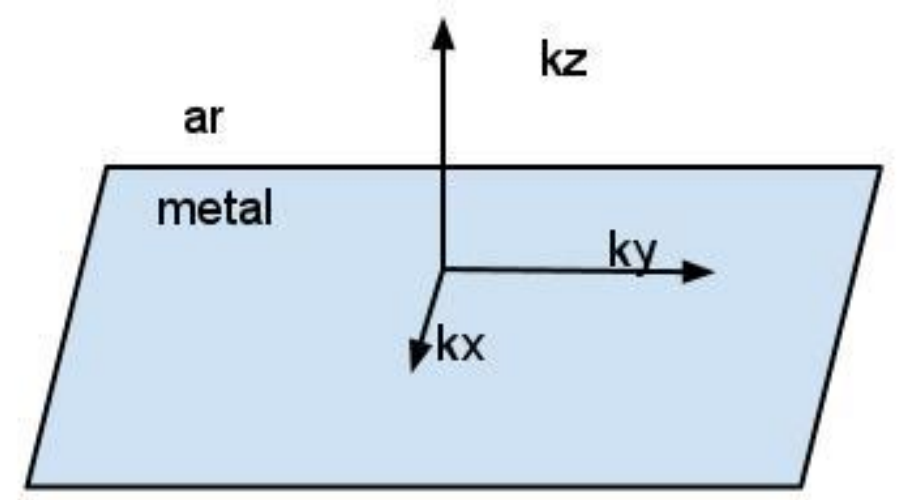

Figura 2.22 superfície da amostra e as direções x,y e z e os vetores kx, ky e kz do campo.

Considerando a constante dielétrica do metal sendo $\varepsilon_{1}=\varepsilon_{1 \mathrm{r}}+\mathrm{i} \varepsilon_{1 \mathrm{i}}$ (Johnson, et al., 1972). Podemos encontrar os modos de propagação da onda no material. Como vemos figura 2.2.2 escolhemos os eixos de coordenadas para simplificar o problema e tratá-lo unidimensionalmente. Com a escolha dos eixos de coordenadas $\varepsilon$ irá depender somente de uma coordenada espacial, então teremos que $\varepsilon=\varepsilon(z)$. O campo pode ser descrito por $\vec{E}(x, y, z)=\vec{E}(z) e^{i k_{x} x}$.

Aplicando o Laplaciano no campo descrito acima, a equação de onda se resume a:

$$
\frac{\partial^{2} \vec{E}(z)}{\partial z^{2}}+\left(\boldsymbol{k}_{0}^{2} \varepsilon-\boldsymbol{k}_{x}^{2}\right) \vec{E}=\mathbf{0}
$$


Uma equação similar existe para o campo magnético $\vec{H}$. Escrevendo as expressões para as diferentes componentes de $\vec{E}$ e $\vec{H}$ e usando as equações de Maxwell: $\nabla \times \vec{E}=-\frac{\partial \vec{B}}{\partial t}$ e $\nabla \times \vec{H}=\frac{\partial \vec{D}}{\partial t}$, chegamos as equações para os modos TM e TE do campo.

Para o modo TM encontramos:

$$
\begin{aligned}
& E_{x}=-i \frac{1}{\omega \varepsilon_{o} \varepsilon} \frac{\partial H_{y}}{\partial z} \\
& E_{z}=-\frac{k_{x}}{\omega \varepsilon_{o} \varepsilon} H_{y}
\end{aligned}
$$

Então a equação de onda para o modo TM é:

$$
\frac{\partial^{2} H_{y}}{\partial z^{2}}+\left(k_{0}^{2} \varepsilon-k_{x}^{2}\right) H_{y}=0
$$

Para o modo TE temos:

$$
\begin{array}{lll}
H_{x} & =i \frac{1}{\omega \mu_{o}} \frac{\partial E_{y}}{\partial z}, & 2.24 \mathrm{~d} \\
H_{z}=\frac{k_{x}}{\omega \mu_{o}} E_{y}, & 2.24 \mathrm{e}
\end{array}
$$

Portanto a equação de onda do modo TE é:

$$
\frac{\partial^{2} E_{y}}{\partial z^{2}}+\left(k_{0}^{2} \varepsilon-k_{x}^{2}\right) \mathbf{E}_{y}=0
$$


Para gerar um SP o metal nobre é necessário que $\varepsilon_{1 r}<0,\left|\varepsilon_{1 r}\right|>\varepsilon_{2}$ e $\varepsilon_{2}>0$. Agora queremos procurar as soluções que confinam a onda na interface e com um decaimento evanescente na direção $z$.

Usando o modo TM primeiramente, os campos para $z>0$ serão:

$$
\begin{array}{ll}
H_{y}=A_{2} e^{i k_{x} x} e^{-k_{z 2} z}, & 2.25 \mathrm{a} \\
E_{x}=i A_{2} \frac{1}{\omega \varepsilon_{0} \varepsilon_{2}} k_{z 2} e^{i k_{x} x} e^{-k_{z 2} z}, & 2.25 \mathrm{~b} \\
E_{z}=-A_{2} \frac{1}{\omega \varepsilon_{0} \varepsilon_{2}} e^{i k_{x} x} e^{-k_{z 2} z}, & 2.25 \mathrm{c}
\end{array}
$$

e para $z<0$ :

$$
\begin{array}{cl}
H_{y} & =A_{1} e^{i k_{x} x} e^{k_{z 1} z}, \\
E_{x} & =-i A_{1} \frac{1}{\omega \varepsilon_{0} \varepsilon_{1}} k_{z 1} e^{i k_{x} x} e^{k_{z 1} z}, 2.26 \mathrm{a} \\
E_{z} & =-A_{1} \frac{1}{\omega \varepsilon_{0} \varepsilon_{1}} e^{i k_{x} x} e^{k_{z 1} z}, 26 \mathrm{~b}
\end{array}
$$

sendo $\mathrm{k}_{\mathrm{zi}}$ a componente do vetor de onda perpendicular a interface. $\mathrm{O}$ fato dos campos dependerem somente da exponencial real do $\mathrm{k}_{\mathrm{z} i \mathrm{mostra}}$ que nesta direção a onda é confinada. $O$ valor recíproco de $k_{z i}$ define a distância $\left(L_{z i}\right)$ de decaimento evanescente do campo perpendicular a interface.

$$
L_{z i}=\frac{1}{\left|k_{z i}\right|} \quad, \quad 2.2 .7
$$

sendo que o índice i se refere ao meio 1 (metal) ou no meio 2 (ar). 
Pela continuidade de $H_{y}$ e $\varepsilon_{i} E_{z}$ na interface chegamos a conclusão que $A_{1}=A_{2}$ e que:

$$
\frac{k_{z 1}}{\varepsilon_{1}}=-\frac{k_{\mathrm{z} 2}}{\varepsilon_{2}}
$$

Aplicando 2.2.5(a) e 2.2.6(a) em 2.2.4(c) encontramos:

$$
\begin{array}{ll}
k_{z 1}^{2}=k_{x}^{2}-k_{0}^{2} \varepsilon_{1} \quad, & 2.2 .9 \mathrm{a} \\
k_{z 2}^{2}=k_{x}^{2}-k_{0}^{2} \varepsilon_{2} & , \quad 2.2 .9 \mathrm{~b}
\end{array}
$$

Combinando estas duas equações com a equação 2.2.8 chegamos a relação de dispersão do SPP na interface:

$$
k_{x}=\frac{\omega}{c}\left(\frac{\varepsilon_{1} \varepsilon_{2}}{\varepsilon_{1}+\varepsilon_{2}}\right)^{1 / 2}
$$

Podemos fazer o análogo para o modo TE. Porém quando consideramos a continuidade em $E_{y}$ e $H_{x}$, encontramos como condição:

$$
A_{1}\left(k_{z 1}+k_{z 2}\right)=0 \quad \text {. }
$$

Como $\operatorname{Re}\left[K_{z 1}\right]$ e $\operatorname{Re}\left[K_{z 2}\right]$ são maiores que zero a solução do coeficiente $A_{1}$ para que a condição 2.2.11 seja satisfeita é $A_{1}=0$, então $A_{1}=A_{2}=0.0$ que leva a mostrar que não existe SP no modo TE, somente existe no modo TM. 
Para $k_{x}$ ter uma parte real e uma imaginária bem distintas é necessário que $\varepsilon_{1 r}<0$ e que $\left|\varepsilon_{1 r}\right|>\varepsilon_{2}$, e um metal serve perfeitamente nessas duas condições. Se assumirmos que $\omega$ e $\varepsilon_{2}$ são reais e que $\varepsilon_{1 i}<\left|\varepsilon_{1 r}\right|$ vamos obter o valor de $k_{x}$ complexo da forma $k_{x}=k_{x}{ }^{\prime}+i k_{x}{ }^{\prime \prime}$. A parte real e imaginária do vetor $k_{x}$ podem ser escritas como:

$$
\begin{gathered}
k_{x}^{\prime}=\frac{\omega}{c}\left(\frac{\varepsilon_{1 \mathrm{r}} \varepsilon_{2}}{\varepsilon_{1 r}+\varepsilon_{2}}\right)^{\frac{1}{2}}, \\
\boldsymbol{k}_{x}^{\prime \prime}=\frac{\omega}{c}\left(\frac{\varepsilon_{1 \mathrm{r}} \varepsilon_{2}}{\varepsilon_{1 r}+\varepsilon_{2}}\right)^{\frac{3}{2}} \frac{\varepsilon_{1 \mathrm{i}}}{2\left(\varepsilon_{1 \mathrm{r}}\right)^{2}}
\end{gathered}
$$

É necessário agora fazer o ajuste para o caso do metal ser finito. Tratando o experimento não mais como uma única interface (ar/metal) e sim um experimento de duas interfaces (vidro/metal, metal/ar) e o filme fino metálico tendo a espessura $d_{1}$. Usando as condições de contorno agora para duas interfaces, chegamos à relação de dispersão do sistema de camadas:

$$
\left(\frac{k_{z 1}}{\varepsilon_{1}}+\frac{k_{z 0}}{\varepsilon_{0}}\right)\left(\frac{k_{z 2}}{\varepsilon_{2}}+\frac{k_{z 1}}{\varepsilon_{1}}\right)+\left(\frac{k_{z 1}}{\varepsilon_{1}}-\frac{k_{z 0}}{\varepsilon_{0}}\right)\left(\frac{k_{z 2}}{\varepsilon_{2}}-\frac{k_{z 1}}{\varepsilon_{1}}\right) e^{2 i k_{z 1} d_{1}}=0 \quad 2.13
$$

Com esta relação e as relações de Fresnel vamos obter uma aproximação para o $\mathrm{k}_{\mathrm{x}}$. Para melhor entender os cálculos necessários temos como referência o livro sobre plasmons de superfície do Heinz Raether (Raether, 1988). O novo $k_{x}$ será dado por $k_{x}=k_{x}{ }^{\prime}+i k_{x}{ }^{\prime \prime}+\Delta k_{x}$ sendo que este $\Delta \mathrm{k}_{\mathrm{x}}$ é a parcela de ajuste que incluirá a espessura do filme metálico e é dado por:

$$
\Delta k_{x}=r_{01}^{p} e^{2 i k_{z 1} d_{1}} 2\left(\frac{\omega}{c}\right)\left(\frac{\varepsilon_{1} \varepsilon_{2}}{\varepsilon_{1}+\varepsilon_{2}}\right)^{3 / 2} \frac{1}{\varepsilon_{2}-\varepsilon_{1}}
$$


com o coeficiente de Fresnel igual a:

$$
r_{01}^{p}=\frac{a^{2}-\varepsilon_{0}^{2}}{a^{2}+\varepsilon_{0}^{2}}+i \frac{2 a \varepsilon_{0}}{a^{2}+\varepsilon_{0}^{2}}
$$

sendo que $\mathrm{a}^{2}=\left[-\varepsilon_{1 \mathrm{r}}\left(\varepsilon_{0}-1\right)-\varepsilon_{0}\right]$.

Esta equação foi resolvida analiticamente usando o programa Mathematica e assim obtivemos o valor de $\mathrm{k}_{\mathrm{x}}$ com uma melhor precisão. De posse dos novos valores para a parte real e imaginaria de $k_{x}$ calculamos a distância de propagação do SP e a extensão espacial do campo em z.

A parte real do $k_{x}$ nos dará o valor da freqüência de oscilação do SP, ou seja, será o valor do comprimento de onda do SP $\left(\lambda_{\mathrm{sp}}\right)$. Já a parte imaginária dará a atenuação da onda na direção de propagação x. Esta atenuação gera um decaimento exponencial na intensidade do SP ao longo da superfície do metal. O parâmetro desta exponencial é o valor da distância de propagação do SP $\left(L_{x}\right)$ nesta direção. Em uma superfície lisa este decaimento será da forma $e^{-2 k x " X}$ sendo $k_{x}$ " a parte imaginária do $k_{x}$ já após a correção. Então:

$$
L_{x}=\left(2 k_{x}{ }^{\prime \prime}\right)^{-1} . \quad 2.2 .16
$$

Por último podemos calcular qual será o comprimento de onda do SP e este será dado por:

$$
\lambda_{s p}=\frac{2 \pi}{k_{x^{\prime}}}
$$

Assim ficando muito bem resolvido todos os parâmetros e conceitos importantes para a propagação plasmônica na interface da nossa amostra. 
$\mathrm{Na}$ sequência serão discutidos os parâmetros necessários para maximizar a propagação do SP. Estes parâmetros são o comprimento de onda da onda incidente, o seu ângulo de incidência, a espessura e o índice de refração do filme metálico. O programa simula a refletividade e a transmissão de uma onda eletromagnética entre dois ou mais meios, modificando o ângulo de incidência e a espessura do filme, podemos minimizar estes valores buscando o melhor acoplamento do plasmon de superfície. Este programa foi desenvolvido pelo Prof. Antonio Domingues dos Santos.

\subsection{Simulações de refletividade}

A condição de ressonância do SP gera uma alta absorção da onda incidente. Portanto se buscamos encontrar os parâmetros de ressonância podemos investigar o local de máxima absorção da onda. Para garantir a conservação de energia, a soma da energia refletida, transmitida e absorvida tem que ser cem por cento da energia da onda, ou seja, $R+T+A=1$. Portanto para maximizar a absorção temos que procurar o ponto onde a transmissão e a reflexão da luz são mínimos. Para metais nobres como a prata e o ouro a ressonância plasmônica ocorre após o ângulo crítico do metal. Por isto não existe transmissão da luz incidente sobrando somente a luz refletida e absorvida.

Com base nisto para encontrar o ponto de máxima absorção precisamos somente encontrar o ponto de mínima reflexão. Com este objetivo usaremos um programa que simula a refletividade e transmissão de uma onda em um filme do material, tendo de ambos os lados, os meios semi-infinitos ar e vidro. Esta simulação será feita considerando-se quatro parâmetros: o índice de refração do material, o comprimento de onda da onda incidente, o seu ângulo de incidência e a espessura do material.

O programa simula uma onda incidente propagando em um material. $O$ programa discretiza o filme em camadas e calcula os modos próprios de propagação da onda EM em cada uma delas. A resposta ótica do filme vai 
ser obtida através da convolução dos resultados em uma matriz de transferência. Agora vamos demonstrar os cálculos que estão implícitos neste programa.

Partindo do campo elétrico existente entre dois meios quaisquer:

$$
\vec{E}=\sum_{i} A_{i} \widehat{E_{l}} \exp \left(j \frac{2 \pi}{\lambda}\left(k_{x} x+k_{z i} z\right)\right) \exp (-j \omega t)
$$

com i representando cada um dos quatro modos ( $1=T E$ ascendente, $2=T M$ ascendente, $3=$ TE descendente e $4=T M$ descendente) da onda e sendo $A_{i}$ a amplitude a ser determinada em cada modo. Colocando as condições de contorno necessárias para dois meios quaisquer podemos determinar os valores das amplitudes $A_{i}$ que representarão no final a amplitude da onda refletida e transmitida. A primeira continuidade utilizada é a das componentes tangenciais do campo elétrico na interface entre duas camadas $(n$ e $n+1)$ e adotando que $k_{x} x$ e -iwt são iguais para todos os modos, podemos retirá-los do desenvolvimento. Ficando o resultado para 0 eixo $x$ :

$$
\sum_{i} A_{i}^{n} \widehat{E}_{x i}^{n} \exp \left(j \frac{2 \pi}{\lambda}\left(k_{z i}^{n} e^{n}\right)\right)=\sum_{i} A_{i}^{n+1} \widehat{E}_{x i}^{n+1}
$$

A solução para y é análoga.

Agora aplicando a continuidade para o campo magnético e como:

$$
\overrightarrow{\mathbf{k}} \times \overrightarrow{\mathbf{E}}=\omega \overrightarrow{\mathbf{B}}
$$

Teremos então: 


$$
\begin{gathered}
B_{x i}=\frac{k_{y}}{c} E_{z i}-\frac{k_{z i}}{c} E_{y i} \\
B_{y i}=\frac{k_{z i}}{c} E_{x i}, \\
B_{z i}=-\frac{k_{y}}{c} E_{x i}
\end{gathered}
$$

Obtemos assim em x:

$$
\sum_{i} A_{i}^{n} \frac{k_{y}}{c} \widehat{E}_{z i}{ }^{n}-\frac{k_{z i}{ }^{n}}{c} \widehat{E}_{y i}{ }^{n} \exp \left(j \frac{2 \pi}{\lambda}\left(k_{z i}^{n} e^{n}\right)\right)=\sum_{i} A_{i}^{n+1} \frac{k_{y}}{c} \widehat{E}_{z i}{ }^{n+1}-\frac{k_{z i}{ }^{n+1}}{c} \widehat{E}_{y i}{ }^{n+1} 2.3 .5
$$

e em y teremos:

$$
\sum_{i} A_{i}^{n} \frac{k_{z i}^{n}}{c} \widehat{E}_{x i}^{n} \exp \left(j \frac{2 \pi}{\lambda}\left(k_{z i}^{n} e^{n}\right)\right)=\sum_{i} A_{i}^{n+1} \frac{k_{z i}{ }^{n+1}}{c} \widehat{E}_{x i}{ }^{n+1}
$$

Das equações 2.3.2, 2.3.5 e 2.3.6 conseguimos escrever os parâmetros importantes na seguinte forma matricial, que representa a propagação da onda de uma camada $n$ para uma camada $n+1$ :

$$
M^{n+} D^{n} A^{n}=M^{(n+1)-} A^{n+1}
$$

sendo $\mathrm{A}$ as amplitudes da transmissão e reflexão da onda, $\mathrm{D}$ a matriz de propagação em um meio e $\mathrm{M}$ a matriz dos modos próprios de transferência nas interfaces. 
Na equação 2.3.7 temos:

$$
A^{n}=\left[\begin{array}{l}
A_{1}^{n} \\
A_{2}^{n} \\
A_{3}^{n} \\
A_{4}^{n}
\end{array}\right]
$$

E

$$
M^{n^{ \pm}}=\left[\begin{array}{cccc}
m_{11}^{n^{ \pm}} & m_{12}^{n^{ \pm}} & m_{13}^{n^{ \pm}} & m_{14}^{n^{ \pm}} \\
m_{21}^{n^{ \pm}} & m_{22}^{n^{ \pm}} & m_{23}^{n^{ \pm}} & m_{24}^{n^{ \pm}} \\
m_{31}^{n^{ \pm}} & m_{32}^{n^{ \pm}} & m_{33}^{n^{ \pm}} & m_{34}^{n^{ \pm}} \\
m_{41}^{n^{ \pm}} & m_{42}^{n^{ \pm}} & m_{43}^{n^{ \pm}} & m_{44}^{n^{ \pm}}
\end{array}\right]
$$

Onde:

$$
\begin{gathered}
m_{1 i}^{n^{+}}=\widehat{E}_{x i}^{n} \\
m_{1 i}^{n^{-}}=\widehat{E}_{x i}^{n} \\
m_{2 i}^{n^{+}}=\widehat{E}_{y i}^{n} \\
m_{2 i}^{n^{-}}=\hat{E}_{y i}^{n} \\
\boldsymbol{m}_{3 i}^{n^{+}}=\frac{\boldsymbol{k}_{y}}{\boldsymbol{c}} \widehat{\boldsymbol{E}}_{z i}^{n}-\frac{\boldsymbol{k}_{z i}^{n}}{\boldsymbol{c}} \widehat{\boldsymbol{E}}_{y i}^{n}, \\
m_{3 i}^{n^{-}}=\frac{k_{y}}{c} \widehat{E}_{z i}^{n}-\frac{k_{z i}^{n}}{c} \widehat{E}_{y i}^{n} \\
m_{4 i}^{n^{+}}=\frac{k_{z i}^{n}}{c} \hat{E}_{x i}^{n}
\end{gathered}
$$




$$
m_{4 i}^{n^{-}}=\frac{k_{z i}^{n}}{c} \hat{E}_{x i}^{n}
$$

A equação 2.3.7 pode ser reescrita como:

$$
A^{n}=\left(M^{n+} D^{n}\right)^{-1} M^{(n+1)-} A^{n+1} \quad \text { 2.3.11 }
$$

E assim se tivermos um sistema de $n$ camadas a equação 2.3.11 ficaria:

$$
A^{0}=\left(M^{0+} D^{0} R^{0+}\right)^{-1} M^{1-} R^{0-} \ldots\left(M^{(n-1)+} D^{(n-1)} R^{(n-1)+}\right)^{-1} M^{n-} R^{(n-1)-} A^{n} \quad \text {. 2.3. } 12
$$

Obtemos assim as matrizes $A^{0}$ e $A^{n}$ que dão as amplitudes da onda transmitida $\left(A_{1}{ }^{n}\right.$ e $\left.A_{2}{ }^{n}\right)$ e da onda refletida $\left(A_{3}{ }^{0}\right.$ e $\left.A_{4}{ }^{0}\right)$.

Um esquema representativo pode ser visto na tabela 2.3.1.

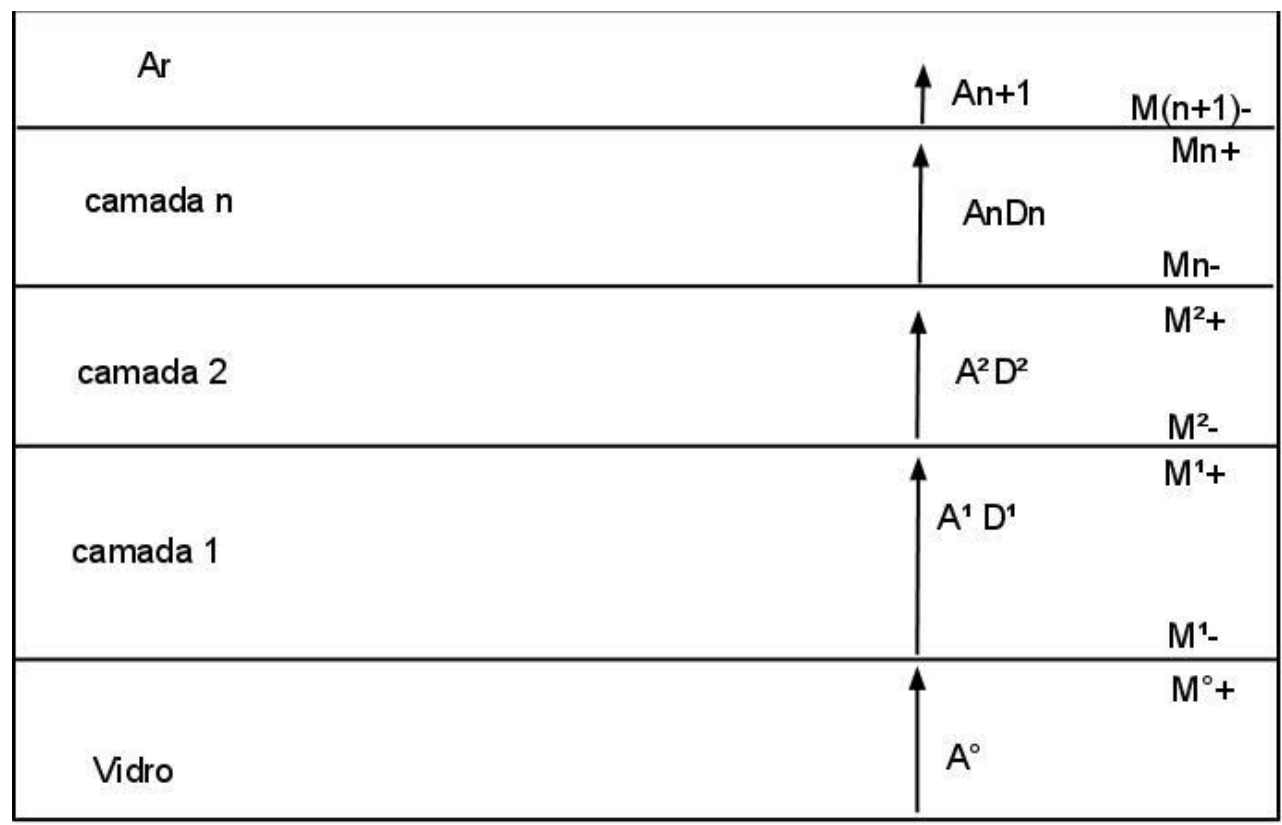

Tabela 2.3.1 Esquema de discretização e propagação nas camadas da amostra. 
Usando este método podemos simular o comportamento da luz refletida nas nossas amostras e procurar pelos valores dos parâmetros que minimizam as ondas refletida e transmitida.

O parâmetro da espessura do filme está implícito no número de camadas que o programa usará; o comprimento de onda e o ângulo de incidência estão implícitos no vetor de onda k. Portanto este é o formalismo do programa que utilizamos para escolher os parâmetros de espessura, ângulo de incidência e comprimento de onda do laser.

Estes são os conceitos teóricos necessários para poder continuar o trabalho e assim desenvolver no próximo tópico o procedimento experimental necessário para atingir os resultados esperados. 


\section{Cap. 3. Procedimento experimental}

Nesta parte do texto iremos discutir as técnicas necessárias para obter os resultados almejados. Descreveremos brevemente o funcionamento do SNOM e as melhorias implementadas no equipamento, e também o método tradicional de medidas e o método para medidas dos SPs. Descreveremos a produção das amostras, sua caracterização e o processo de análise das imagens obtidas pelo SNOM. Para uma melhor compreensão sobre o funcionamento e desenvolvimento do SNOM temos por referência as teses de doutorado de Mariana Pojar (Mariana, 2008) e Jeroen Schoenmaker (Schoenmaker, 2005) que dissertam sobre os princípios de desenvolvimento deste equipamento no LMM (Laboratório de Materiais Magnéticos).

\subsection{SNOM}

O SNOM como já dito antes é um microscópio ótico de varredura em campo próximo que funciona baseado em um AFM operando em modo shear-force. A diferença principal entre ele e um AFM é que no SNOM a sonda é constituída por uma fibra ótica. O cabeçote do SNOM possui um bloco metálico no qual fixamos um diapasão (tuning-fork) de freqüência de ressonância em $32768 \mathrm{~Hz}$. Sobre o bloco+diapasão é colado, com resina fotopolimerizável, a fibra ótica. Do lado oposto à sonda está um cristal piezoelétrico que faz o bloco todo vibrar com a freqüência de ressonância do conjunto ponta+diapasão. Todo este arranjo é comandado por um módulo eletrônico de controle, denominado Dulcinea, produzido pela NanoTec (Nanotec). A amplitude de vibração do conjunto diapasão+ponta é coletada pela própria Dulcinea fechando o sistema de excitação e coleta do modo topográfico do SNOM.

Para fazer a aproximação da sonda à amostra usamos um programa produzido pela NanoTec chamado WSxM. Nele a amplitude do diapasão é 
monitorada o tempo todo buscando variações desta amplitude. Quando a sonda está a algumas dezenas de nanômetros da amostra a força de interação entre a sonda e a amostra muda a amplitude de vibração do diapasão e observando esta mudança o programa sabe que a aproximação foi feita. Este mesmo software é quem garante a distância da ponta-amostra durante toda a varredura através de um mecanismo de retroalimentação negativa do tipo PI que comanda outro acionador piezo-elétrico que se encontra embaixo da amostra. Este último acionador piezo-elétrico corresponde ao eixo $Z$ do sistema de varredura do SNOM.

Para a obtenção da imagem ótica da amostra, um feixe de laser ( $\lambda=405 \mathrm{~nm}$ ou $658 \mathrm{~nm}$ ) é usado para iluminar localmente a amostra, através da ponta da fibra ótica. A luz espalhada pela amostra é coletada por um fotodiodo de avalanche e o sinal é enviado a um Lock-in amplifier digital da EG\&G modelo 7265. Através do sistema de controle Dulcinea, a imagem ótica da amostra é construída.

$\mathrm{Na}$ figura 3.1.1 podemos ver o diagrama de blocos do SNOM para ilustrar melhor o funcionamento do sistema. $\mathrm{Na}$ imagem podemos ver que no SNOM existem dois grandes blocos de funcionamento. O primeiro bloco é o do modo AFM que controla toda a parte da topografia e varredura da amostra como descrito acima. O segundo bloco é o que controla as imagens óticas da amostra. Ainda temos alguns módulos periféricos, como o software WSxM, a placa DSP e a Dulcinea que garantem o funcionamento do modo AFM e da varredura da amostra. Por fim temos uma bobina que gera um campo magnético na amostra para trabalharmos com os efeitos deste campo na ótica, que são conhecidos como efeitos magneto-óticos. 


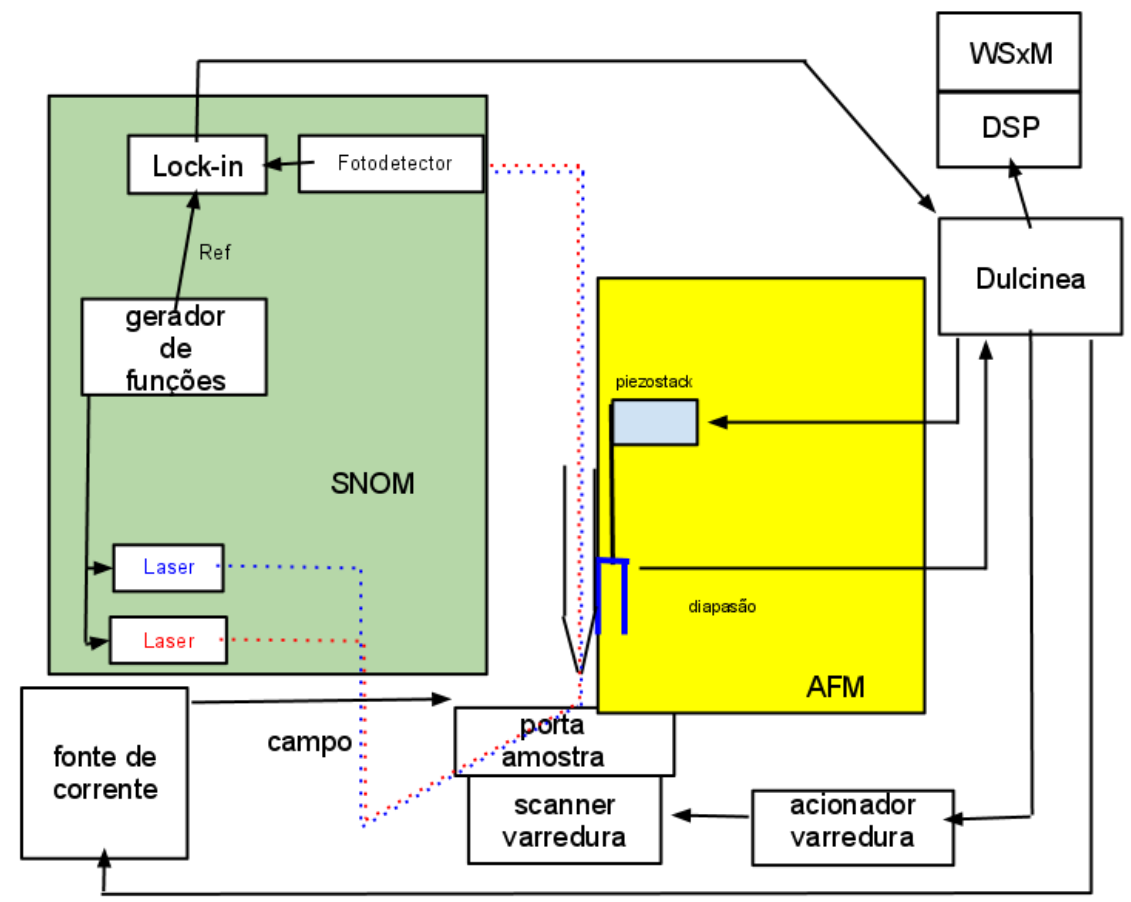

Figura 3.1.1 Diagrama de blocos do SNOM para a configuração de SP.

A sonda do SNOM é uma fibra ótica da 3M (FS-SN-3224), monomodo para $630 \mathrm{~nm}$, afinada quimicamente. A fibra ótica tem um cladding de $125 \mu \mathrm{m}$ e um núcleo de $4 \mu \mathrm{m}$ de diâmetro. Para servir como sonda do SNOM, esta fibra precisa ter algumas centenas de nanômetros em sua extremidade. Para isto colocamos esta fibra ótica em uma solução de $\mathrm{NH}_{4} \mathrm{~F}(40 \%): \mathrm{HF}(48 \%): \mathrm{H}_{2} \mathrm{O}$, na proporção $5: 1: 1$, com uma camada protetora de óleo mineral Nujol na superfície. Através da técnica de formação de menisco esta fibra sofre uma corrosão deixando sua ponta com o tamanho desejado. Com um dispositivo criado no laboratório é possível fazer três sondas por vez e elas levam em torno de 8 horas para ficarem afinadas. $\mathrm{Na}$ figura 3.1.2 vemos o esquema descritivo do processo de afinamento das sondas, que está muito bem descrito nas teses citadas acima. 


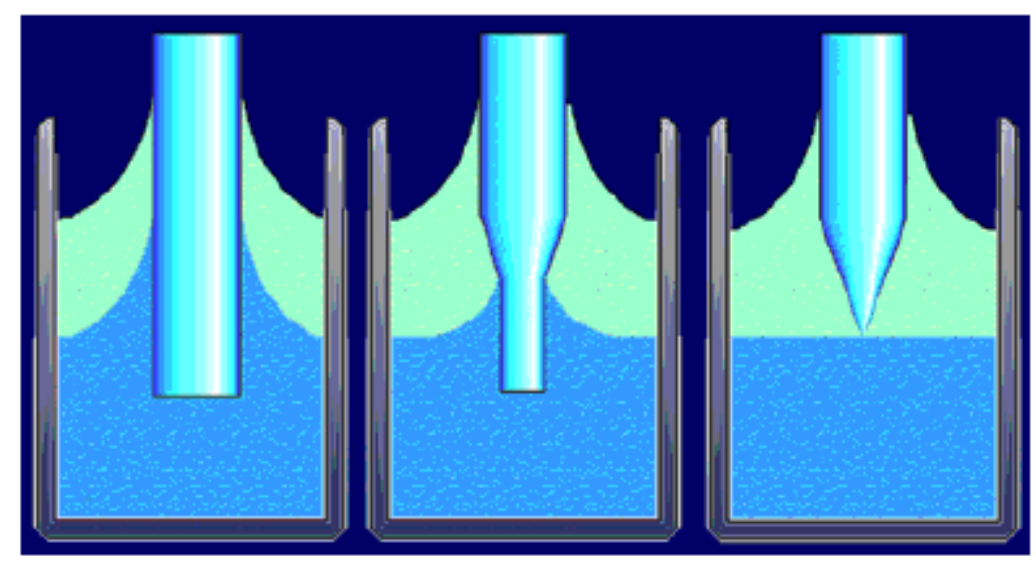

Figura 3.1.2 ataque químico na fibra de vidro para produção das sondas.

Para garantir uma menor dispersão da luz para quando a sonda for utilizada como guia para luz incidente (figura 3.1.3.d), metalizamos a sonda. Esta metalização é feita com um filme fino de $\mathrm{Au}$ ou $\mathrm{Ti}$, pelo processo de magnetron-sputtering no próprio laboratório. Para o caso da sonda como receptora de luz, isto ocorre quando a luz incide por baixo da amostra notamos que esta metalização não é necessária, pois a única luz que irá entrar na sonda é aquela que entrar preponderantemente pela sua extremidade.

Para obtenção das imagens óticas no SNOM existem cinco maneiras diferentes de iluminação e deteção da luz. Vemos esquematicamente na figura 3.1.3 as formas de iluminação e deteção da luz. (NCS, 2000):

a) A sonda como emissora de luz para transmissão:

Neste método a sonda do SNOM serve como guia de luz para o laser, esta sonda está muito próxima da amostra e existe um detetor que esta atrás da amostra coletando a luz transmitida.

b) A sonda como receptora de luz e incidência por baixo da amostra: Aqui a luz incidente está embaixo da amostra e a sonda do SNOM serve como coletora da luz espalhada pela amostra. Este é o método usado para imagens plasmônicas.

c) Sonda como emissora e receptora:

A sonda leva a luz para a amostra como no caso 1, e ela serve também como coletora da luz que foi espalhada pela amostra. 
d) Sonda como emissora de luz para reflexão:

A sonda serve de guia para a luz e em campo distante, em um ângulo pertinente para receber a luz espalhada pela amostra, existe um receptor que coleta a luz, medindo sua intensidade. Este método é o que tradicionalmente se usa no nosso SNOM.

e) Sonda como receptora da luz espalhada:

Uma fonte luminosa espalha luz sobre a amostra e a sonda do SNOM serve como coletora para esta luz espalhada.

Em nosso laboratório prioritariamente o funcionamento do SNOM é pelo método 3.1.3.d para imagens ópticas comuns, mas para a observação dos SPs usamos o método 3.1.3.b para podermos ter uma melhor análise de sua propagação.

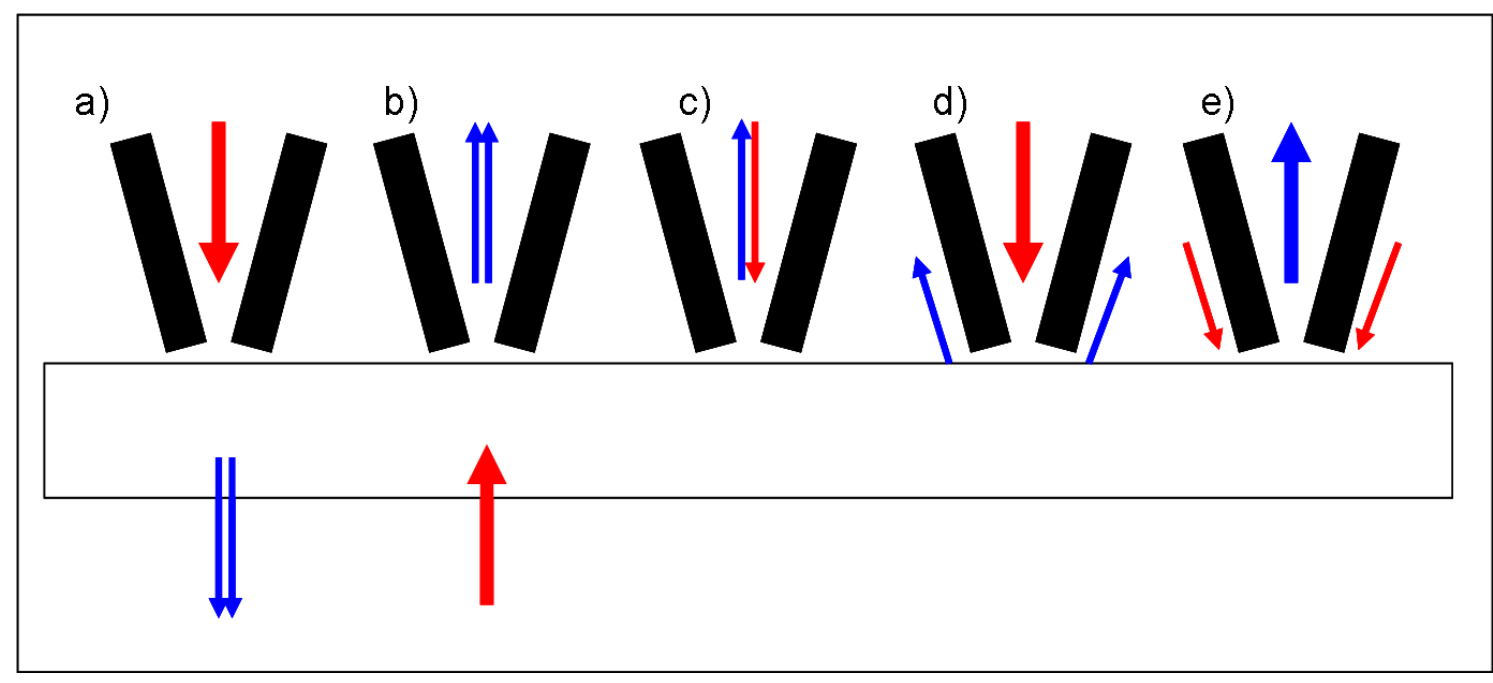

Figura 3.1.3 modos de operação para a sonda do SNOM.

Para a imagem ótica da amostra, em qualquer uma das duas configurações, usamos um gerador de funções da Hewlett Packward modelo 33120A, que envia um sinal com freqüência $~ 3 \mathrm{kHz}$ a um dos dois lasers que estão acoplados ao SNOM. O Lock-in amplifier, que está ligado ao fotodetetor, está sincronizado com este sinal adquirindo somente a luz que está com a freqüência de oscilação característica do laser (tipicamente 3276,8 Hz). Está escolha de freqüência é feita porque como seu valor está muito acima dos ruídos eletrônicos e mecânicos, ele 
elimina este tipo de ruído. Como se pode notar esta freqüência é $1 / 10$ da freqüência de ressonância do diapasão eliminando assim batimentos entre estas duas freqüências. Após a coleta da luz pelo fotodetetor, o Lock-in amplifier envia o sinal adquirido para a Dulcinea, permitindo desta maneira a formação da imagem ótica da interação entre a luz do laser e a amostra.

O acoplamento plasmônico somente acontece quando a luz incidente tem a polarização correta. Para garantir a polarização da luz incidente usamos compensadores óticos à fibra, conhecidos como "orelhas de Mickey" (Schoenmaker, 2005 p. cap 4.2). Este dispositivo usa as tensões elásticas na fibra para gerar uma birrefringência. Esta birrefringência decompõe a luz em suas duas componentes, podendo assim controlar a polarização da luz. Assim, podemos maximizar a polarização requerida. Sendo que para o caso de plasmons de superfície a polarização deve ser $p$ (TM).

O SNOM ainda tem a capacidade de caracterizar a amostra magneticamente através de curvas de histerese local e susceptibilidade magnética diferencial. Para isto ele dispõe de um eletroímã acoplado a sua base, que tem a capacidade de aplicar um campo magnético na amostra, de até 3600 e. O sinal magnético é obtido a partir dos efeitos Kerr magnetoóticos transversal e longitudinal.

$\mathrm{Na}$ imagem de susceptibilidade magnética enviamos um sinal $A C$ de baixa freqüência $(150 \mathrm{~Hz})$, pelo eletroímã, que modula a magnetização da amostra. Neste caso o fotodetetor está sincronizado com esta freqüência de oscilação.

$\mathrm{Na}$ curva de histerese como a sonda encontra-se parada em um ponto da amostra, podemos nomear esta de curva de histerese local. Na curva de histerese local se pretende chegar à magnetização de saturação da amostra usando um campo que alterna entre, no máximo, +3600 e e -3600 e. O campo magnético tem a freqüência de oscilação muito baixa $\left(\sim 10^{-1} \mathrm{~Hz}\right)$.

Como o efeito Kerr é relacionado à reflexão da luz incidente, no caso dos SPs, seria mais adequado se falar em efeito Faraday, já que estamos trabalhando com a luz transmitida ou tunelamento de fótons. 
No próximo tópico discutiremos as melhorias feitas no SNOM durante meu mestrado.

\subsection{Melhorias no SNOM}

Nestes últimos dois anos o SNOM passou por algumas mudanças para melhorar cada vez mais o seu funcionamento, sensibilidade e estabilidade. A primeira mudança foi a instalação de um módulo de controle e aquisição chamado Dulcinea Control Unit da NanoTec. Este hardware nos trouxe uma maior estabilidade e facilidade para adquirir as imagens fornecidas através do WSxM. Pois agora é este hardware que cuida da aquisição do sinal do cristal piezo-elétrico que controla a distância ponta-amostra. Foi também instalado nesta mesma época um novo sistema de varredura que permitiu um aumento na área de varredura da amostra. Anteriormente a área de varredura era de $63 \times 63 \mu \mathrm{m}^{2}$ e agora passou para $90 \times 90 \mu \mathrm{m}^{2}$. Este sistema de varredura tem a particularidade de ser insensível aos campos magnéticos aplicados.

Foi confeccionado um circuito para melhorar o ganho do sinal do diapasãoe com este novo circuito notamos algumas melhorias no SNOM. Uma das melhorias foi que a relação sinal-ruído no diapasão ficou muito melhor, conseguindo uma melhor estabilidade do sistema. A outra vantagem foi que com esta melhora na relação sinal-ruído, o fator de qualidade do conjunto ponta+diapasão sofreu um forte aumento. $O$ fator de qualidade anterior era de no máximo 1000 e passou para no máximo 2200 , assim podendo se obter imagens de melhor qualidade e ainda gerando uma maior estabilidade no instrumento.

Como para medir SPs a idéia era utilizar da configuração Kretschmann, construímos um novo porta-amostra para este tipo de medida. Este faz com que a incidência da luz esteja no ângulo correto e ainda seja por baixo da amostra. A sonda do SNOM serve agora como coletora de luz e não mais como emissora. Por isto foi desenvolvido o novo modo de funcionamento no 
SNOM. Este modo permite que o equipamento funcione como um PSTM, adquirindo imagens óticas a partir de tunelamento de fótons.

Por fim houve a instalação de um segundo laser (405 nm) no sistema e também o alinhamento dos lasers. Para a instalação e alinhamento foi construída uma peça constituída de um espelho e um prisma que visava garantir a incidência dos dois feixes de laser em uma mesma fibra ótica. Com esta peça pronta se alinhou os dois lasers para poder ganhar a liberdade de escolha com qual laser trabalhar. Um exemplo para o uso dos dois lasers em conjunto é o atual desenvolvimento do SNOM para litografia ótica de escrita direta. Como o fotoresiste utilizado para esta técnica no SNOM é sensível ao laser violeta, o laser vermelho (658 nm) serve de guia para se obter a imagem ótica da amostra e depois de escolhido o local onde vai ser litografado o objeto, se troca o laser para o violeta $(405 \mathrm{~nm})$ e se litografa o que for requerido.

\subsection{Produção das amostras}

Como visamos maximizar o acoplamento do SP, antes de produzir as amostras fizemos todas as simulações necessárias para calcular o ângulo de incidência da luz e a espessura correta da amostra para cada um dos dois lasers.

Pesquisando na literatura vimos que o valor para espessura de um filme de prata e ouro que melhor acoplava o SP era entre 50 e $60 \mathrm{~nm}$ que é a espessura onde encontramos a ressonância plasmônica, e este foi o princípio das simulações. Com a variável espessura fixada em $50 \mathrm{~nm}$ criamos outra variável que mudava o ângulo de incidência e assim calculamos o ângulo que minimizava a refletividade para esta espessura. Com este valor de ângulo de incidência calculado, fizemos o caminho inverso e fixando o ângulo de incidência variamos a espessura do metal visando agora calcular qual era a melhor espessura para este ângulo. 
Assim conseguimos calcular o valor de espessura e ângulo de incidência que melhor acoplava o SP para a prata e o ouro.

Em uma segunda etapa de simulações resolvemos criar amostras que fossem magnéticas. Para isto simulamos um filme de prata intercalado com um filme fino de cobalto. Otimizamos a espessura do filme de prata e o ângulo de incidência. Também modificamos a espessura do filme de cobalto no interior da prata para produzir amostras com espessuras diferentes de cobalto.

Com o valor da espessura de prata, ouro e prata+cobalto calculado foi possível começar a produção das amostras. A deposição dos filmes foi feita usando o Sistema de Magnetron Sputtering que temos no nosso laboratório. Primeiramente fizemos uma amostra de calibração para obter a taxa de deposição para os elementos que seriam depositados ( $\mathrm{Ag}, \mathrm{Au}, \mathrm{Co}$ ). Esta amostra foi levada ao LAMFI (Laboratório de Analise de Materiais por Feixe lônico) e pela técnica de Retroespalhamento Rutherford (RBS) obtivemos as taxas de deposição de cada material. Em seguida começou o processo de deposição das amostras.

Em uma primeira etapa de deposições o substrato, que é uma lamina de vidro, foi limpo no próprio LMM. Esta limpeza não ficou boa, deixando o substrato com pequenas sujeiras e quando depositamos o material em cima destas lâminas descobrimos um filme com defeitos. Estas amostras foram muito úteis, porque a partir delas pudemos comparar a diferença do acoplamento plasmônico entre um filme regular e um filme com irregularidades.

Na segunda etapa de deposições o substrato foi limpo na sala limpa do LSI (Laboratório de Sistemas Integrados) na Escola Politécnica com o auxílio da Dr. Mariana Pojar. Nesta etapa conseguimos substratos bem limpos e regulares. Com os substratos limpos voltamos a depositar as amostras. Com as amostras prontas pudemos começar a caracterização do SP para diferentes materiais e em diferentes circunstâncias.

Algumas destas amostras foram novamente levadas ao LAMFI e foi feito o processo de RBS para garantir os valores de espessura dos filmes 
depositados. Os valores de espessura calculados bem como os medidos por RBS vão ser mostrados na parte de resultados desta dissertação.

Para as amostras de prata com cobalto foi feita a caracterização magnética visando extrair o valor de sua coercividade através de um VSM (Vibrating Sample Magnetometer). Depois elas foram levadas ao SNOM buscando extrair a imagem de susceptibilidade magnética e a curva de histerese local.

\subsection{Porta-amostra para o modo PSTM do SNOM}

Para garantir o ângulo de incidência entre a fibra ótica, que guia o feixe de laser, e a amostra foi construído um suporte. Neste foi feito um furo de $\sim 0,3 \mathrm{~mm}$, com o ângulo correto, no qual entra a fibra ótica que define o ângulo de incidência da luz. Para a fibra não quebrar enquanto estivéssemos manipulando o suporte foi usada uma agulha de seringa como guia para a fibra ótica. Para fixar esta agulha foi usado um adesivo EPOXI. Este mesmo produto foi usado para prender completamente a fibra ótica dentro da agulha. O conjunto todo foi cortado com uma serra diamantada e depois lixado vagarosamente para garantir uma superfície plana no suporte e deixar a saída da fibra ótica bem lisa. Na figura 3.4.1 vemos o suporte construído antes de ser lixado. Nesta imagem podemos ver que a fibra ótica ainda esta passando pelo suporte. Depois esta fibra foi cortada e a superfície do suporte foi polida. Dessa forma, a extremidade da fibra ficou cortada de maneira que o seu plano seja paralelo ao substrato de vidro da amostra. 


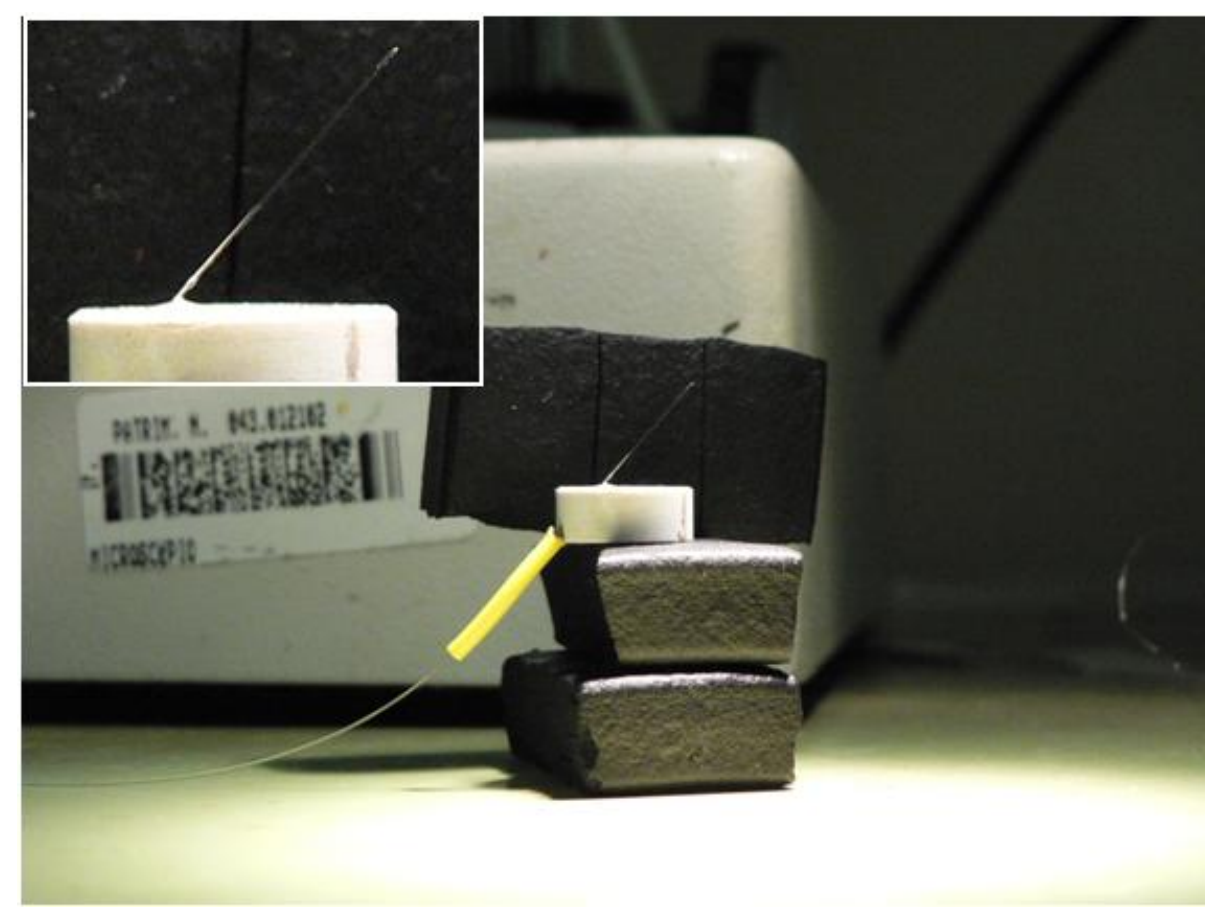

Figura 3.4.1 suporte construído para acoplar a fibra ótica com a amostra.

$\mathrm{Na}$ figura 3.4.2 podemos ver uma imagem da superfície do portaamostra. Esta imagem foi obtida com uma câmera acoplada em um microscópio ótico tradicional. Nela podemos ver o núcleo da fibra bem liso como esperávamos que estivesse para garantir uma melhor distribuição da luz.

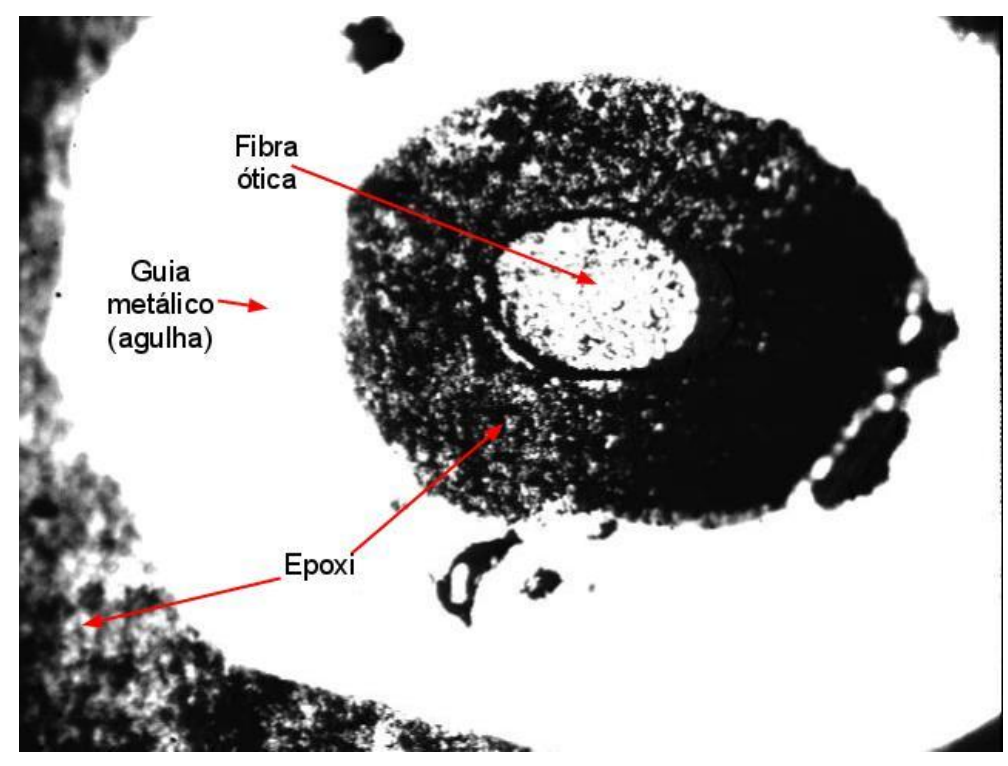

Figura 3.4.2 Saída da fibra ótica no porta-amostra. 
Com o suporte pronto, podemos fixar a amostra no porta-amostra. Para o acoplamento da luz entre a fibra ótica e a lâmina de vidro, que contém o filme metálico, usamos uma gota de líquido para casamento do índice de refração (óleo com o mesmo índice de refração do vidro). Com isto, a luz que está chegando pela fibra ótica vai incidir com o ângulo correto no metal não sofrendo dispersão pelo caminho. Para garantir que a amostra não se mova durante a aquisição das imagens fixamos a amostra sobre o suporte com cola branca comum. Na figura 3.4.3 vemos uma fotografia do conjunto suporte+amostra já fixado para medida. $O$ ponto vermelho no meio da imagem é o ponto de incidência do laser por baixo da amostra.

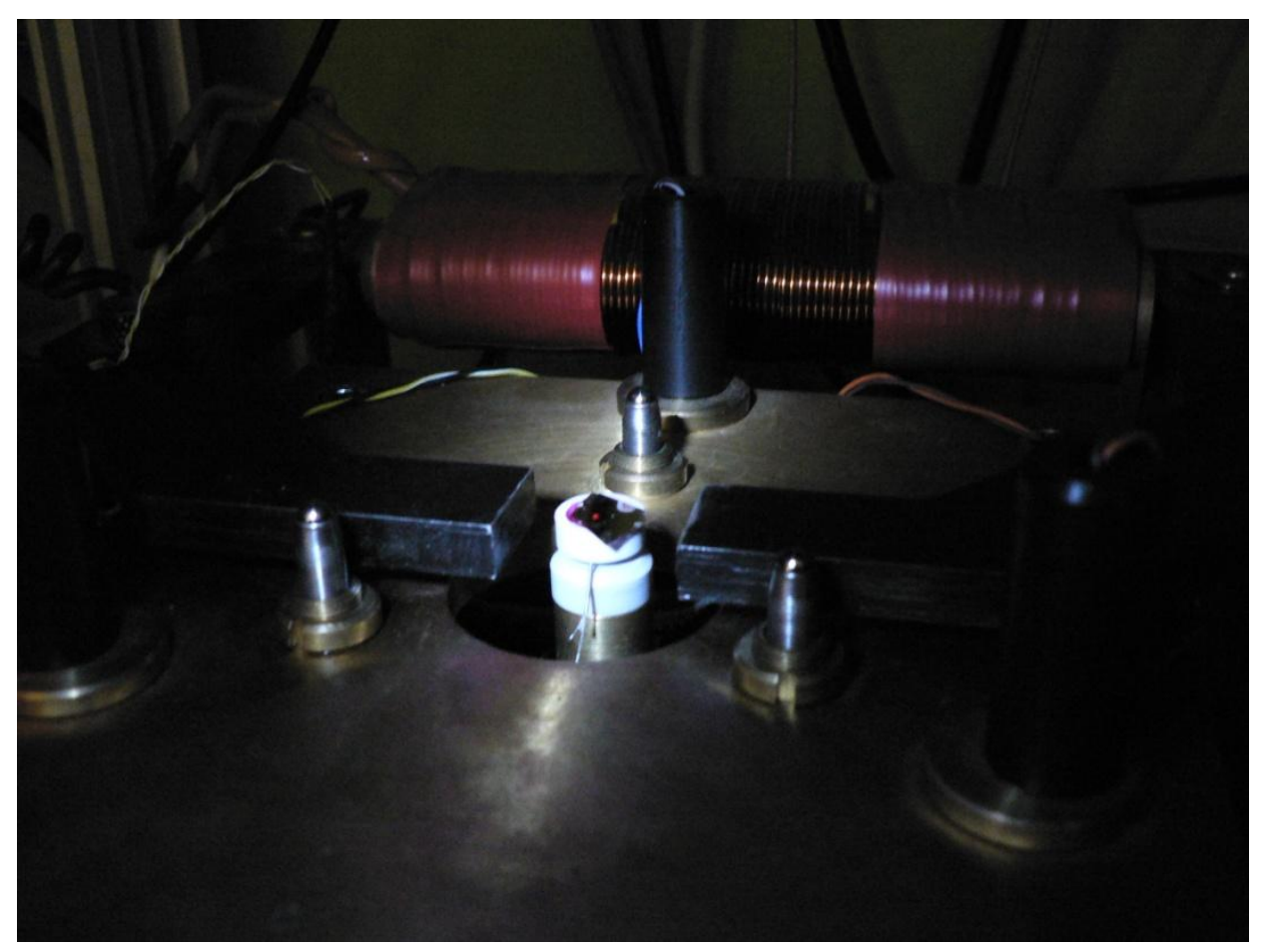

Figura 3.4.3 amostra já afixada no suporte.

No próximo tópico discutiremos como garantir que a polarização da luz seja a correta para que o SP esteja bem acoplado. 


\subsection{Visualização do acoplamento pela Lupa}

O SNOM possui uma lupa de visualização da amostra, que é constituída por uma webcam e uma lente objetiva fotográfica com um tubo de extensão. Esta lupa é utilizada para visualizar a posição da sonda do SNOM sobre a amostra. E através de sua imagem, no caso dos plasmons de superfícies, que primeiramente garantimos um bom acoplamento.

Para que haja um bom acoplamento plasmônico entre a luz e a amostra é necessário que a luz incidente esteja com a polarização p. Precisamos, portanto garantir esta polarização. Para o ajuste da polarização da luz usamos o dispositivo "orelhas de Mickey" como dito anteriormente. Como os parâmetros de espessura e ângulo de incidência são os corretos, conseguimos ver o acoplamento do SP pela lupa. Pela posição que a webcam se encontra, nós conseguimos ver dois pontos de luz na amostra, um que é o ponto de incidência da luz no filme de metal nobre onde vai ficar acoplado o SP, e o segundo é a luz refletida pelo filme que chega de volta ao porta-amostra.

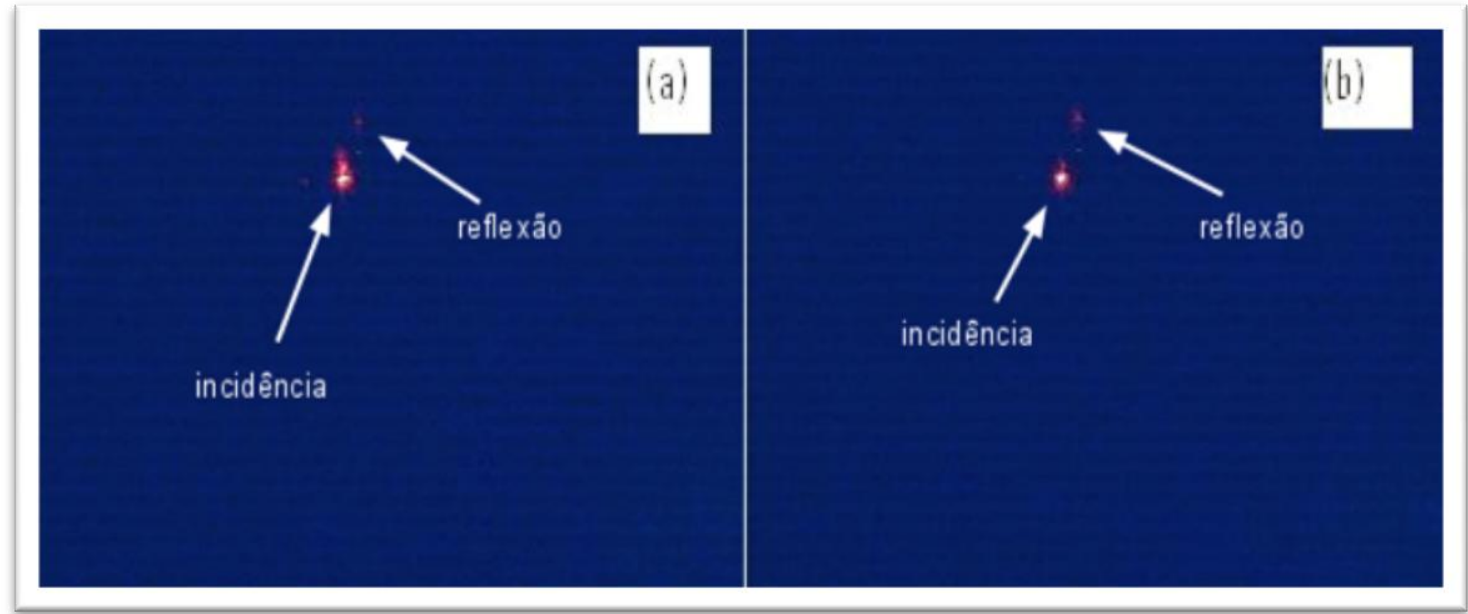

Figura 3.5.1 incidência na amostra (a) com polarização p, (b) com polarização s.

A luz refletida tem eminentemente a polarização $s$, já o SP tem por princípio a polarização $p$, então se maximizarmos a luz na superfície do filme e minimizarmos a luz na base do porta-amostra, podemos garantir que 
a luz que está chegando a amostra tem preferencialmente a polarização $\mathrm{p}$. Na figura 3.5.1 podemos ver este efeito em duas fotos adquiridas pela lupa. Na figura 3.5.1(a) temos a imagem para a polarização p. Vemos dois pontos um bem forte referente à incidência e outro bem fraco referente à reflexão. Na figura 3.5.1(b) vemos que o ponto de incidência perdeu intensidade já o de reflexão ganhou intensidade. Este é o modo de polarização s. Interessante notar também que na figura 3.5.1(a) não se vê somente um ponto na incidência, pode-se ver um feixe de luz que propaga na vertical. Este é o primeiro indício da propagação do SP. Este mesmo tipo de imagem é encontrado no artigo de Bouhelier (Bouhelier, et al., 2005).
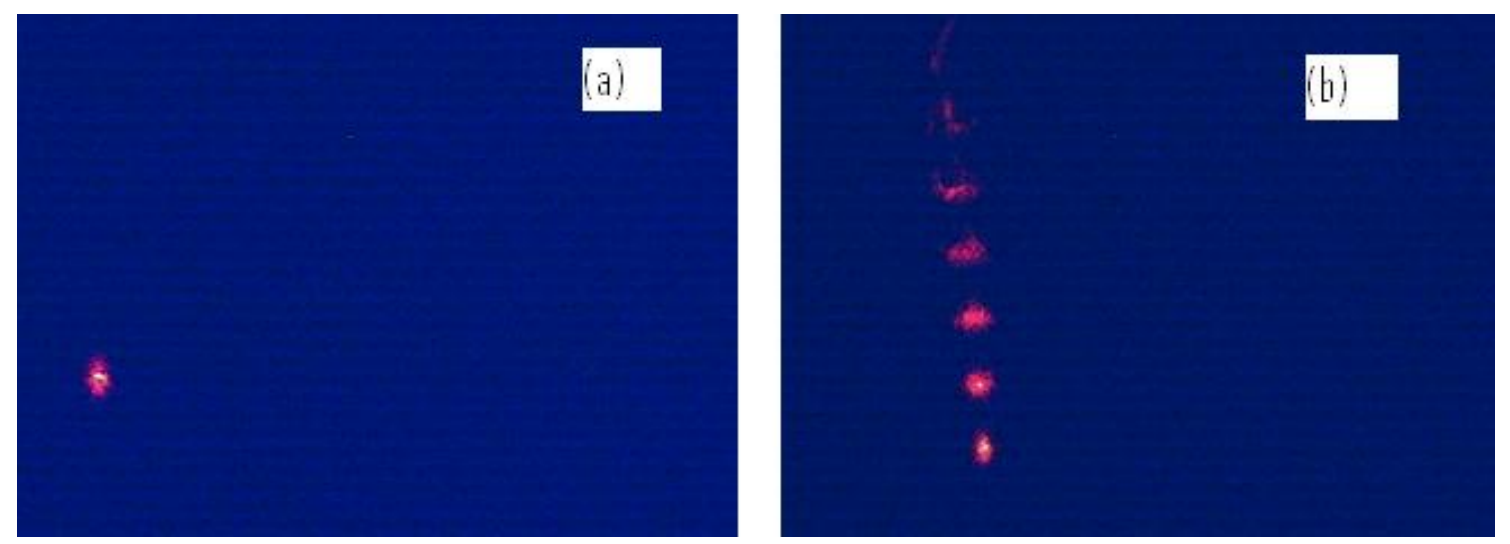

Figura 3.5.2 imagem de incidência na amostra com SP (a) bem acoplado , (b) mal acoplado.

Outro ponto importante neste acoplamento é a amostra estar bem fixa e encostada no porta-amostra. Se ela não estiver encostada no suporte, pode ocorrer que o ângulo entre a luz incidente e a amostra não seja o correto e assim toda a luz incidente vai ser refletida pela amostra. Na figura 3.5.2(a) novamente podemos ver uma incidência em ângulo correto. Na figura 3.5.2(b) vemos o caso de incidência incorreta. Como o ângulo não é o correto se nota múltiplas reflexões da luz dentro da lâmina de vidro e por isso aparecem muitos pontos de luz na amostra.

Tendo garantido estes pontos podemos dar início a aproximação da sonda e a visualização da propagação do plasmon de superfície pelo SNOM. 


\subsection{Observação do plasmon de superfície pelo SNOM}

Nesta última parte da discussão experimental colocaremos os pontos principais para se obter uma imagem de boa qualidade do plasmon de superfície. Com a amostra fixada no porta-amostra e verificada a polarização da luz incidente, aproximamos a sonda do SNOM do ponto de incidência e começamos uma varredura visando ao máximo centralizar a propagação do SP. Na figura 3.6.1 vemos a sonda do SNOM colocada próximo ao centro de incidência da luz na amostra. Neste caso o laser que está incidindo na amostra é o violeta. Vemos a imagem da sonda à direita e à esquerda do centro de incidência, isto ocorre por causa do reflexo da sonda na superfície da amostra.

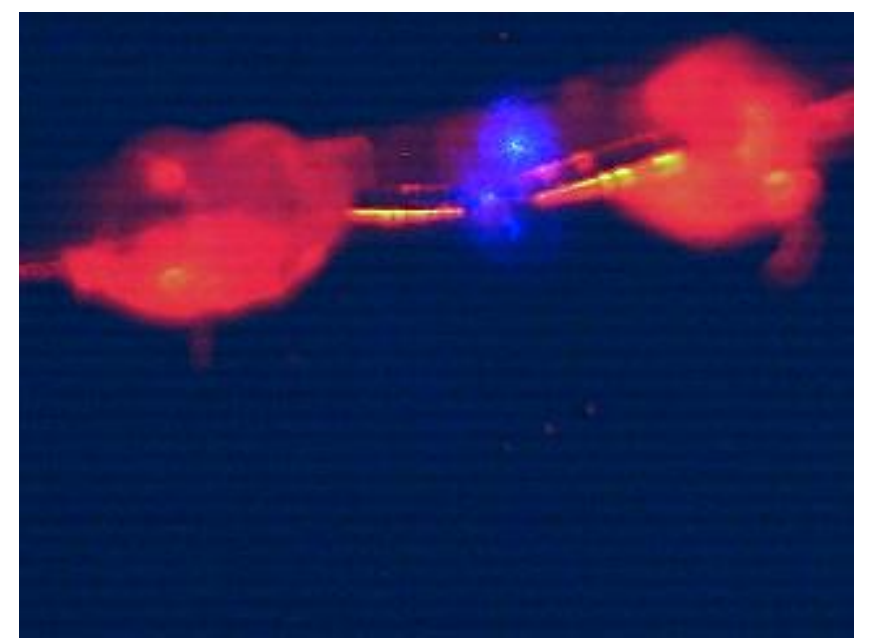

Figura 3.6.1 sonda em regulação com a incidência do laser violeta na amostra.

As áreas de varreduras feitas por nós variam de $6 \times 6 \mu \mathrm{m}^{2}$ a $70 \times 70 \mu \mathrm{m}^{2}$ sendo possível assim analisar a estrutura fina da propagação do SP e também a distância de propagação de longo alcance. De posse destas imagens podemos comparar os valores teóricos da propagação do SP com os valores experimentais obtidos.

Com o intuito de verificar o decaimento exponencial do SP no ar usamos uma ferramenta do programa WSxM que faz duas imagens simultâneas. A primeira imagem é uma varredura em distância normal de regulação, e uma 
segunda imagem com a sonda do SNOM a uma distância da amostra escolhida pelo usuário. Esta ferramenta chama-se Retrace. Foram obtidas imagens usando esta ferramenta que demonstram a dependência da distância sonda-amostra para a visualização do SP.

Para analisar a dependência do SP com o material fizemos imagens com as diferentes amostras: prata, ouro e prata com cobalto. Também foi feita a análise da propagação do SP para dois comprimentos de onda da luz incidente: $405 \mathrm{~nm}$ e $658 \mathrm{~nm}$. Assim podemos obter um resultado bem estruturado sobre a visualização do SP no SNOM.

Através do WSxM e de programas de análise de dados (Origin, Excel e Mathematica) fizemos toda a análise das imagens e dos dados experimentais obtidos e os comparamos com os valores teóricos calculados anteriormente.

Concluímos assim a descrição do instrumental experimental necessário ao projeto. No próximo capítulo trataremos dos resultados obtidos para cada um dos casos citados acima e também as análises feitas sobre cada uma das imagens obtidas pelo SNOM para melhor compreensão do experimento. 


\section{Cap. 4. Resultados Experimentais}

Dentro deste capítulo iremos apresentar os resultados obtidos para a produção das amostras e propagação do SP para estas amostras.

\subsection{Produção das amostras}

Nesta primeira parte dos resultados apresentaremos as simulações feitas para a escolha da espessura das amostras, bem como o ângulo de incidência que maximize o acoplamento do SP. Apresentaremos também os resultados obtidos pela técnica de RBS para as espessuras das amostras produzidas.

\subsubsection{Simulações}

Para as simulações da espessura e o ângulo de incidência da luz ideal para as amostras, utilizamos um programa feito pelo Prof. Antonio Domingues dos Santos. Apresentaremos agora alguns gráficos que vão elucidar os melhores valores para os parâmetros acima citados.

$\mathrm{Na}$ figura 4.1.1(a) temos a refletividade em função do ângulo de incidência e em (b) temos a refletividade em função da espessura de prata na amostra. Em ambos os casos o comprimento de onda escolhido é o do laser vermelho do nosso laboratório $(658 \mathrm{~nm})$. Para a prata a constante dielétrica é $\varepsilon_{1}=-20,1+0,45 i$, este valor foi retirado do artigo do Christy et al. (Johnson, et al., 1972). 


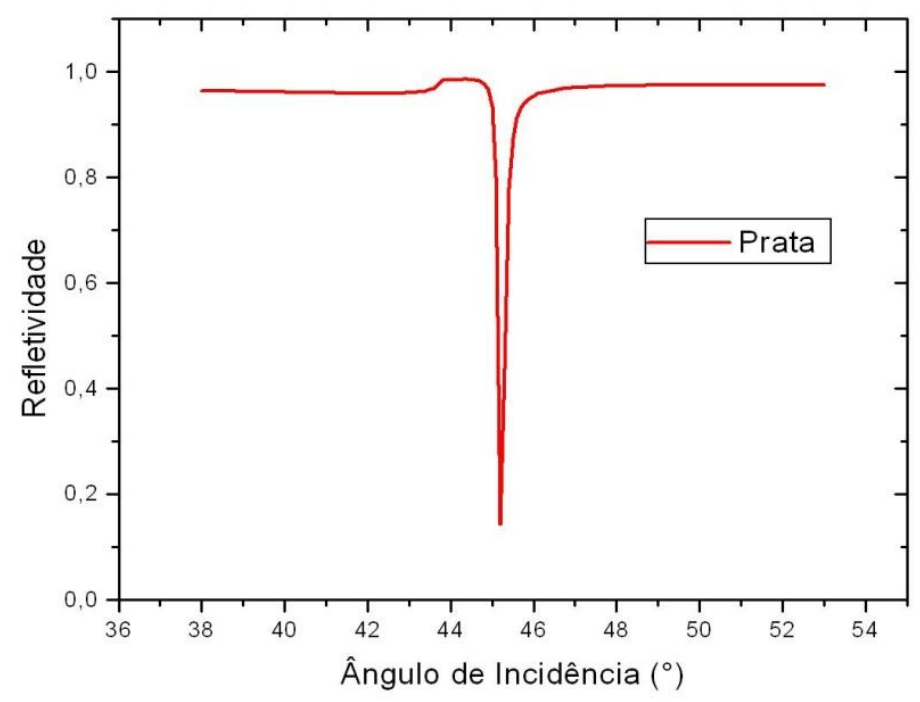

(a)

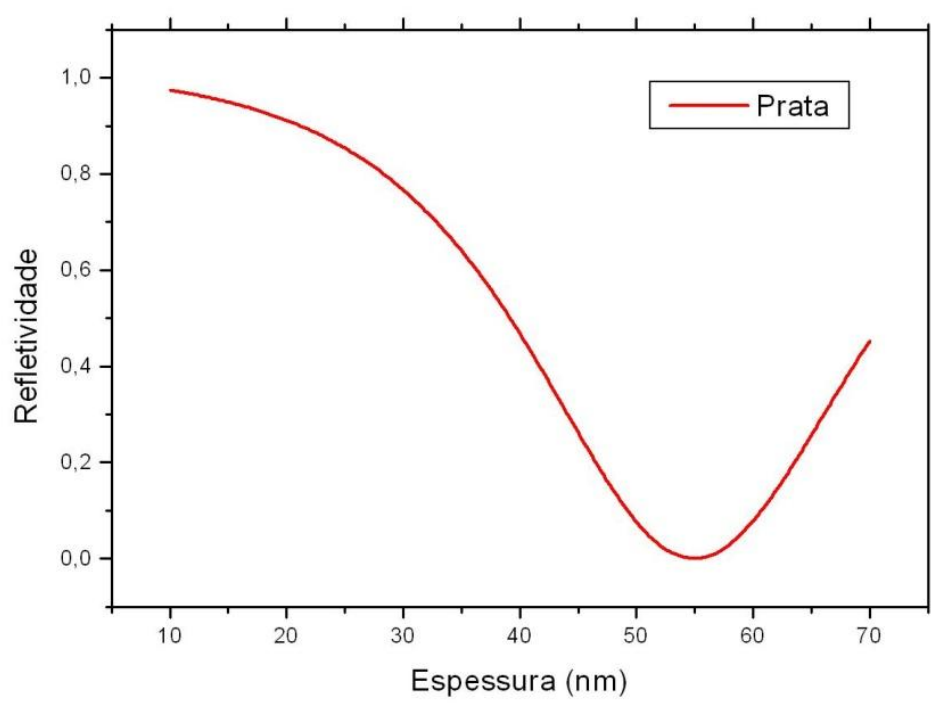

(b)

Figura 4.1.1 (a) Refletividade x Ângulo de incidência (b) Refletividade x Espessura da prata

Destes dois gráficos obtivemos o valor de ângulo de incidência para a construção do suporte. $O$ ângulo encontrado foi de $45,23^{\circ}$ e por não termos essa precisão de ângulo, e por causa da abertura do núcleo da fibra ótica ser maior que $1^{\circ}$, adotamos o valor de $45^{\circ}$. Para a espessura encontramos 0 valor de $55 \mathrm{~nm}$, e este será o valor utilizado para a produção das amostras que contenham prata. 
O mesmo foi feito para o ouro e o valor de ângulo de incidência encontrado foi de $46^{\circ}$ que é muito próximo do valor para a prata. Como a abertura da fibra em dimensão angular é maior que esta diferença, podemos supor que o suporte com $45^{\circ}$ de incidência é suficiente para o acoplamento do plasmon de superfície nos dois tipos de amostras. Para a espessura do ouro foi encontrado $53 \mathrm{~nm}$, portanto usaremos este valor como padrão. Para o ouro a constante dielétrica é $\varepsilon_{1}=-13,6+1$,0i também retirado do artigo do Johnson et al.

A abertura numérica da fibra (NA) é de 0,12 , o que equivale a um ângulo de aceitação de $13^{\circ}$. Então o ângulo de incidência é $45^{\circ} \pm 6,5^{\circ}$, por isto este ângulo acopla SP tanto para as amostras de prata como para as de ouro.

Para as amostras contendo o filme fino de cobalto usaremos a prata com $55 \mathrm{~nm}$ de espessura para acoplar o SP. Após a análise das simulações o valor de $55 \mathrm{~nm}$ de prata com a camada de cobalto ainda apresentava ângulo de incidência muito próximo a $45^{\circ}$. Na figura 4.1.2 vemos quatro curvas que representam as amostras de prata com $55 \mathrm{~nm}$ com um filme fino de cobalto de 1, 3, 5, 10nm de espessura. Neste gráfico podemos notar que os valores de ressonância batem exatamente no mesmo valor que para a prata pura de $55 \mathrm{~nm}$. Também podemos ver que conforme se aumenta a espessura do filme de cobalto a refletividade tem um acréscimo. Assim as amostras com menos cobalto tem melhor acoplamento. Para o cobalto o valor da constante dielétrica é $\varepsilon_{1}=-13,2+19,2 i$ obtida do artigo (Johnson, et al., 1974). 


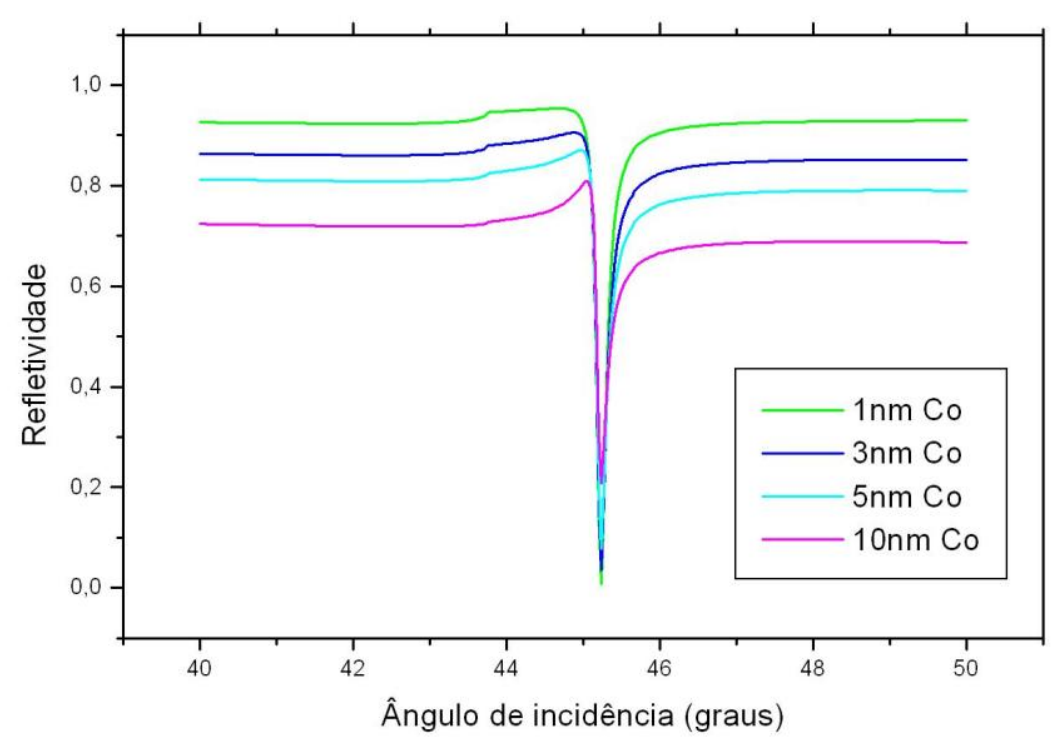

Figura 4.1.2 Refletividade $x$ ângulo de incidência para uma amostra de prata com cobalto.

Após estes resultados mostrados podemos passar para a produção das amostras e na sequência a caracterização destas.

\subsubsection{Produção das amostras}

As amostras foram produzidas pelo método de magnetron sputtering no próprio laboratório. As amostras ainda foram caracterizadas por RBS para sabermos se a espessura depositada foi a esperada.

A deposição de todos os materiais foi feita com potencia de $100 \mathrm{~W}$, com fluxo de argônio de $20 \mathrm{sccm}$, a 5 mTorr de pressão e a temperatura ambiente.

Após a deposição as amostras foram levadas para o LAMFI onde foi feito o RBS para obter as espessuras de prata e cobalto de cada uma delas. $\mathrm{O}$ RBS foi feito com um feixe de $15 \mathrm{nA}$, com $15 \mu \mathrm{C}$ de carga e energia de 2,25 MeV. Através do espectro de RBS e o programa de análise RUMP foi possível extrair a espessura dos filmes. 
Na tabela 4.1.1 vemos os valores das espessuras esperadas e medidas para cada uma das amostras.

\begin{tabular}{|c|c|c|c|c|}
\hline Amostra & $\begin{array}{c}\text { Espessura } \\
\text { de Ag } \\
\text { esperada(nm) }\end{array}$ & $\begin{array}{c}\text { Espessura } \\
\text { de Co } \\
\text { esperada(nm) }\end{array}$ & $\begin{array}{c}\text { Espessura } \\
\text { de Ag } \\
\text { medida }(\mathrm{nm})\end{array}$ & $\begin{array}{c}\text { Espessura } \\
\text { de Co } \\
\text { medida (nm) }\end{array}$ \\
\hline Ag55 & 55 & 0 & 57,4 & 0 \\
\hline Ag55Co1 & 55 & 1 & 58 & 1,2 \\
\hline Ag55Co3 & 55 & 3 & 58,4 & 3,1 \\
\hline Ag55c010 & 55 & 10 & 57 & 10,3 \\
\hline Ag55Co05 & 55 & 0,5 & 57,2 & 0,6 \\
\hline
\end{tabular}

Tabela 4.1 1 espessura da prata e do cobalto esperada e as medidas por RBS.

Portanto finalizando assim a parte de produção das amostras que foram analisadas no SNOM. No próximo tópico iremos colocar os resultados encontrados para a propagação do SP nas amostras e depois discutiremos as imagens encontradas.

\subsection{Imagens do SP nas amostras}

Nesta parte da dissertação iremos mostrar as imagens obtidas com 0 SNOM, no modo PSTM, para a propagação do SP em diferentes materiais e com diferentes composições.

Primeiro iremos mostrar os resultados da propagação do SP para a amostra Ag55 tanto para o laser vermelho como para o laser violeta. Pois como estudado na parte das simulações, ela deve ser a amostra com melhor acoplamento. Logo a propagação do SP deve ser mais evidente e mais longa. Iremos chamar de varredura em escala grande aquelas em que a área de varredura é superior a $50 \times 50 \mu \mathrm{m}^{2}$ e varreduras de escala pequena aquelas em que ela é menor que $10 \times 10 \mu \mathrm{m}^{2}$. 
As imagens topográficas têm cores em tons de laranja e a escala que aparecerá ao seu lado é medida em nanometros. As imagens óticas usando o laser vermelho têm cores em tons de vermelho e a escala é em Volts. As imagens óticas com o laser violeta têm cores em tons de azul e a escala também é em Volts.

Na figura 4.2.1 vemos duas imagens uma topográfica e uma ótica onde notamos a propagação do SP. Esta imagem foi feita com um filme de prata de $55 \mathrm{~nm}$ sendo iluminado pelo laser vermelho e a área de varredura desta imagem é de $60 \times 60 \mu \mathrm{m}^{2}$. Para a imagem ótica temos uma escala em z arbitrária, pois o que o Lock-in amplifier envia a Dulcinea é um sinal de 0$10 \mathrm{~V}$, onde $10 \mathrm{~V}$ é o máximo da escala escolhida.

O fundo de escala do Lock-in amplifier neste primeiro caso era de $1 \mathrm{mV}$.

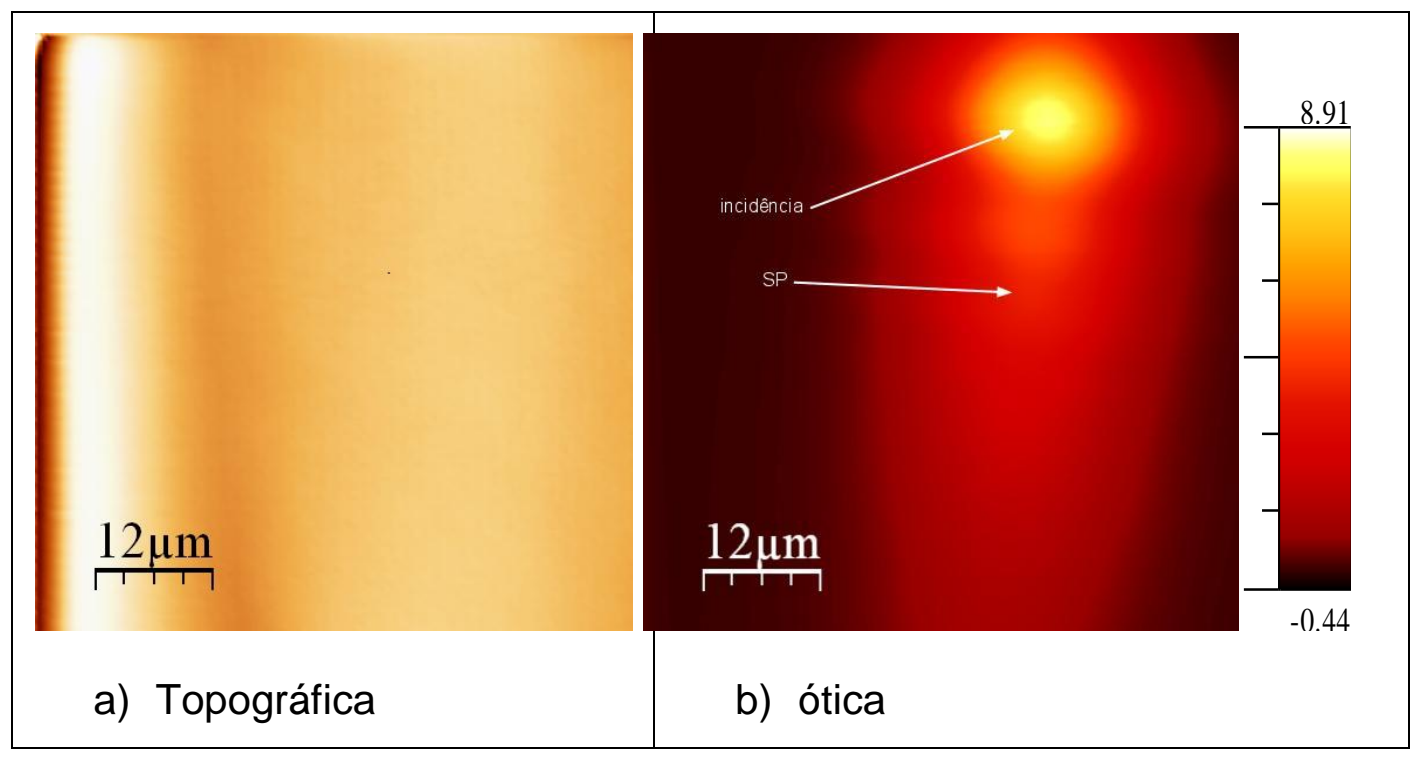

Figura 4.2.1 Propagação do SP em filme de prata de 55nm com laser vermelho.

$\mathrm{Na}$ imagem topográfica vemos a direta um declive que é por conta de um problema no sistema de varredura do SNOM, porém este declive não parece afetar as imagens óticas. Apesar deste declive a imagem topográfica não apresenta nenhum detalhe relevante, está completamente lisa. Já na imagem ótica vemos um alto contraste, evidenciando na parte superior, o ponto de incidência da luz, e deste ponto para a parte inferior vemos um feixe luminoso que caracteriza a propagação do SP. São visualizáveis 
também oscilações na intensidade do sinal ótico, ao longo da propagação do plasmon de superfície. Estas oscilações são estáveis no tempo e se repetem em imagens sucessivas, portanto evidenciando um padrão existente dentro da propagação do SP.

Para a mesma amostra foram feitas outras imagens que comprovaram o caráter da propagação do SP. Na figura 4.2.2 temos a mesma amostra, porém evidenciando uma forte oscilação dentro da propagação do SP. A imagem também tem área de varredura de $60 \times 60 \mu \mathrm{m}^{2}$. O fundo de escala é de $500 \mu \mathrm{V}$.

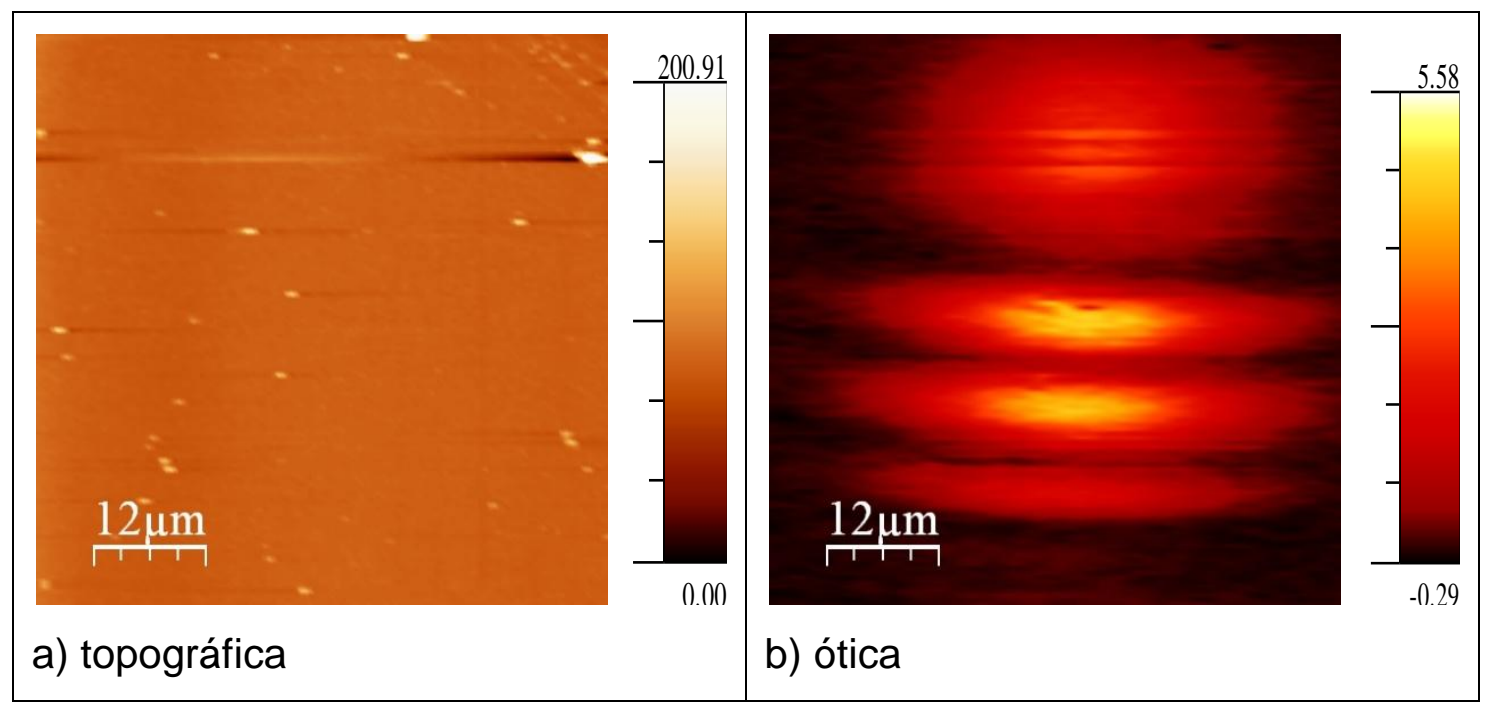

Figura 4.2.2 filme de prata com $55 \mathrm{~nm}$ com laser vermelho.

$\mathrm{Na}$ imagem ótica é possível ver com mais clareza as oscilações na intensidade ótica. Vemos o centro de incidência no alto da imagem e abaixo vemos três faixas claras que representam a propagação do plasmon de superfície.

Para a obtenção da figura 4.2.3, o sistema de varredura $X Y$ foi rotacionado de $90^{\circ}$. Na imagem ótica (a) temos a varredura padrão. Já na ótica (b) foi feita uma imagem com a sonda varrendo sistematicamente a mesma linha para poder evidenciar o decaimento exponencial do SP e a sua estabilidade ao longo do tempo característico de medida. A extensão da varredura foi preservada e o fundo de escala ótico é $500 \mu \mathrm{V}$. 


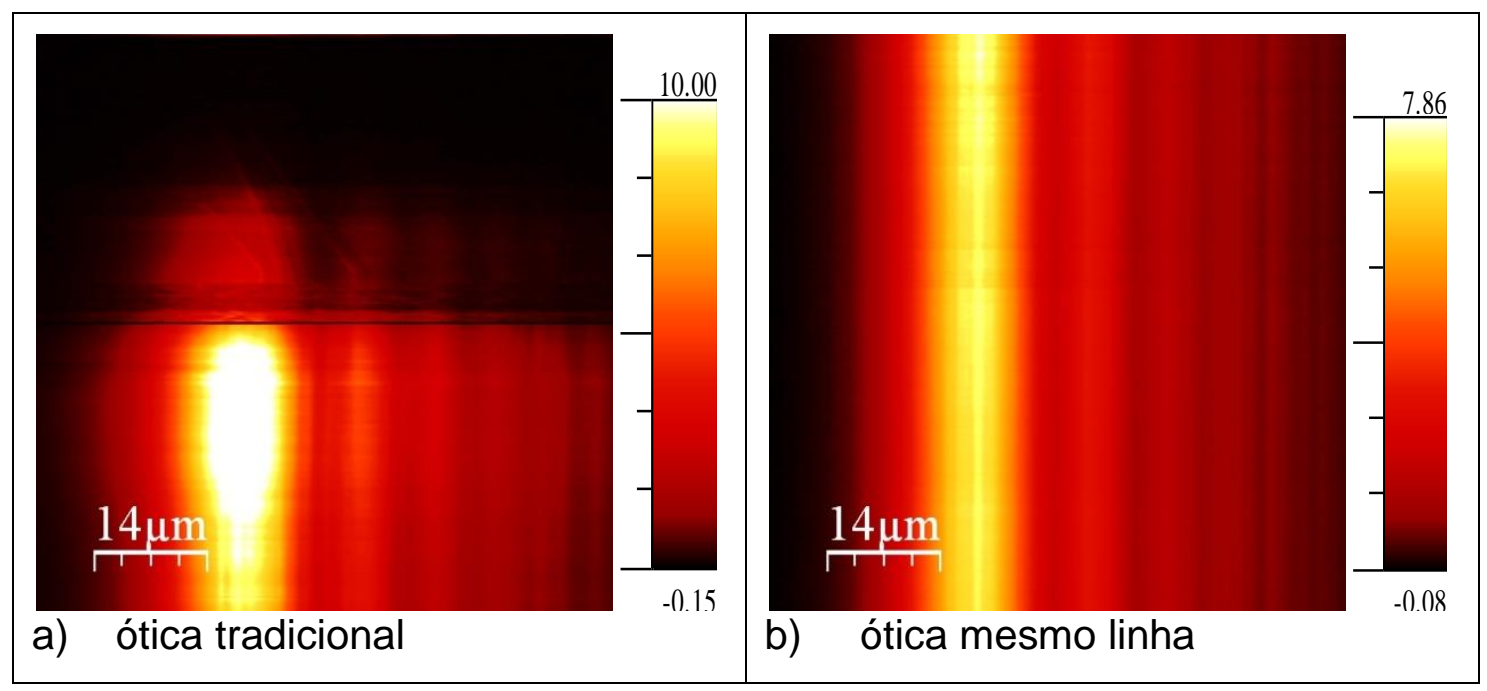

Figura 4.2.3 filme de prata $55 \mathrm{~nm}$ com laser vermelho e varredura a $90^{\circ}$.

Ainda com o filme de prata de $55 \mathrm{~nm}$ mudamos a incidência do laser do vermelho para o laser violeta e obtivemos uma imagem ótica da propagação para este novo comprimento de onda, como vemos na figura 4.2.4. A imagem tem área de varredura de $60 \times 60 \mu \mathrm{m}^{2}$. E o fundo de escala é $20 \mu \mathrm{V}$. Infelizmente uma sujeira perturbou a imagem no meio da varredura por isso existe uma falha na imagem. Vemos a falha na imagem topográfica que também pode ser vista na imagem ótica. Também podemos notar que a propagação do plasmon de superfície para esta incidência é menor que as observadas com o laser vermelho.

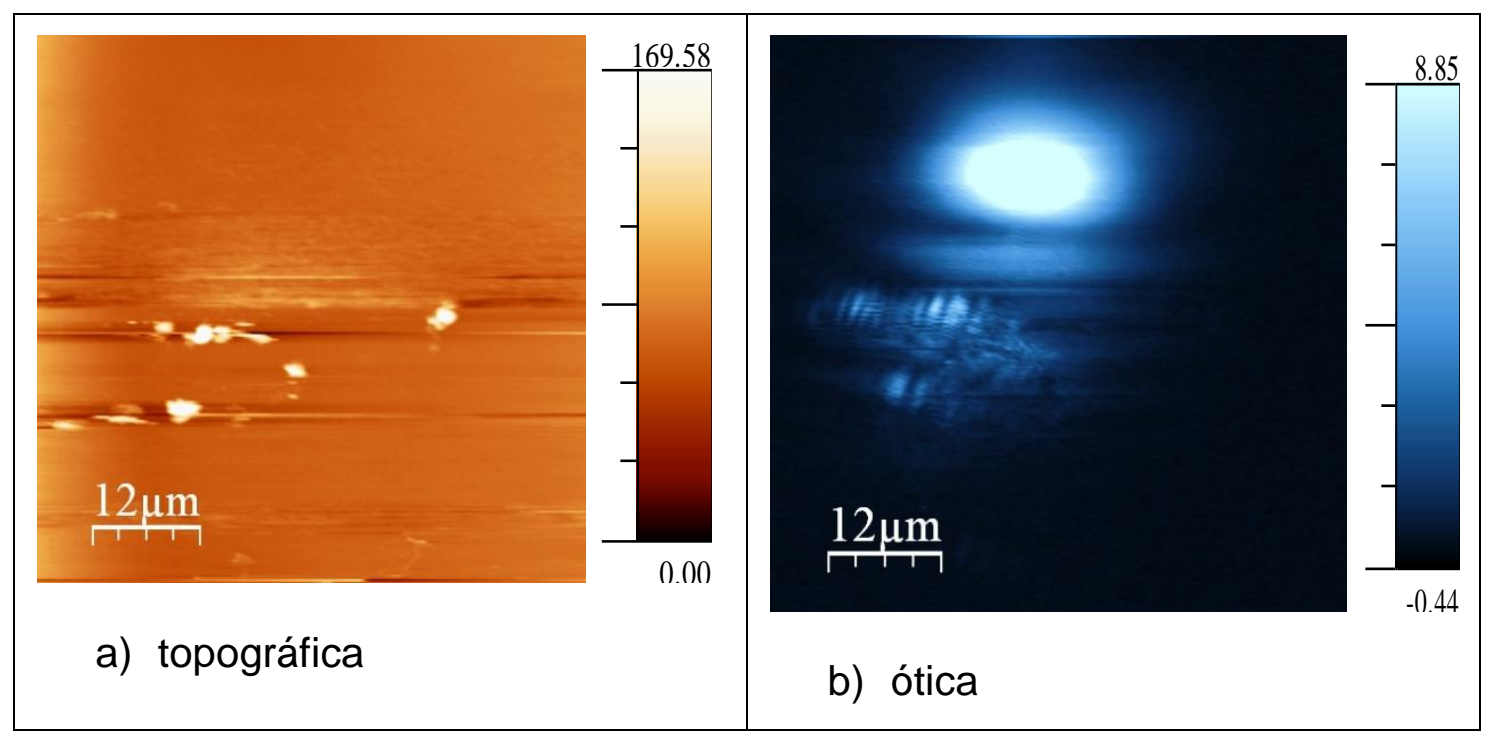

Figura 4.2.4 filme de prata de $55 \mathrm{~nm}$ com laser violeta. 
O mesmo foi feito para o filme de ouro. Na figura 4.2.5 vemos a imagem ótica para o laser vermelho (a) e para o laser violeta (b). Ambas tem varredura de $60 \times 60 \mu \mathrm{m}^{2}$. Para o laser vermelho o fundo de escala é $5 \mathrm{mV}$ e para o laser violeta $20 \mu \mathrm{V}$. Vemos, através desta figura, que a distância de propagação do SP para a laser vermelho é maior que para o laser violeta.

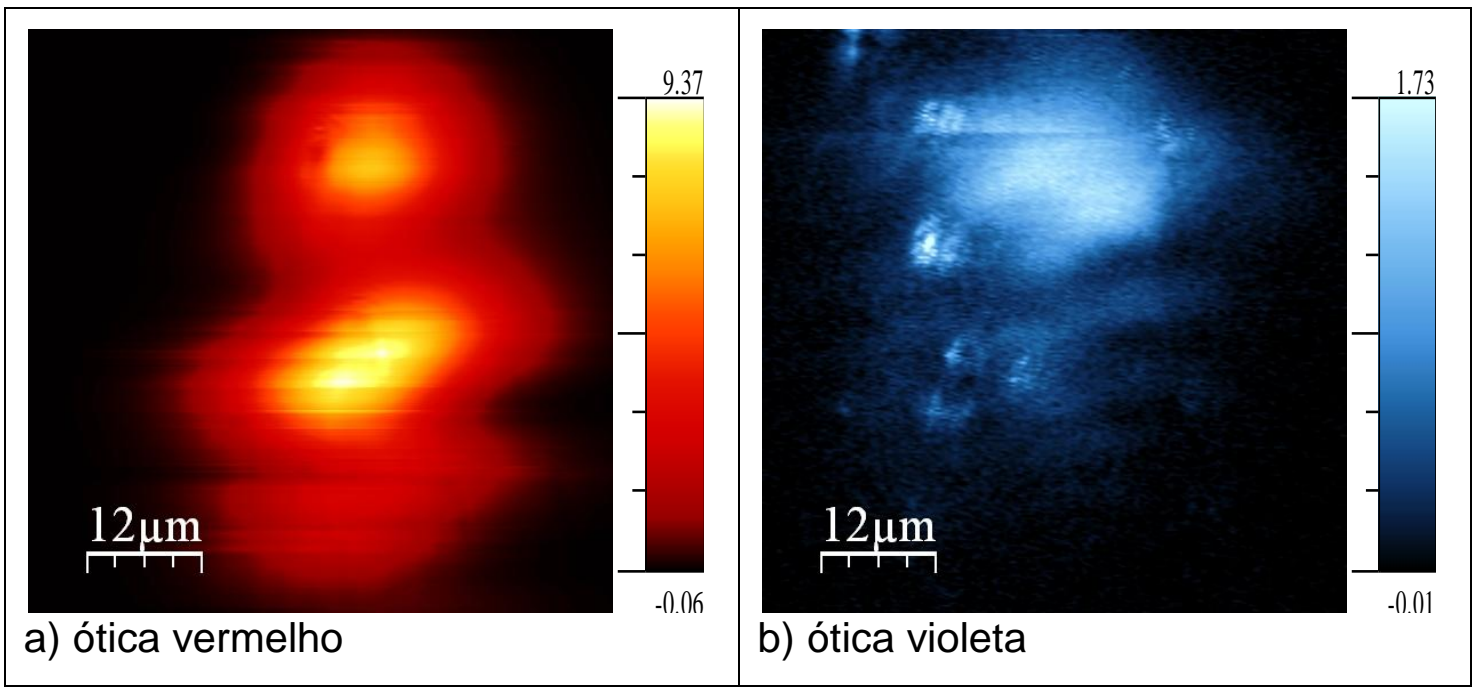

Figura 4.2.5 filme de ouro com $55 \mathrm{~nm}$ com laser vermelho(a) e violeta(b).

Na varredura de área de escala grande $\left(>50 \times 50 \mu \mathrm{m}^{2}\right)$ fizemos também as imagens de propagação do SP para os filmes de prata com cobalto. $\mathrm{Na}$ primeira imagem, vista na figura 4.2.7, temos o filme de $55 \mathrm{~nm}$ de prata com $1 \mathrm{~nm}$ de cobalto. As disposições destes filmes são: substrato de vidro, $5 \mathrm{~nm}$ de prata, filme de cobalto com diferentes espessuras e $50 \mathrm{~nm}$ de prata na superfície. Vemos um esquema das amostras na figura 4.2.6. 


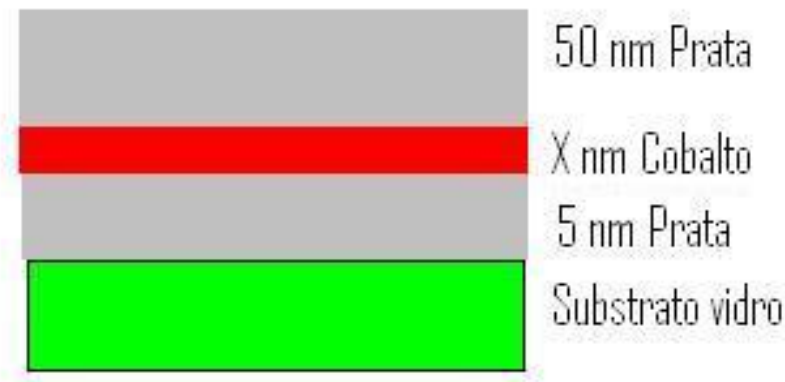

Figura 4.2.6 configuração das amostras de prata e cobalto produzidas.

A área de varredura da imagem para a amostra com $1 \mathrm{~nm}$ de cobalto (Ag55Co1) é de $60 \times 60 \mu \mathrm{m}^{2}$ e seu fundo de escala ótico é $200 \mu \mathrm{V}$. Nesta imagem iremos utilizar uma ferramenta do WSXM que permite fazer uma imagem 3D para melhor visualização do SP. O laser utilizado foi o vermelho.

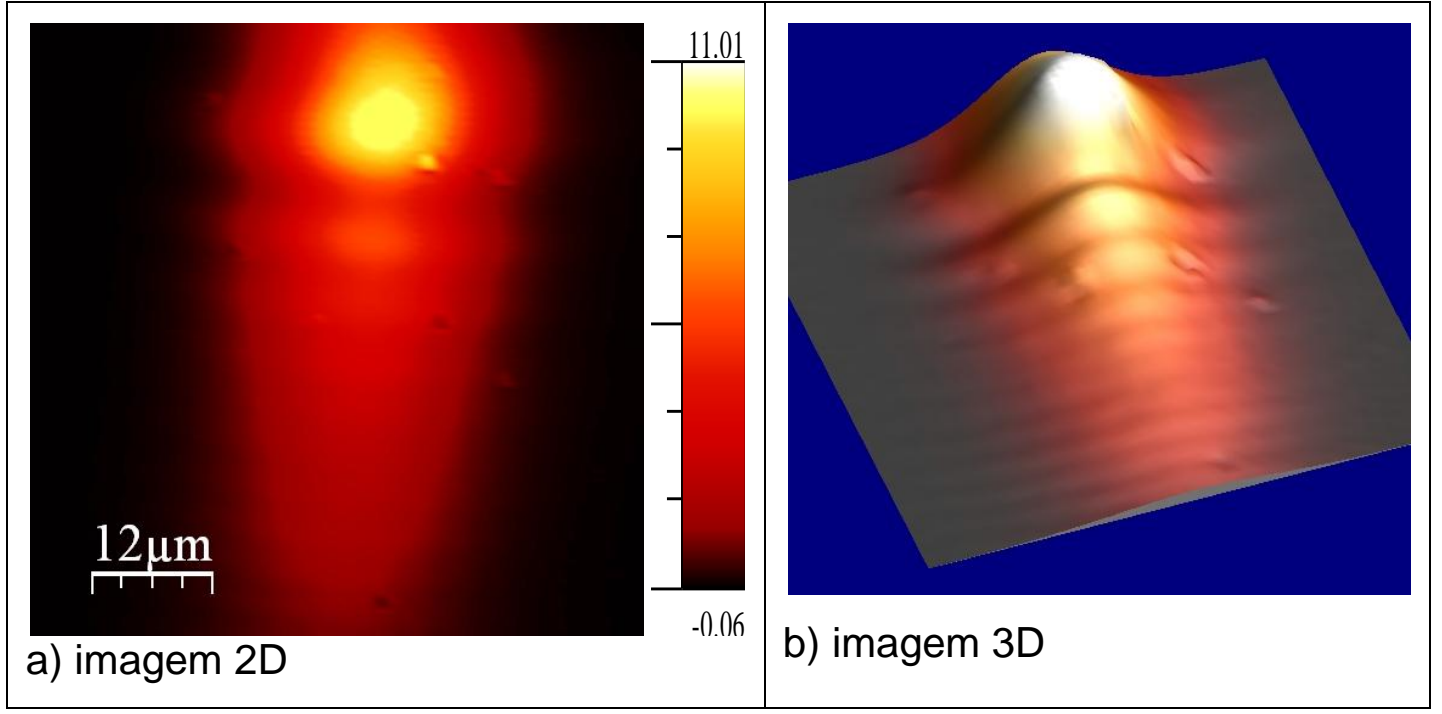

Figura 4.2.7 filme de prata com $1 \mathrm{~nm}$ de cobalto com laser vermelho.

$\mathrm{Na}$ imagem em 3D podemos ter uma melhor percepção das oscilações na intensidade ótica que estão em todas as imagens de propagação do SP.

O mesmo foi feito para a amostra de $3 \mathrm{~nm}$ e $10 \mathrm{~nm}$ de cobalto. $\mathrm{Na}$ amostra Ag55Co10 foi obtida também a propagação com o laser vermelho e violeta (figura 4.2.9). Para a amostra $\mathrm{Ag} 55 \mathrm{Co} 3$ (figura 4.2.8) somente foi feito a imagem com o laser vermelho. A área de varredura das imagens é de $60 \mathrm{x}$ 
$60 \mu \mathrm{m}^{2}$. Na figura 4.2.8 (b) a escala ótica é de $100 \mu \mathrm{V}$ e em 4.2.9 (a) a escala ótica é de $20 \mu \mathrm{V}$, já em (b) a escala é de $100 \mu \mathrm{V}$.

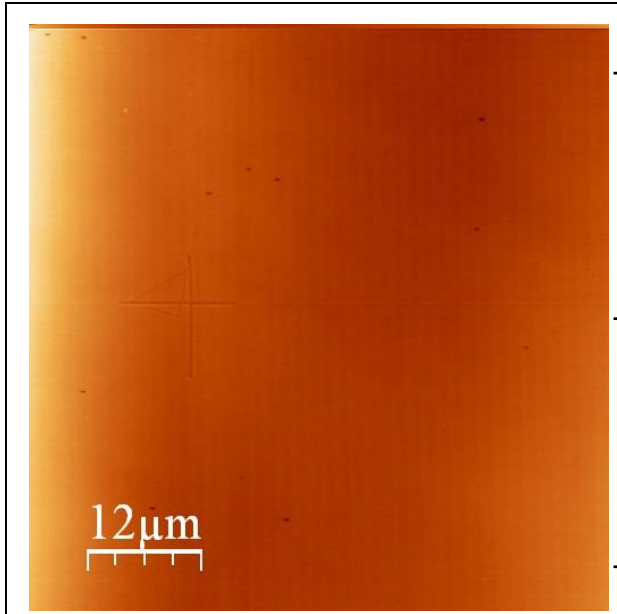

a) topográfica

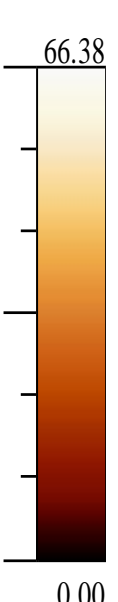

0.00

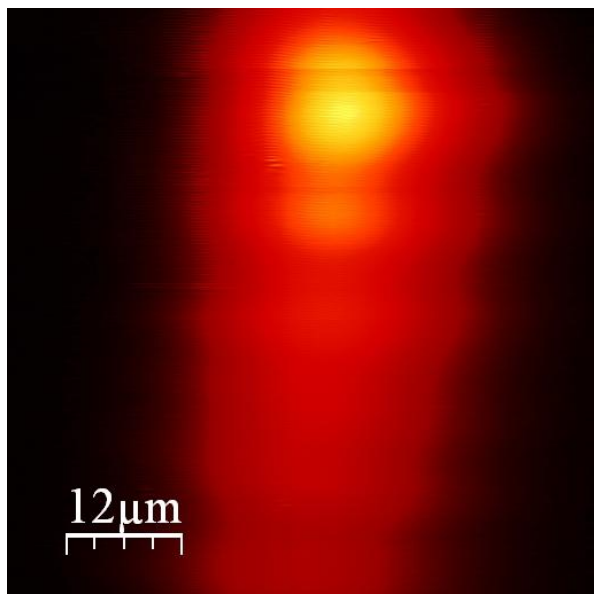

b) otica

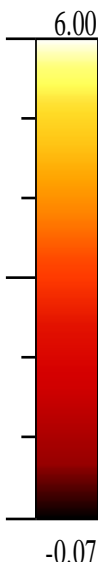

$-0.07$

Figura 4.2.8 filme de $55 \mathrm{~nm}$ de prata com $3 \mathrm{~nm}$ de cobalto com o laser vemelho.

Temos na imagem topográfica uma superfície lisa e quase sem defeitos. $\mathrm{Na}$ imagem ótica podemos ver o mesmo padrão de propagação visto anteriormente. Um centro de incidência no topo da imagem e abaixo disto a propagação do SP.

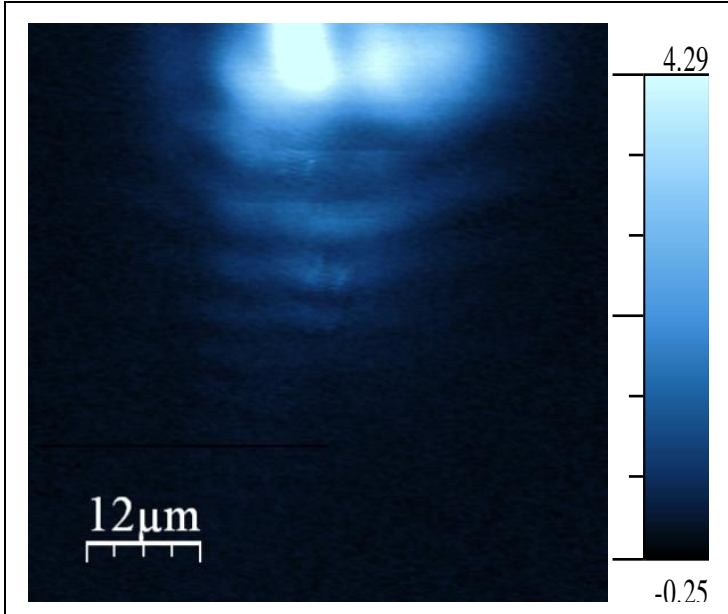

a) ótica laser violeta

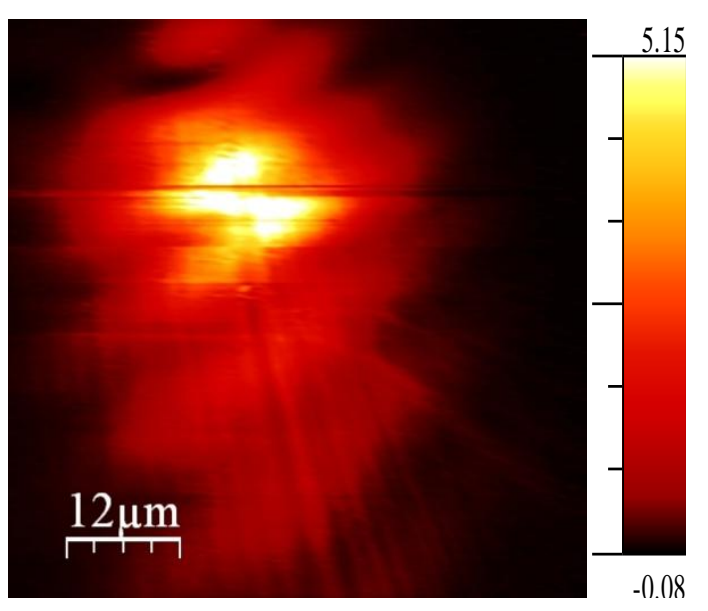

b) ótica laser vermelho

Figura 4.2.9 Amostra de $55 \mathrm{~nm}$ de prata com $10 \mathrm{~nm}$ de cobalto (a) com laser violeta, (b) com laser vermelho. 
Para esta amostra vemos as imagens óticas com laser violeta (a) e vermelho (b). Temos o mesmo padrão de propagação do SP. E podemos ver por esta imagem que a distância de propagação do SP para o vermelho é maior que para o violeta como já vimos em outros casos.

Após a demonstração dos resultados para as amostras com substrato limpo, vamos mostrar agora alguns resultados específicos que podem ser obtidos quando existem defeitos nas amostras. Então a partir de agora estamos usando as amostras produzidas com o substrato sujo.

Nesta primeira imagem (figura 4.2.10) vemos um filme de $55 \mathrm{~nm}$ de prata com dois centros espalhadores que podem ser vistos na imagem ótica e topográfica. A área de varredura da imagem é $60 \times 60 \mu \mathrm{m}^{2}$ e sua escala ótica é $100 \mu \mathrm{V}$, ela foi obtida com laser vermelho.

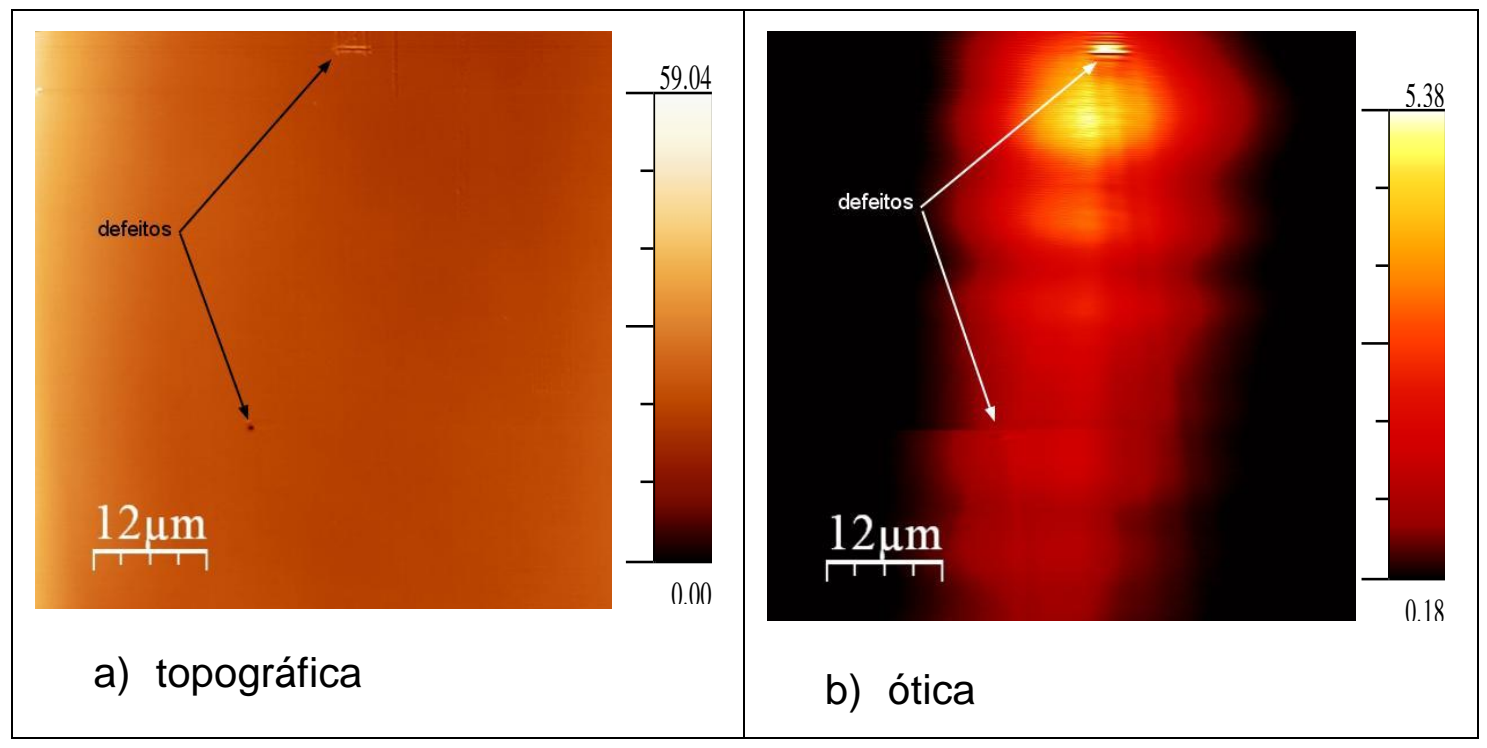

Figura 4.2.10 Amostra de 55nm de prata com laser vermelho.

Nesta figura vemos a imagem topográfica (a) onde temos dois defeitos marcados pelas setas. $\mathrm{Na}$ imagem ótica também podemos ver os mesmo defeitos. É importante notar que a partir destes defeitos o SP sofre um espalhamento que gera linhas com direção de propagação ligeiramente inclinadas em relação ao eixo do SP.

Na figura 4.2.11 vemos duas amostras diferentes (a) $55 \mathrm{~nm}$ de prata com $10 \mathrm{~nm}$ de cobalto e (b) $55 \mathrm{~nm}$ de prata com $3 \mathrm{~nm}$ de cobalto. Ambas são com 
área de varredura de $60 \times 60 \mu \mathrm{m}^{2}$. E em (a) temos $100 \mu \mathrm{V}$ e (b) $500 \mu \mathrm{V}$ de escala ótica.

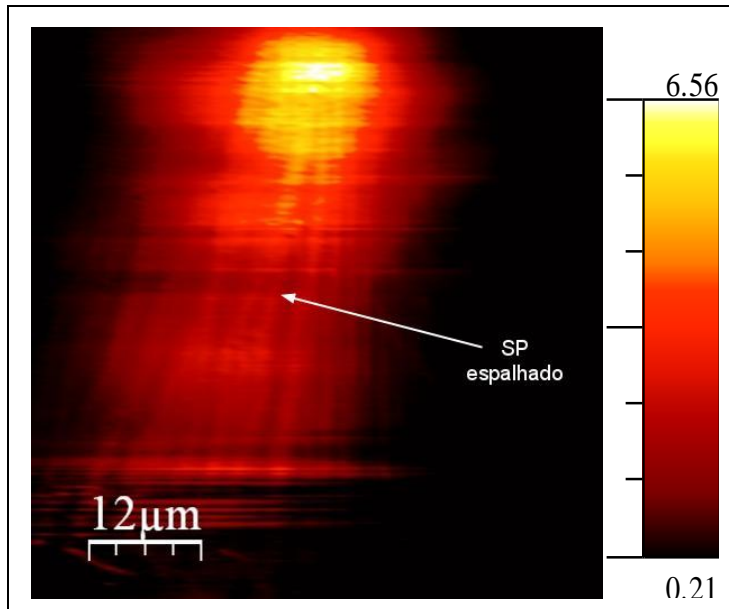

a) ótica Ag55Co10

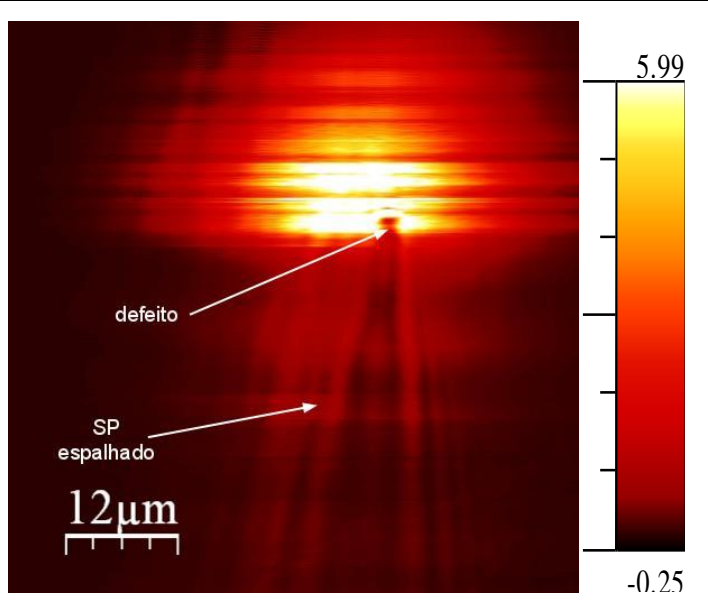

b) ótica Ag55Co3

Figura 4.2.11 Amostra de 55nm de prata (a) com 10nm de cobalto, (b) $3 \mathrm{~nm}$ de cobalto ambas laser vermelho.

Com estas duas imagens podemos ver o efeito do defeito espalhando 0 $\mathrm{SP}$ e também os feixes que são formados após este espalhamento.

$\mathrm{Na}$ figura 4.2.12 temos a imagem topográfica e ótica da amostra de $55 \mathrm{~nm}$ de prata com $1 \mathrm{~nm}$ de cobalto. A área de varredura é $60 \times 60 \mu \mathrm{m}^{2}$ e a escala ótica de $1 \mathrm{mV}$.

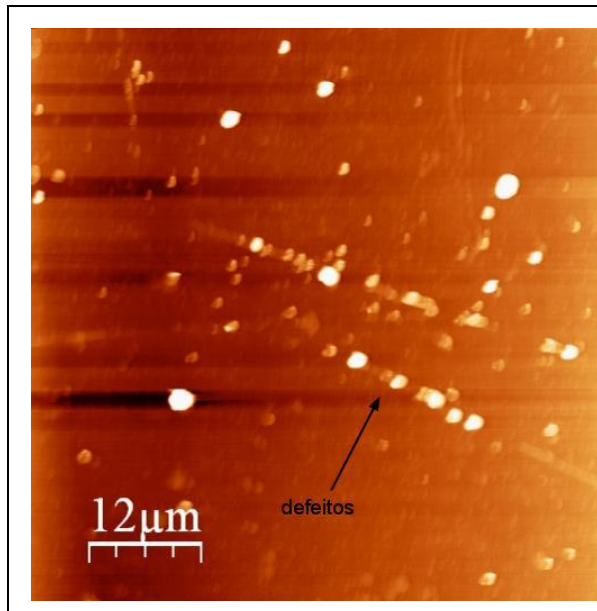

a) topográfica

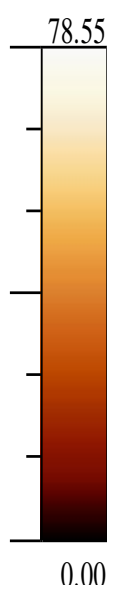

0.00

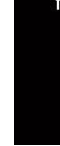

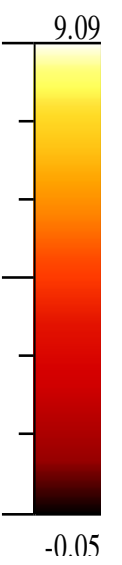

b) ótica

Figura 4.2.12 Amostra de $55 \mathrm{~nm}$ de prata com $1 \mathrm{~nm}$ de cobalto com laser vemelho. 
Com esta figura podemos notar na imagem topográfica uma fileira de defeitos que também é vista na imagem ótica. Também podemos ver 0 mesmo padrão de feixes espalhados após os defeitos.

Com uma amostra de $55 \mathrm{~nm}$ de prata e $3 \mathrm{~nm}$ de cobalto foi obtida uma imagem com a polarização $p$ maximizada e depois outra com a polarização $s$ maximizada. Na figura 4.2.13 vemos estas imagens, a área de varredura é de $60 \times 60 \mu \mathrm{m}^{2}$ e a escala ótica de $100 \mu \mathrm{V}$.

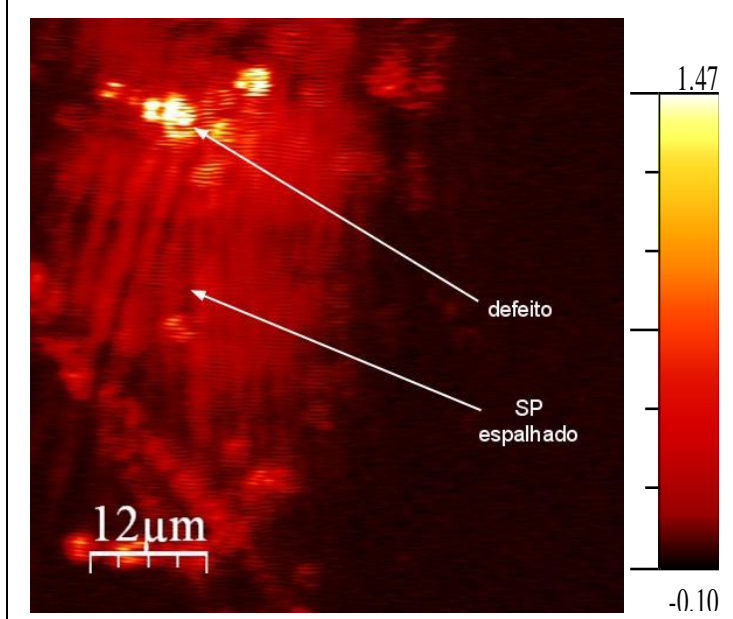

a) polarização $p$

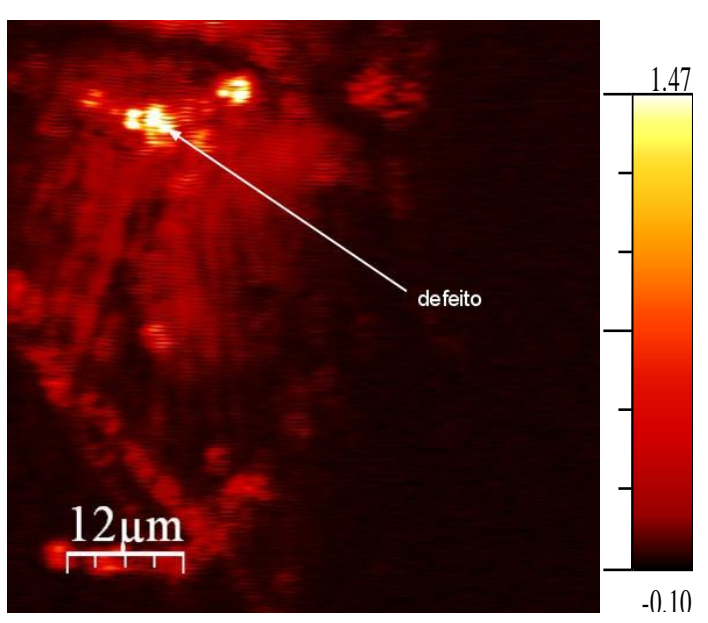

b) polarização s

Figura 4.2.13 Amostra de $55 \mathrm{~nm}$ de prata com $3 \mathrm{~nm}$ de cobalto com laser vermelho.

Com a figura 4.2.13 vemos a imagem ótica com a polarização $p$ maximizada. Com ela podemos ver um SP espalhado após os encontrar os defeitos da amostra. Com a imagem de polarização $s$ vemos uma pequena propagação do SP, que é bem menor que a da polarização $p$.

Assim finalizando os primeiros resultados de propagação do SP para cada amostra estudada no SNOM no modo PSTM.

\subsection{Estudos dos grãos de prata e ouro}

O SNOM, cada dia mais, se torna um equipamento com melhor resolução topográfica e ótica e por isso conseguimos obter imagens topográficas e imagens de fase dos grãos de prata e ouro das amostras. 
Começaremos pelas imagens dos grãos de prata. A imagem foi obtida com uma varredura de $6 \times 6 \mathrm{~m}^{2}$. Na figura 4.3.1 vemos a imagem topográfica convencional (a) e a imagem construída com a fase do sinal topográfico (b). Doravante, este último tipo de imagem será chamado de imagem de fase. Apesar da imagem de fase definir melhor a presença dos grãos de prata e ouro, ela não pode ser usada para definir o tamanho dos grãos, pois esta imagem é muito sensível às descontinuidades na superfície do material e variações na condição de atrito entre a ponta e a amostra. Portanto não sendo o valor real do tamanho dos grãos, mas um valor aproximado. A escala do eixo $z$ da imagem de fase é dada em volts e não em nanômetros por isso os valores entre ela e a topográfica são tão diferentes. No entanto, é possível se perceber alguma correlação entre as duas imagens.

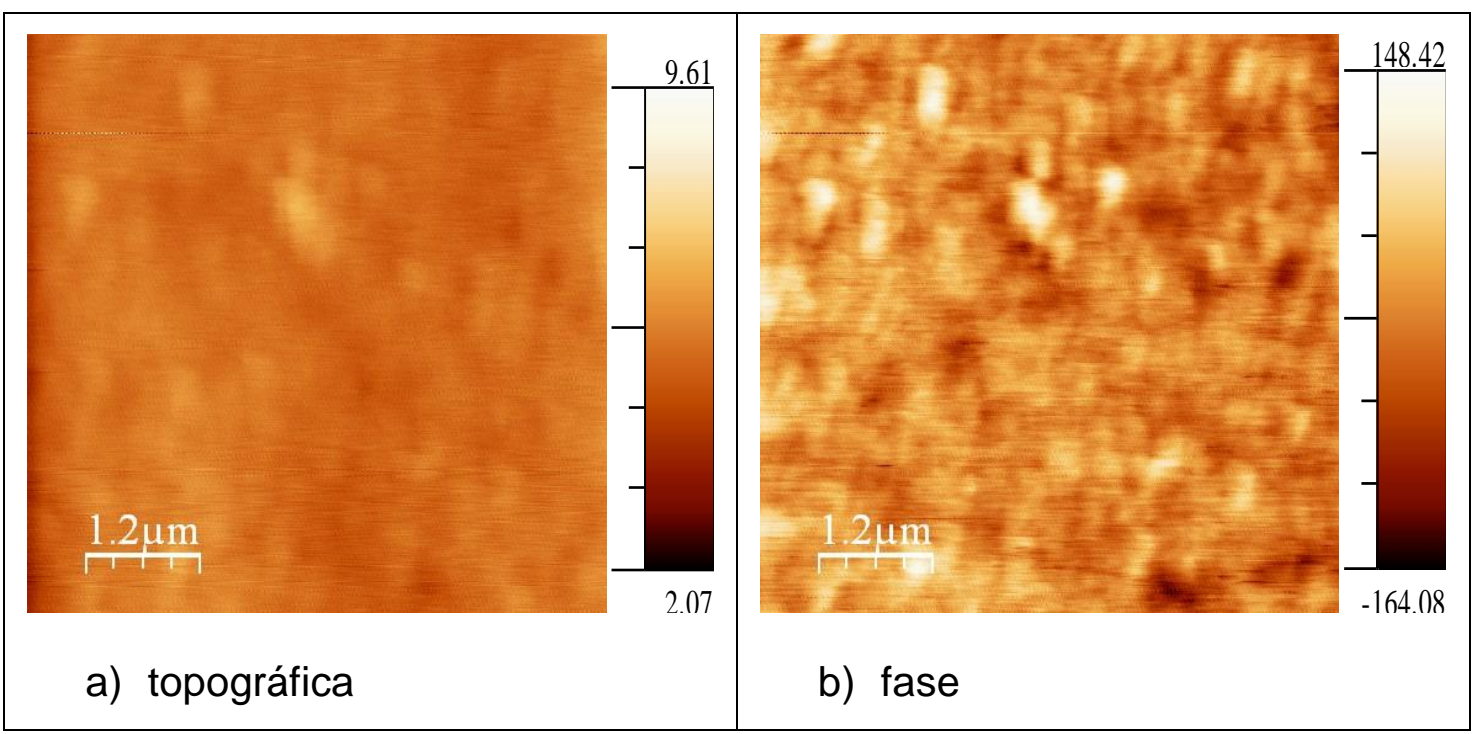

Figura 4.3.1 amostra de $55 \mathrm{~nm}$ de prata.

O mesmo tipo de imagem foi obtido para os grãos de ouro. A varredura também foi de $6 \times 6 \mu \mathrm{m}^{2}$. Os grãos do filme de ouro são maiores que os de prata e o filme se mostra mais homogêneo, por isso na imagem topográfica quase não é possível ver os grãos. Já na imagem de fase eles ficam evidentes. 


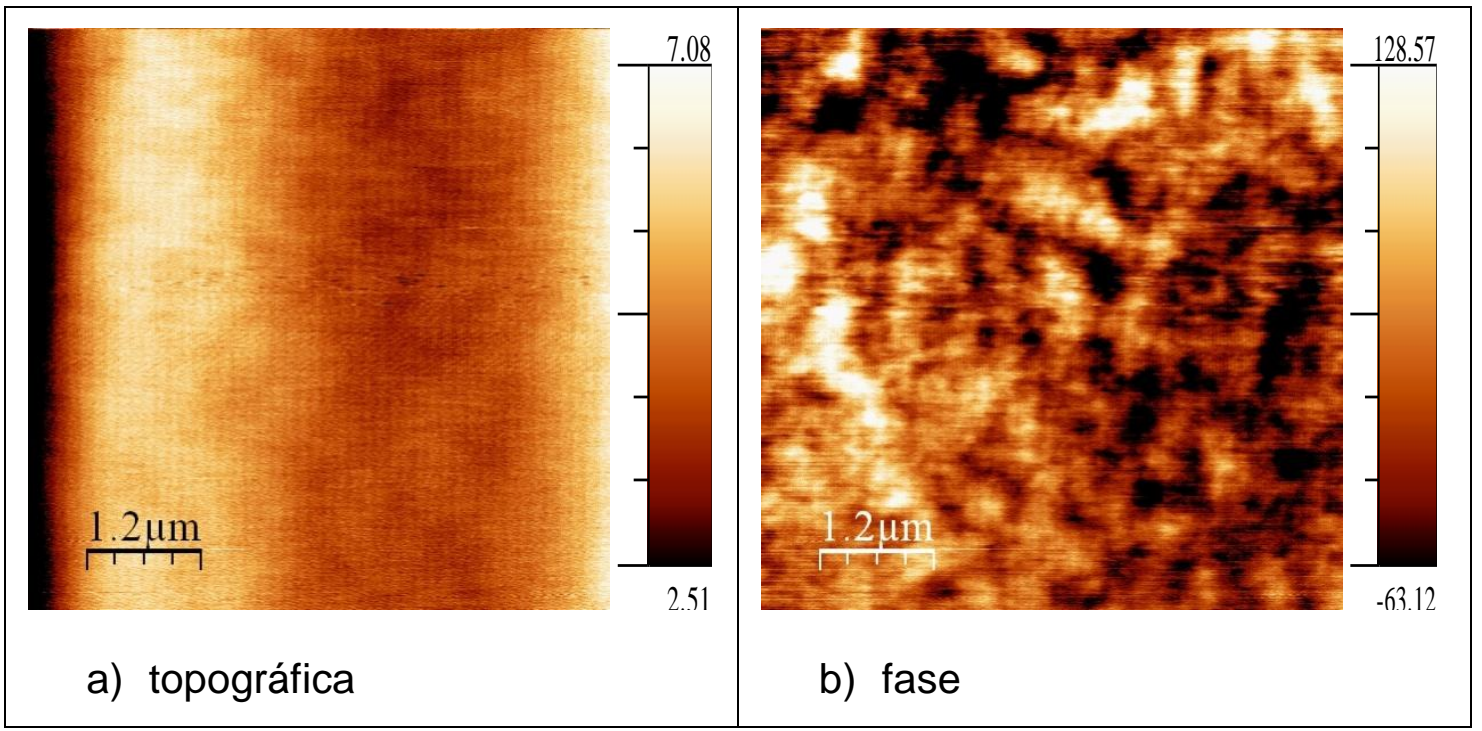

Figura 4.3.2 amostra de $55 \mathrm{~nm}$ de ouro.

Esta análise dos grãos só foi encontrada por que existe dentro da propagação do SP uma estrutura de interferência ótica que só é possível analisar quando feita uma varredura com escala reduzida. Este é o assunto de análise do próximo tópico.

\subsection{Interferência ótica}

Nas imagens de propagação do SP é observada uma interferência ótica de comprimento de oscilação de algumas centenas de nanômetros. Para cada amostra foi feita uma imagem ótica de varredura de $6 \times 6 \mu \mathrm{m}^{2}$ visando caracterizar esta interferência devido ao material e o tipo de laser utilizado.

Na figura 4.4.1 temos a imagem topográfica de fase $(a, c)$ e a imagem ótica (b,d) da amostra de prata com $55 \mathrm{~nm}$. Em (b) a imagem ótica foi obtida com o laser vermelho e em (d) com o laser violeta. Nas imagens óticas foi feito, com o auxílio do programa WSxM, uma imagem de FFT (Fast Fourier Transform) para obter o comprimento desta oscilação. Esta técnica permite obtermos qual o período de oscilação que aparece com maior freqüência em uma imagem. Para o filme de prata com 55nm os valores desta oscilação são de $344 \mathrm{~nm}$ para o laser vermelho e $312 \mathrm{~nm}$ para o laser violeta. 
Vemos que apesar do laser violeta apresentar um acoplamento pior para o SP, ele apresenta a interferência ótica assim como o vermelho.

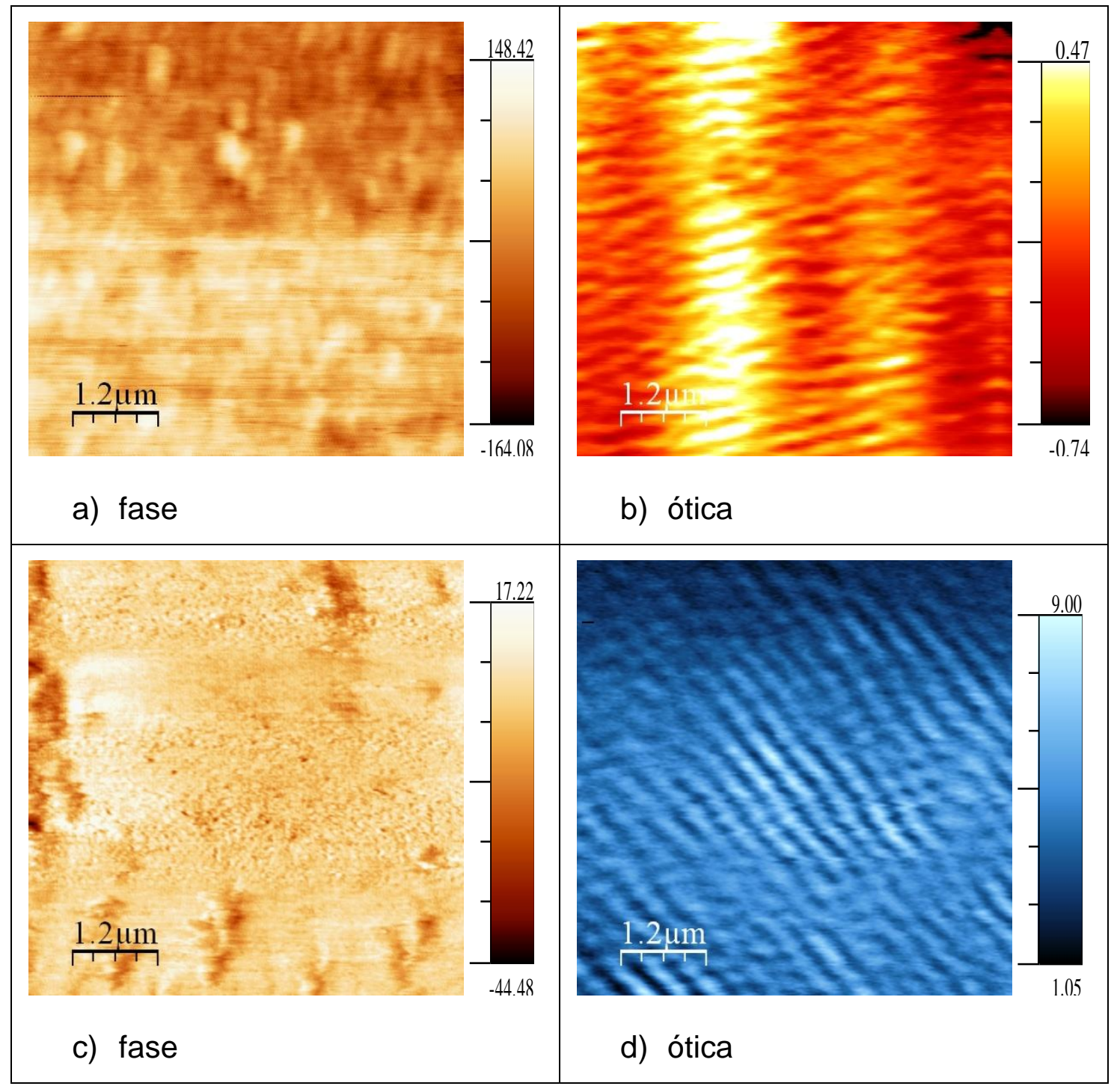

Figura 4.4.1 filme de $55 \mathrm{~nm}$ de prata para o laser violeta $(c, d)$ e vermelho(a,b).

$\mathrm{Na}$ figura 4.4.2 vemos a imagem de FFT da oscilação ótica na amostra de prata com incidência com laser vermelho (a) e violeta (b). A partir deste tipo de imagem que conseguimos obter o valor do período de oscilação ótica para cada uma das amostras. 


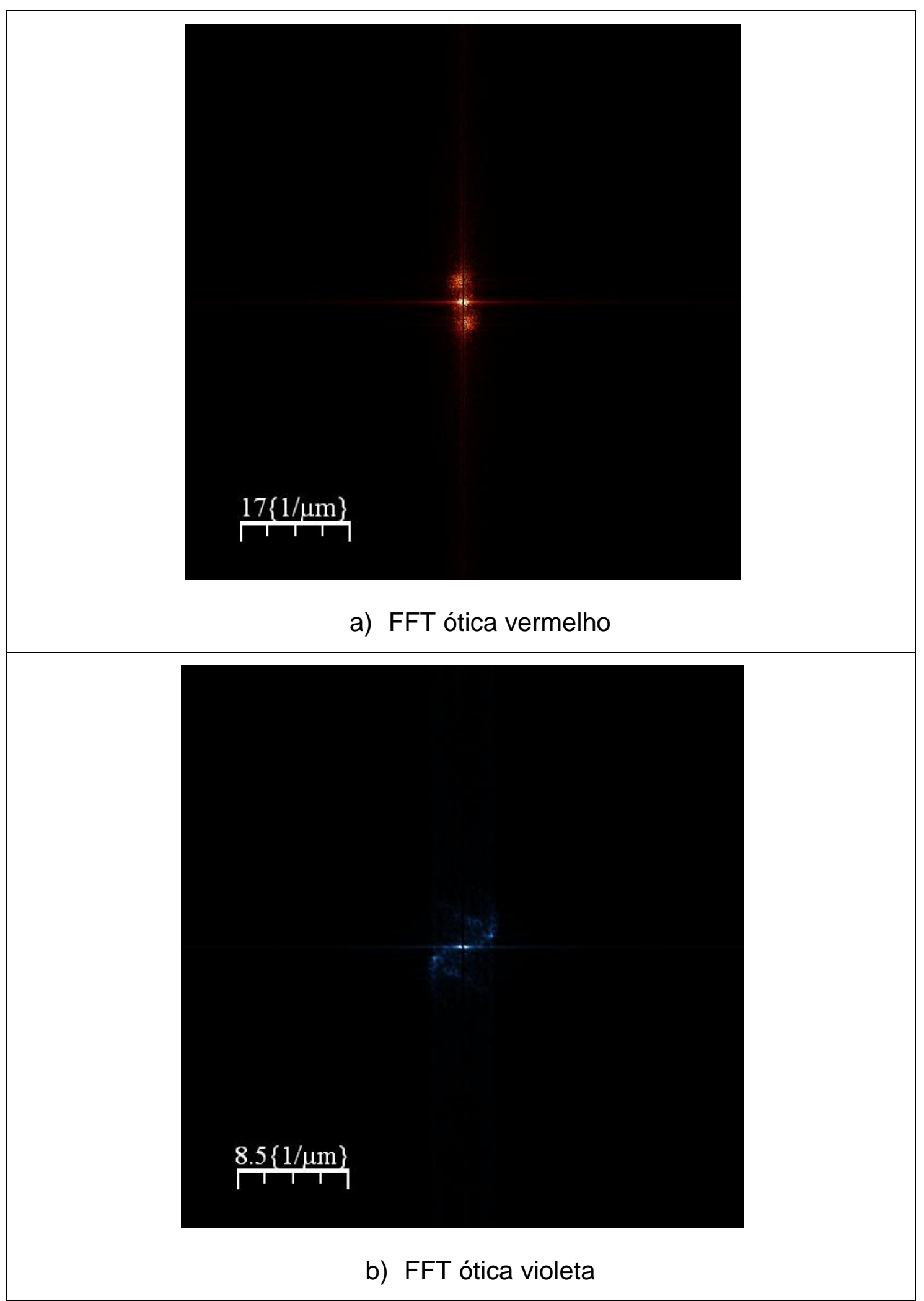

Figura 4.4.2 FFT da imagem ótica para a amostra de prata com $55 \mathrm{~nm}$ para o laser vermelho (a) e violeta (b). 
Nas imagens de FFT vemos pontos mais claros que representam 0 período de maior freqüência na imagem ótica para os lasers violeta e vermelho.

Com a amostra de ouro de $55 \mathrm{~nm}$ também foram obtidas imagens com os dois lasers. Os comprimentos de oscilação obtidos foram: vermelho $-305 \mathrm{~nm}$ e violeta $-275 \mathrm{~nm}$. Na figura 4.4.3 temos as imagens óticas do ouro para o laser vermelho (a) e violeta (b). A mesma interferência ótica é vista nas amostras de ouro e para os dois lasers.

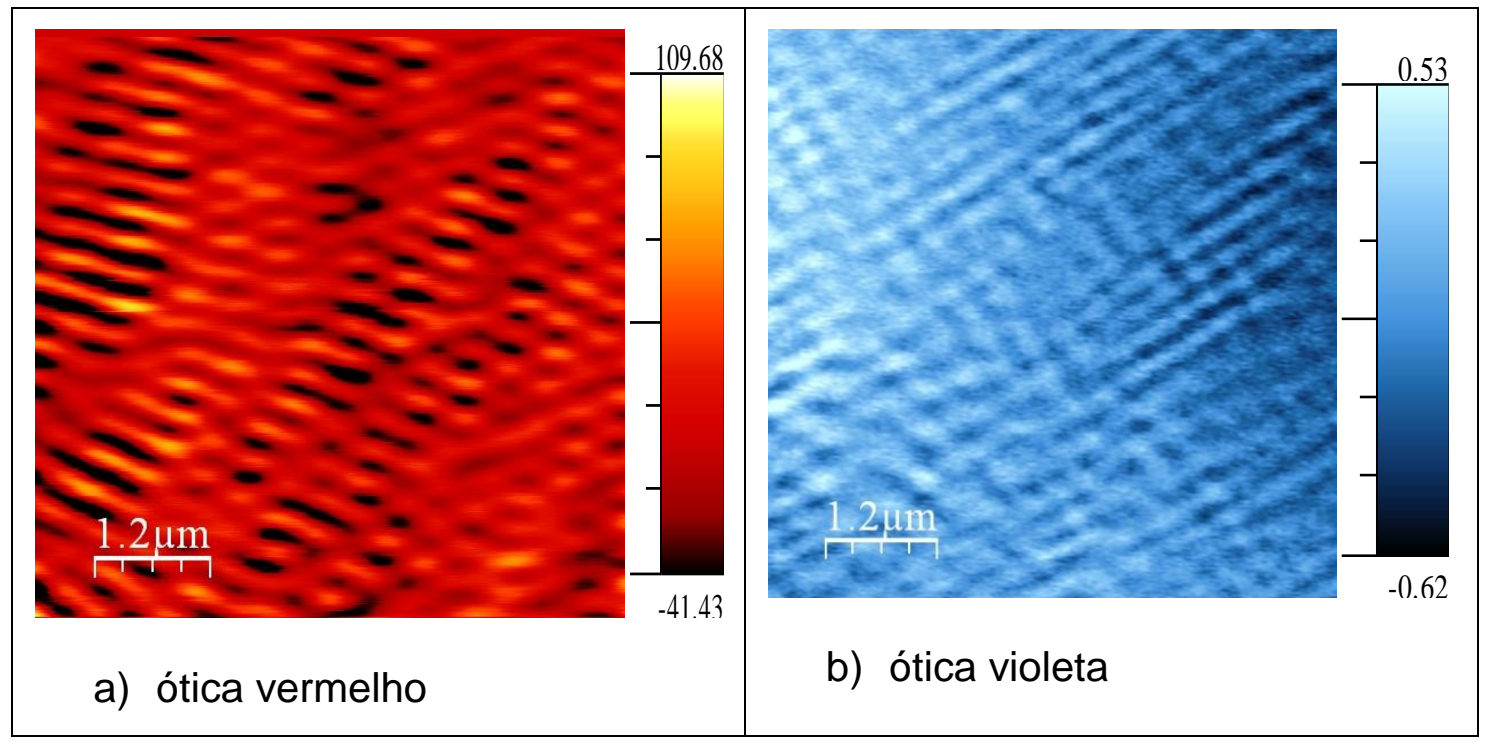

Figura 4.4.3 Amostra de 55nm de ouro para o laser violeta (b) e vermelho(a).

Nas amostras de prata com cobalto temos duas imagens. Na figura 4.4.3 temos as amostras de (a) $55 \mathrm{~nm}$ de prata com $0,5 \mathrm{~nm}$ de cobalto e (b) $55 \mathrm{~nm}$ de prata com $3 \mathrm{~nm}$ de cobalto ambos com laser vermelho. Para a amostra de $\mathrm{Ag} 55 \mathrm{Co0}, 5$ encontramos uma oscilação de período de $404 \mathrm{~nm}$ e para a amostra Ag55Co3 encontramos $420 \mathrm{~nm}$. Para as amostras com cobalto também encontramos a mesma interferência ótica vista para as amostras anteriores. Isto mostra que é um efeito típico da propagação do SP. 


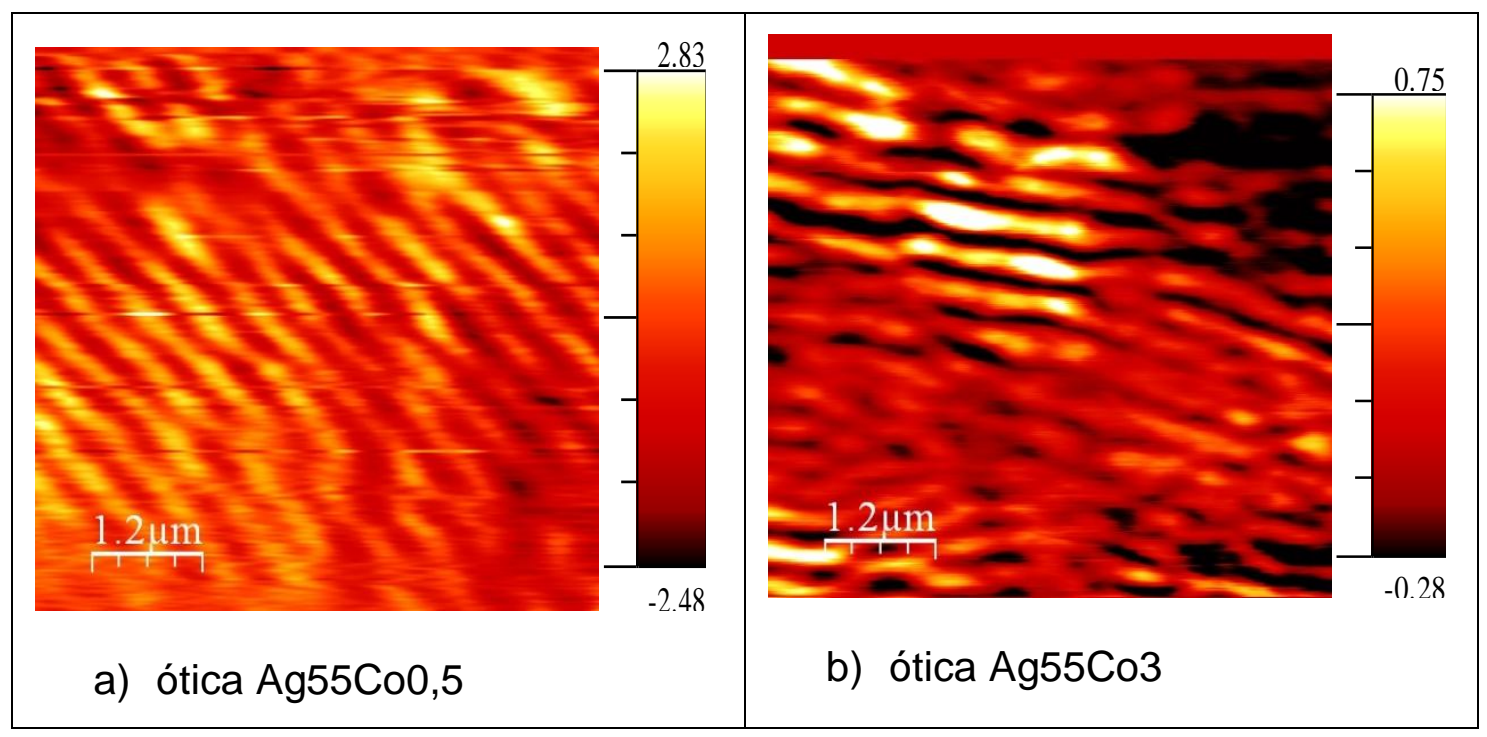

Figura 4.4.4 Amostra de 55nm de prata com (a) 0,5nm de cobalto e (b) $3 \mathrm{~nm}$ de cobalto ambos com laser vermelho.

Assim finalizando os resultados para a interferência ótica encontrada dentro da propagação do SP. No próximo tópico vamos mostrar alguns resultados que podemos obter com uma ferramenta do programa WSxM chamada retrace.

\subsection{Imagens com Retrace}

O decaimento do SP no ar, teoricamente, não deve passar de algumas centenas de nanômetros. Visando constatar isto vamos utilizar a ferramenta retrace do WSxM. Com o retrace podemos fazer duas imagens com distâncias sonda-amostra diferentes. A primeira imagem é em distância normal de regulação, e a segunda imagem é a uma distância maior que na primeira imagem. Esta segunda distância é escolhida pelo usuário. Sendo assim possível observar esta dependência do SP com a distância sondaamostra.

O primeiro resultado do retrace foi obtido com uma amostra de prata de $55 \mathrm{~nm}$. A imagem foi obtida com o scanner varrendo a $90^{\circ}$ e com 0 deslocamento em $Y$ desligado, ou seja, varrendo uma única linha diversas vezes. As distâncias sonda-amostra usadas no retrace foram: (a) 20nm, (b) 
$40 \mathrm{~nm}$, (c) $80 \mathrm{~nm}$, (d) $160 \mathrm{~nm}$, (e) $240 \mathrm{~nm}$, (f) $320 \mathrm{~nm}$, (g) 400nm, (h) 480nm, (i) $560 \mathrm{~nm}$, (j) $640 \mathrm{~nm}$, (k) $20 \mathrm{~nm}$. Estas imagens se encontram na figura 4.5.1, onde vemos em (1) a imagem com retrace a imagem e em (2) com distância normal. A varredura é de $70 \times 70 \mu \mathrm{m}^{2}$. Vemos nesta imagem uma variação da intensidade do sinal ótico conforme a ponta se afasta da amostra. E após algumas centenas de nanômetros o SP não é mais coletado pela ponta do SNOM.

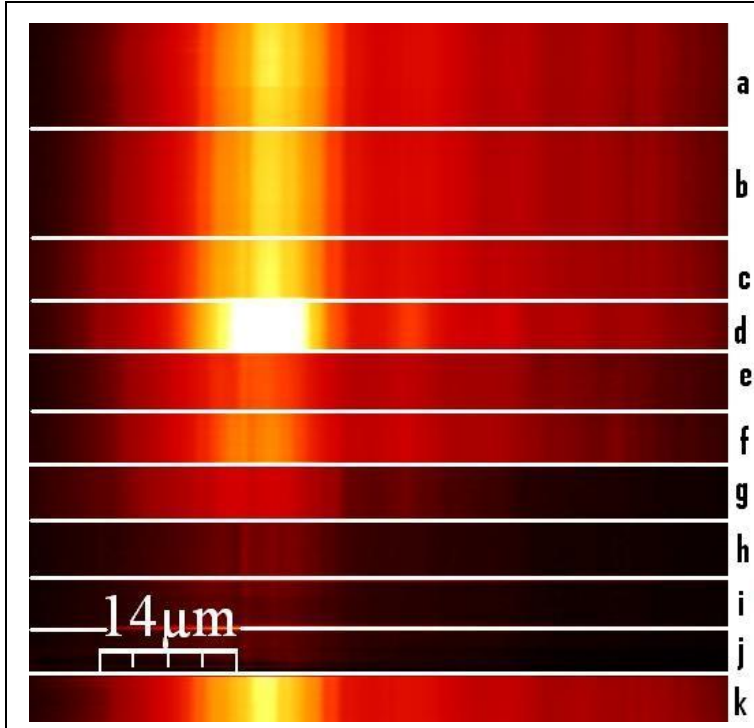

1) Retrace

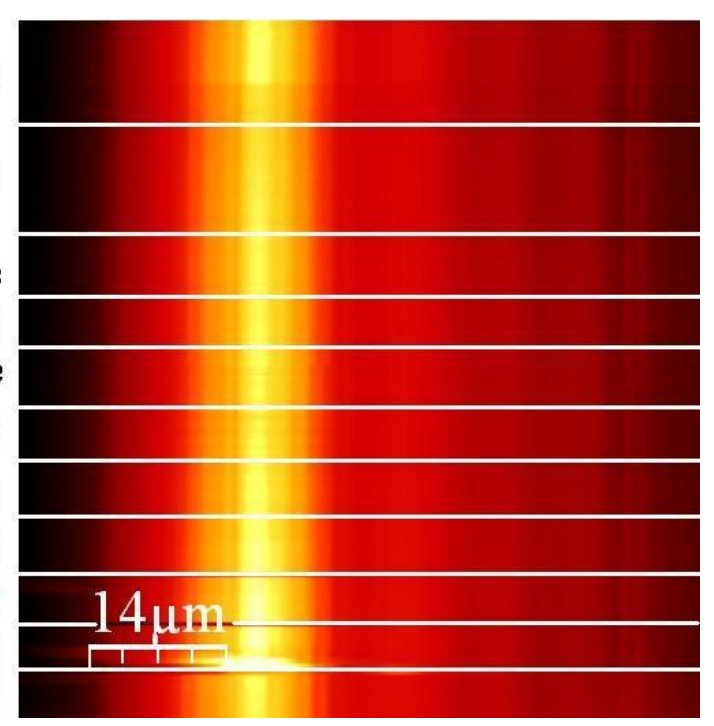

2) Normal

Figura 4.5.1 imagem ótica normal(1) e com retrace(2). (a) $20 \mathrm{~nm}$, (b) $40 \mathrm{~nm}$, (c) $80 \mathrm{~nm}$, (d) $160 \mathrm{~nm}$, (e) $240 \mathrm{~nm}$, (f) $320 \mathrm{~nm},(\mathrm{~g}) 400 \mathrm{~nm}$, (h) $480 \mathrm{~nm}$, (i) $560 \mathrm{~nm}$, (j) $640 \mathrm{~nm}$, (k) $20 \mathrm{~nm}$.

O próximo resultado foi obtido em uma amostra de $55 \mathrm{~nm}$ de prata com $3 \mathrm{~nm}$ de cobalto. Na figura 4.5.2 vemos a imagem com distância normal (a) e com retrace (b). A distância selecionada para o retrace é de $700 \mathrm{~nm}$. Nesta imagem vemos a imagem ótica para uma das amostras com substrato sujo, portanto podemos ver muitos defeitos que servem de centros espalhadores do SP. A varredura é de $60 \times 60 \mu \mathrm{m}^{2}$ e a escala ótica é $100 \mu \mathrm{V}$. 


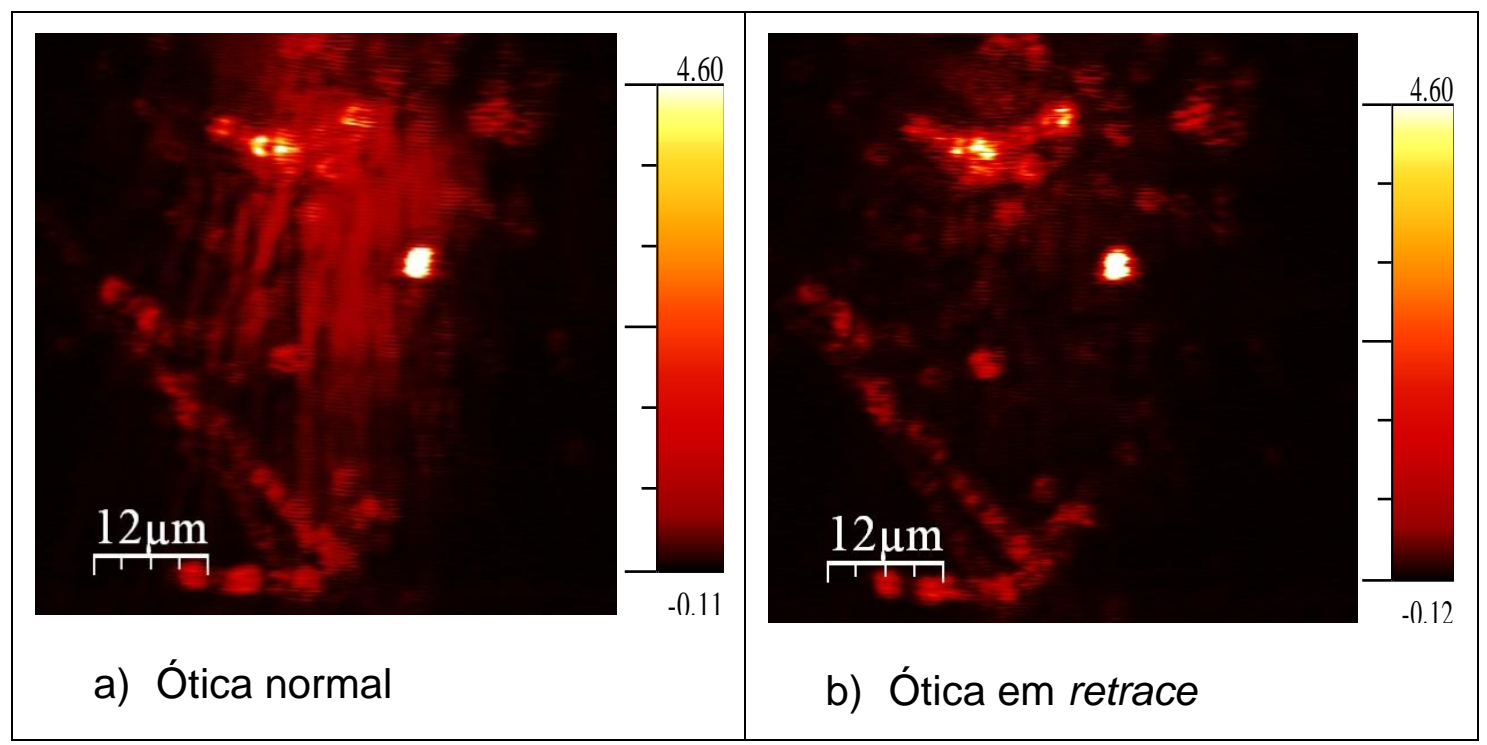

Figura 4.5.2 amostra de $55 \mathrm{~nm}$ de prata com $3 \mathrm{~nm}$ de cobalto. Imagem de retrace a 700nm de distância.

$\mathrm{Na}$ imagem ótica normal (a) vemos alguns defeitos que espalham o SP, e os feixes de espalhamento que seguem após estes defeitos. Na ótica em retrace vemos os mesmos defeitos que espalham o SP, porém não podemos mais observar o feixe espalhado do SP.

Com a amostra de $55 \mathrm{~nm}$ de prata e $3 \mathrm{~nm}$ de cobalto fizemos o mesmo que na imagem anterior. Na figura 4.5.3 vemos a imagem ótica normal (a), imagem com retrace (b) e topográfica (c). A imagem de retrace começou com 50nm, depois tem uma pequena faixa de $300 \mathrm{~nm}$ e o restante da imagem é com 700nm. A varredura é de $60 \times 60 \mu m^{2}$ e a escala ótica é $100 \mu \mathrm{V}$.

Com esta figura vemos a imagem ótica normal (a) onde se vê o centro de incidência e a propagação do SP. A imagem ótica em retrace onde podemos ver a diminuição da intensidade luminosa com o afastamento da ponta, e também podemos ver os defeitos que aparecem circulados. $\mathrm{Na}$ imagem topográfica (c) vemos os mesmos defeitos da imagem em retrace também circulados. 


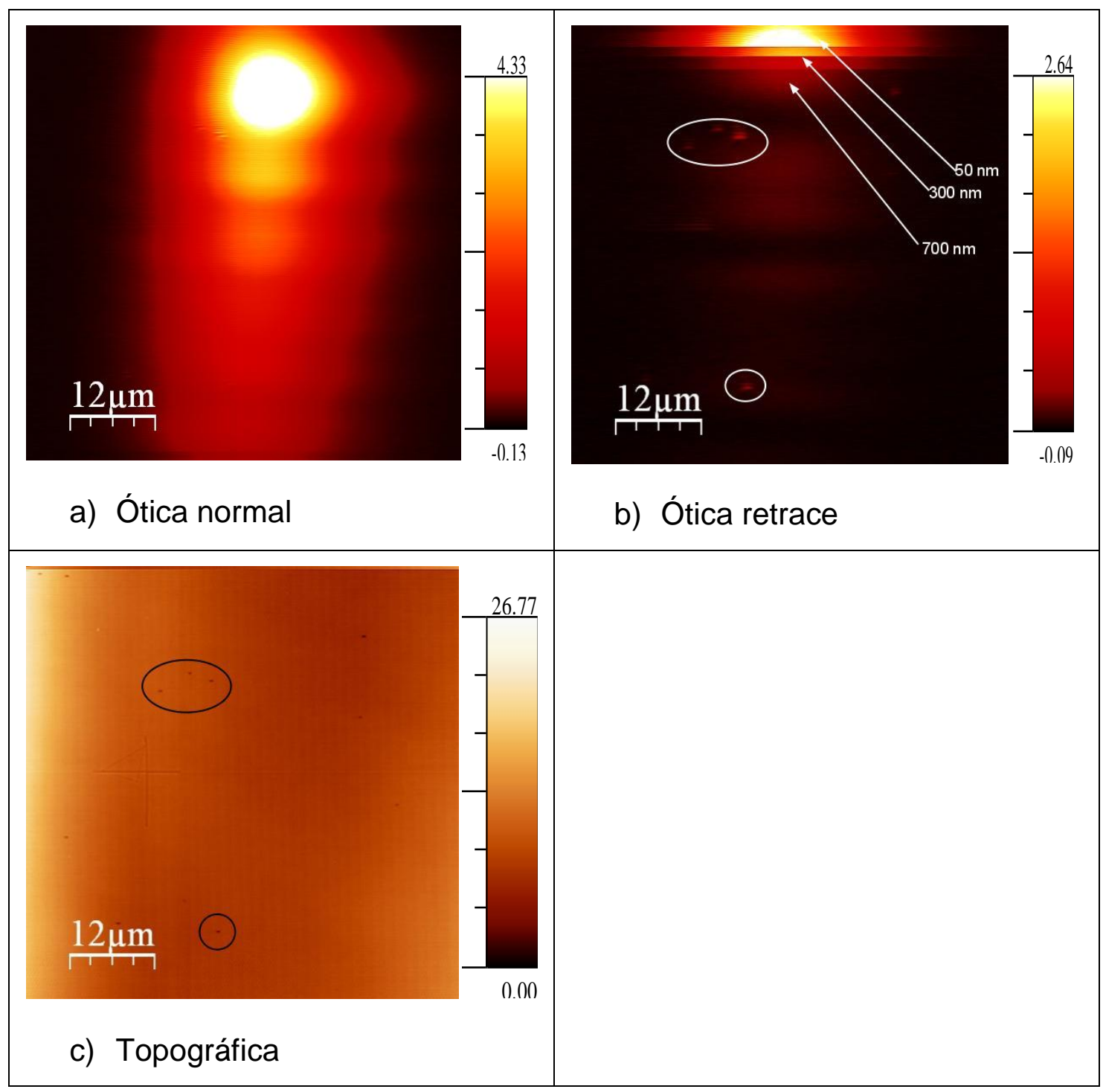

Figura 4.5.3 amostra de $55 \mathrm{~nm}$ de prata com $3 \mathrm{~nm}$ de cobalto. Retrace(b) a $700 \mathrm{~nm}$ de distância.

Com o intuito de analisar a influência da distância da sonda-amostra na interferência ótica, fizemos uma varredura de $6 \times 6 \mu^{2}$ e alteramos esta distância no decorrer da varredura. A amostra é a de $55 \mathrm{~nm}$ de prata e $0,5 \mathrm{~nm}$ de cobalto. A figura 4.5.4 mostra esta imagem com o retrace nas distâncias de: (a) $800 \mathrm{~nm}$, (b) $30 \mathrm{~nm}$, (c) $60 \mathrm{~nm}$, (d) $90 \mathrm{~nm}$, (e) $150 \mathrm{~nm}$, (f) $210 \mathrm{~nm}$, (g) $300 \mathrm{~nm}$, (h) $360 \mathrm{~nm}$, (i) 420nm, (j) 500nm, (k) 700nm. E a escala ótica é de $500 \mu \mathrm{V}$. 


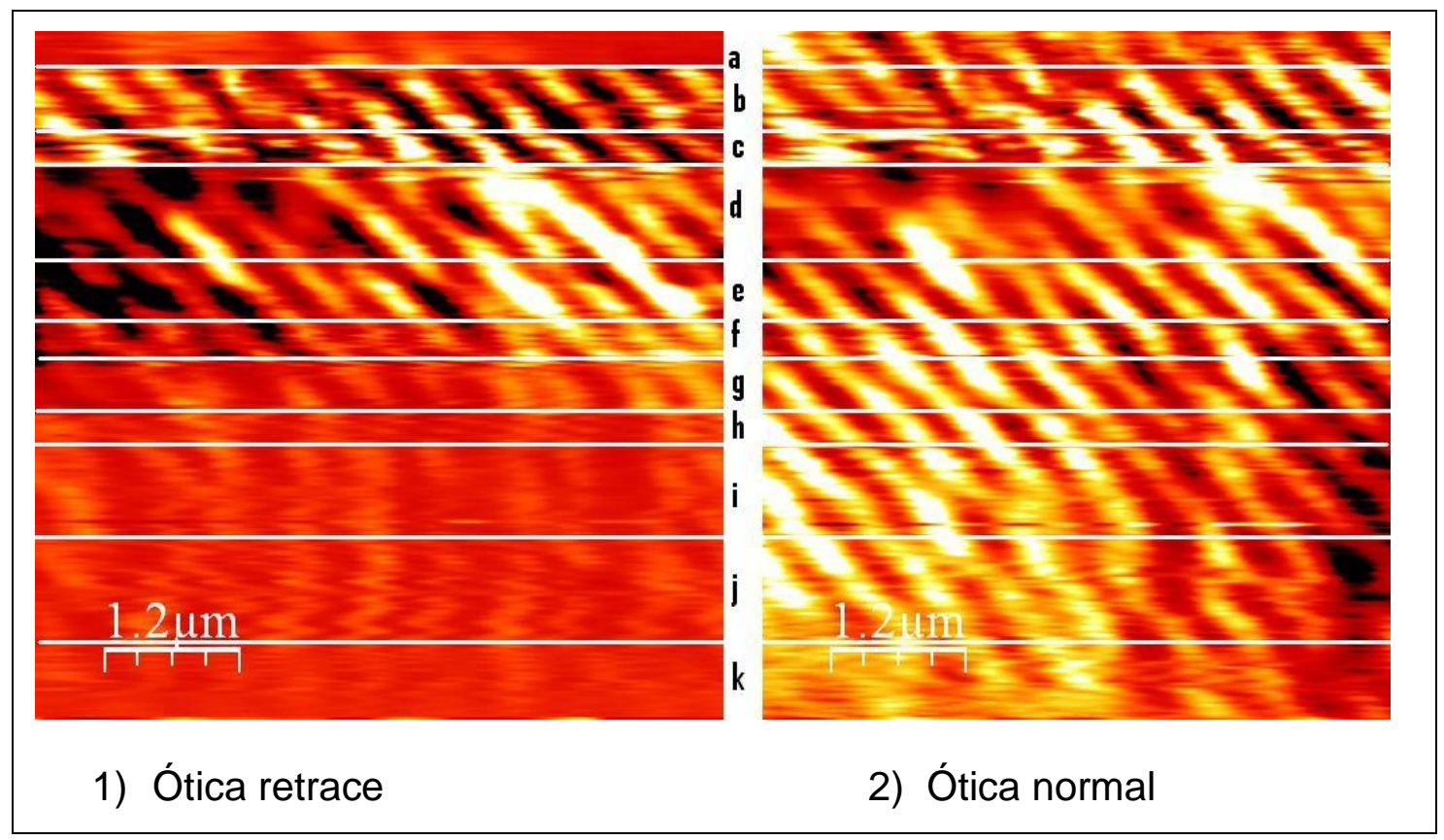

Figura 4.5.4 amostra de $55 \mathrm{~nm}$ de prata com $0,5 \mathrm{~nm}$ de cobalto. Imagem ótica normal(2) e com retrace(1). (a) $800 \mathrm{~nm},($ b) $30 \mathrm{~nm}$, (c) $60 \mathrm{~nm}$, (d) $90 \mathrm{~nm}$, (e) $150 \mathrm{~nm}$, (f) $210 \mathrm{~nm}$, (g) $300 \mathrm{~nm}$, (h) $360 \mathrm{~nm}$, (i) $500 \mathrm{~nm},(j) 700 \mathrm{~nm}$.

O mesmo padrão encontrado na figura 4.5.1 pode ser observado nesta imagem. A diminuição da intensidade luminosa com o afastamento da ponta e também o desaparecimento da interferência ótica, a partir de uma distância sonda-amostra.

\subsection{Medidas magnéticas}

Para a caracterização magnética das amostras com cobalto, primeiramente medimos sua magnetização com um VSM. As medidas foram feitas com as amostras colocadas na perpendicular ao campo e no plano do campo. O gráfico 4.6.1 mostra a amostra de $55 \mathrm{~nm}$ de prata com $3 \mathrm{~nm}$ de cobalto para três tipos de medidas diferentes: com o campo magnético perpendicular ao plano da amostra, campo magnético paralelo ao plano da amostra e no eixo fácil de magnetização, e campo paralelo ao plano da amostra e no eixo difícil de magnetização. 


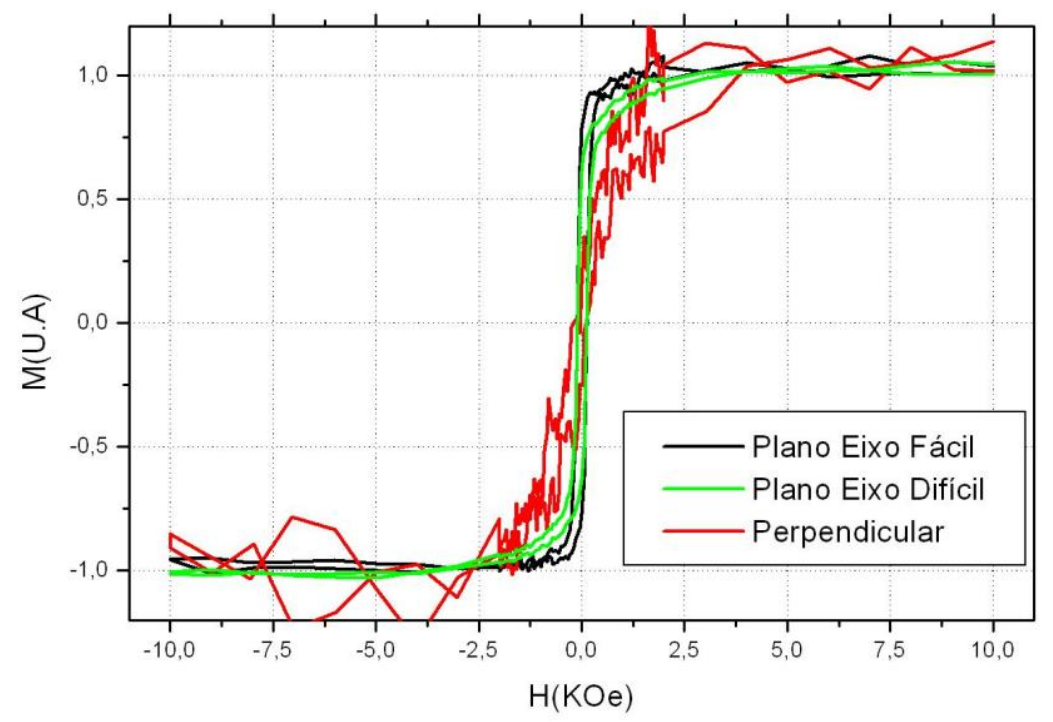

Figura 4.6.1 Medida de magnetização para a amostra de $55 \mathrm{~nm}$ de prata com $3 \mathrm{~nm}$ de cobalto.

Este mesmo tipo de medida foi feito para as outras amostras e a partir delas pudemos obter a coercividade do material. No gráfico 4.6.2 vemos as medidas para diversas amostras no plano do campo e no eixo fácil de magnetização.

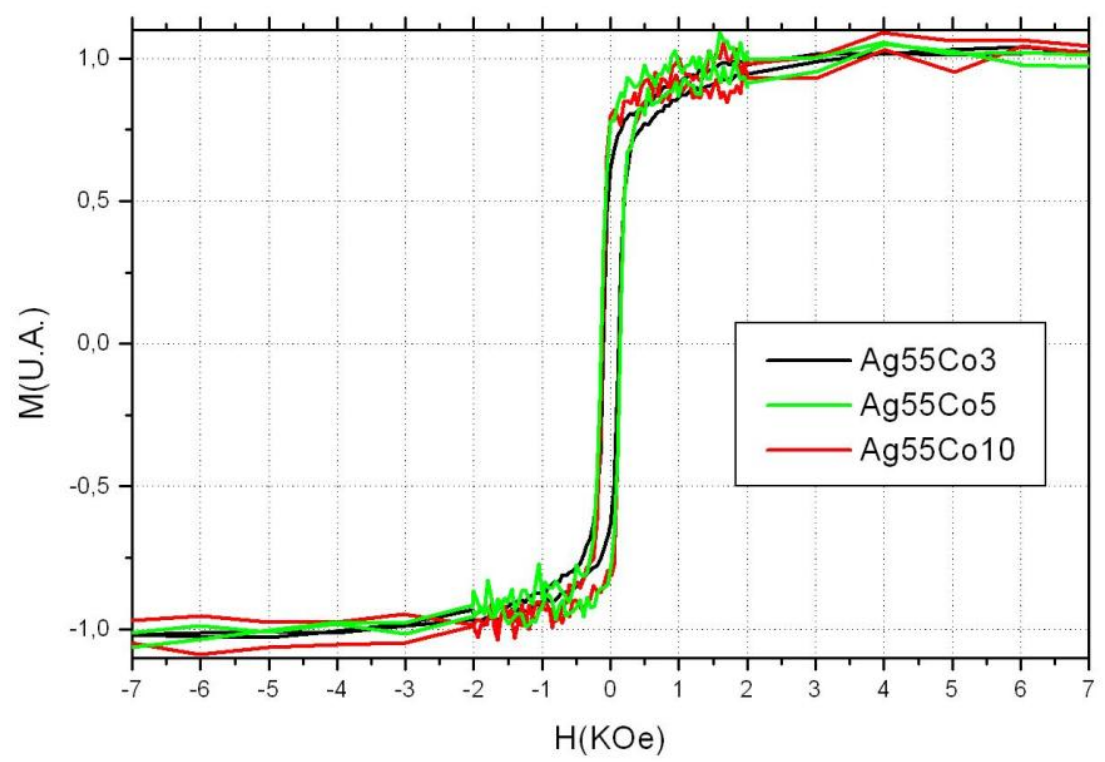

Figura 4.6.2 Medida de magnetização para amostras com $55 \mathrm{~nm}$ de prata e $3 \mathrm{~nm}$ de cobalto(preto), $5 \mathrm{~nm}$ de cobalto(verde), $10 \mathrm{~nm}$ de cobalto(vermelho). 
Como pode ser visto para as três concentrações de cobalto a curva de histerese é muito parecida e o campo coercivo é bem próximo um do outro. Para a de $3 \mathrm{~nm}$ de cobalto o valor é de 1100 e, para a de $5 \mathrm{~nm}$ de cobalto é 1200 e e para a de $10 \mathrm{~nm}$ de cobalto é 1300 e. Para as amostras com $0,5 \mathrm{~nm}$ de cobalto e $1 \mathrm{~nm}$ de cobalto a curva ficou muito ruidosa, dificultando assim a medida da coercividade.

Como a coercividade é menor que o campo que podemos aplicar no SNOM, esperávamos que fosse possível caracterizar a amostra magneticamente também pelo nosso equipamento. Porém ao começarmos a medir a susceptibilidade magnética e a curva de histerese pelo SNOM, notamos que alguma peça do equipamento respondia magneticamente ao campo aplicado. Isto causava uma perturbação na posição da sonda em relação à amostra.

Como vimos anteriormente o plasmon de superfície tem uma estrutura fina de interferência ótica da ordem de $300-400 \mathrm{~nm}$. Aparentemente, esta perturbação magnética no equipamento fazia com que a sonda se deslocasse ligeiramente. Portanto sofrendo variações no sinal ótico recebido, que eram maiores que o sinal do efeito Kerr magneto-ótico esperado. Assim não sendo possível obter medidas de susceptibilidade magnética no SNOM. Esta perturbação também inviabilizou a medida da curva de histerese local pelo mesmo motivo que o da susceptibilidade magnética.

$\mathrm{Na}$ figura 4.6.3 vemos uma primeira medida de susceptibilidade magnética feita pelo SNOM na amostra de $55 \mathrm{~nm}$ de prata com $3 \mathrm{~nm}$ de Co, para diferentes intensidades do campo magnético alternado aplicado. 

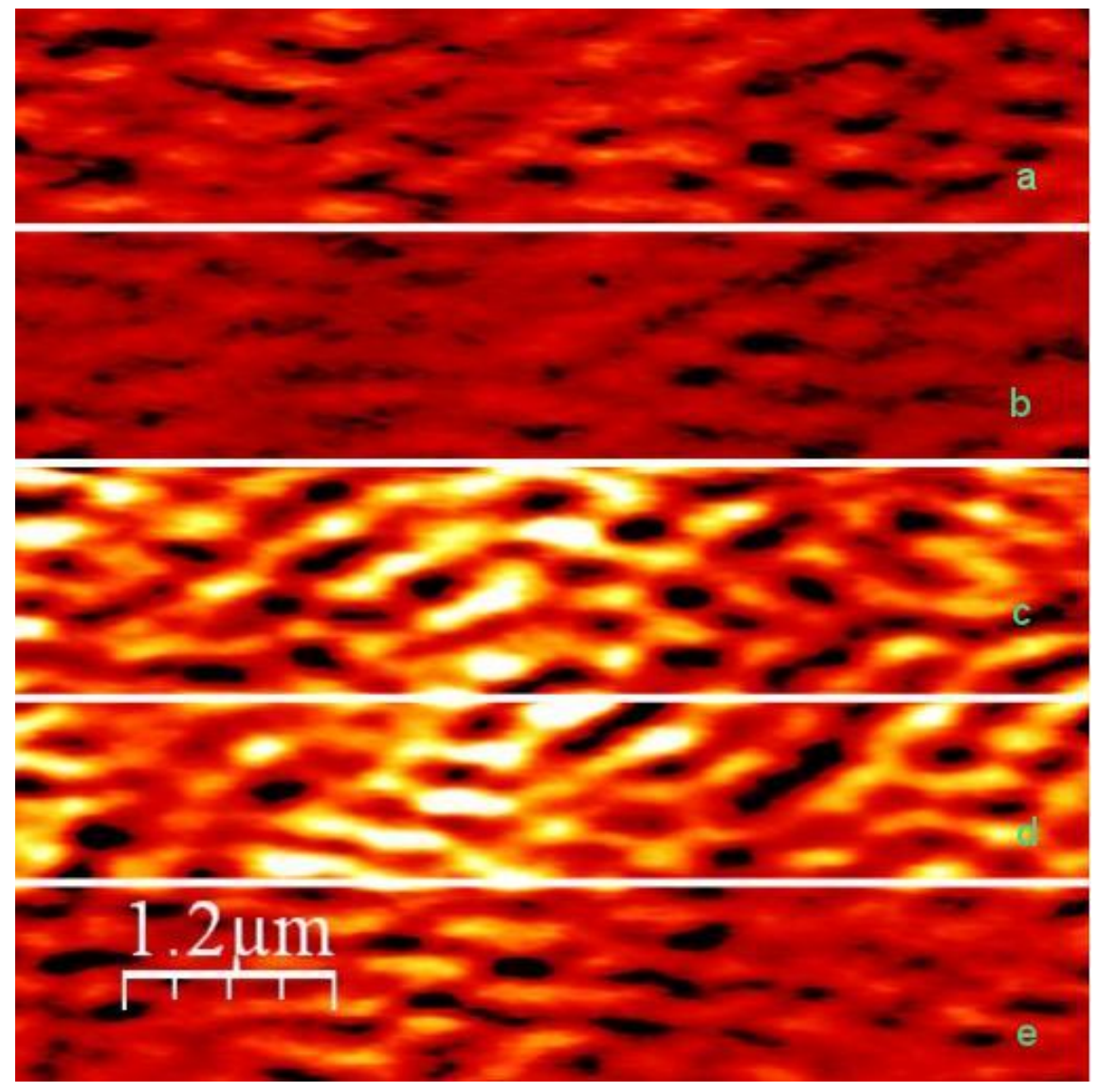

Figura 4.6.3 Amostra de 55nm de prata com 3nm de cobalto. Com excitação de: (a) 0,8V; (b) 0,4V; (c) 2,2V; (d) $3,0 \mathrm{~V}$; (e) $1,5 \mathrm{~V}$.

Estes resultados estão dentro do esperado, pois conforme se aumenta a amplitude de excitação do campo, se espera um aumento no sinal magnetoótico, até um máximo, que é a magnetização de saturação da amostra. Esta magnetização de saturação parece ocorrer em (c) com 2,2V, pois a partir deste valor não existe diferença da amplitude do sinal medido

Apesar do resultado obtido, o fato que também é possível ver variação de sinal ótico no filme de prata com $55 \mathrm{~nm}$ de espessura nas imagens de susceptibilidade, elimina a possibilidade do sinal obtido para o filme magnético ser um efeito puramente magneto-ótico.

Chegamos a conclusão que deve existir o sinal magneto-ótico devido a esta saturação observada na imagem. Porém existe também um acoplamento magnético em alguma peça do próprio SNOM que gera uma variação de sinal ótico. Estamos tentando solucionar este problema 
localizando o foco deste acoplamento e também tentando entender melhor este padrão de interferência ótica do plasmon de superfície.

Resolvendo isto, existe a expectativa de podermos melhorar os sinais magneto-óticos vistos da maneira tradicional pelo SNOM, pois o acoplamento plasmônico em si age como um filtro de polarização para a luz. Portanto para futuros resultados pretendemos conseguir fazer medidas magneto-plasmônicas no SNOM, no modo PSTM. O que seria um trabalho totalmente inovador.

Assim finalizando os resultados experimentais obtidos para 0 acoplamento plasmônico e para a caracterização magnética das amostras. No próximo capítulo iremos discutir estes resultados obtidos no acoplamento plasmônico em cada amostra. 


\section{Cap. 5. Análise e discussão}

Dentro deste capítulo iremos analisar os resultados mostrados no capítulo anterior. Também discutiremos as novas possibilidades de medidas que foram abertas devido a estes resultados. Iniciaremos fazendo uma discussão do SP para cada amostra. Em seguida discutiremos as características especificas dos resultados apresentados. Por fim faremos uma comparação sobre 0 esperado teoricamente e 0 medido experimentalmente.

\subsection{Propagação do SP}

\subsubsection{Amostra de prata}

Iremos discutir a propagação do SP em cada amostra, comparando com as medidas da literatura e analisando quais foram os pontos positivos e quais os pontos que devemos melhorar em um próximo trabalho.

Em uma primeira análise vamos considerar os filmes de prata pura. Como pode ser visto na figura 4.2.1. a imagem topográfica é completamente lisa, não existindo portanto centros espalhadores ou descontinuidades no filme de prata. Já na imagem ótica da mesma varredura, vemos um circulo luminoso de $15 \mu \mathrm{m}$ de diâmentro no alto da figura. Este círculo se refere ao ponto de incidência da luz na superfície da amostra. A direção de propagação do SP é evidentemente para baixo na figura. Interessante notar que a propagação do SP vai além do final da figura, pois no limite da figura ainda vemos que existe intensidade luminosa. Portanto a propagação do SP na prata pura e com o laser vermelho passa de $50 \mu \mathrm{m}$ de distância.

A direção de propagação é exatamente a que esperávamos. Pois a iluminação está entrando com esta direção. Ainda nesta figura e com o auxilio da figura 4.2.2 vemos que a propagação do SP tem uma interferência de larga escala. O período desta oscilação é de aproximadamente $10 \mu \mathrm{m}$. 
Ainda não é muito claro para nós a origem desta oscilação, mas levantamos algumas hipóteses. Como a frente de onda não é exatamente plana, ela pode estar gerando uma incidência com ângulos e amplitudes diferentes e isto causaria uma interferência na onda observada. A superfície da prata não é exatamente plana, como vemos nas imagens de fase, que revelam os grãos do material. Esta irregularidade pode causar este tipo de efeito de interferência. $O$ interessante é notar que na maioria das imagens em larga escala, este padrão aparece mesmo que com intensidade baixa.

Em nenhum artigo pesquisado foi encontrado este tipo de interferência. O que nos leva a acreditar que isto é uma característica específica da nossa montagem.

A propagação do SP como vista pelo nosso SNOM, no modo PSTM, pode ser comprovada também pelos artigos de Dawson et al. (Dawson, et al., 1994) e Zayats (Zayats, et al., 2003) . Nestes dois artigos vemos exatamente o mesmo tipo de propagação do SP. No caso do Dawson com um PSTM (Photon Scanning Tunneling Microscope) e no caso do Zayats com um SNOM.

A figura 4.2.3 onde a varredura foi feita a $90^{\circ}$ comprova a direção de propagação do SP, e em (b) é interessante notar que existe um decaimento muito característico, do sinal luminoso, quando mantemos fixa a linha de varredura. $\mathrm{Na}$ continuidade desta discussão iremos mostrar alguns gráficos deste decaimento e a comparação com os valores teóricos. Mas vale ressaltar que o decaimento encontrado neste tipo de imagem é um decaimento exponencial, o que era esperado para a propagação do SP. Nesta figura ainda se pode ver a interferência ótica de período longo como dito anteriormente.

Vale notar que a área de varredura é $70 \times 70 \mu \mathrm{m}^{2}$. Mesmo com uma área de varredura maior a propagação do SP ainda é mais distante que ela. Com todas as imagens obtidas e também com as análises feitas por nós, podemos dizer que a propagação do SP passava de $70 \mu \mathrm{m}$. Este dado é realmente muito bom, pois nos artigos pesquisados nunca foi encontrada uma propagação tão longa. Em um artigo do Polman (Verhagen, et all, 2009) 
ele encontra distâncias de propagação próximas do que vemos no nosso experimento, porém neste caso ele ultiliza de estruturas que focam o SP em um nanofio.

Esta análise foi feita para o laser vermelho. No caso do laser violeta como vemos na figura 4.2.4, apesar de encontrar uma imperfeição no filme, vemos que existe uma propagação do SP. Visivelmente esta propagação não é tão longa quanto a do laser vermelho, isto já era esperado, pois o acoplamento do SP para o laser violeta não é tão bom quanto para o laser vermelho. Por esta razão vemos a propagação do SP tão curta $(\sim 15 \mu \mathrm{m})$ para o caso do laser violeta.

Se notarmos os valores do fundo de escala ótico para o laser violeta é sempre muito menor que para o laser vermelho. Por exemplo, para a amostra de $55 \mathrm{~nm}$ de prata, para o laser vermelho na figura 4.2.1 o fundo de escala é $1 \mathrm{mV}$, já para o laser violeta na figura 4.2.4 é de $20 \mu \mathrm{V}$. Então com o decaimento exponencial do SP, o sinal do laser violeta rapidamente cai para baixo do ruído de fundo do Lock-in amplifier, que nas nossas medidas é de $0,2 \mu \mathrm{V}$. Esta é outra razão para a propagação do laser violeta ser menos longa que a do laser vermelho.

\subsubsection{Amostra de ouro}

As imagens para o ouro foram muito interessantes, pois a partir delas pudemos comprovar a influência do comprimento de onda do laser na propagação do SP. Na figura 4.2.5 vemos a propagação do SP com laser vermelho (a) e com laser violeta (b). Para o laser vermelho o acoplamento do SP para um filme de $55 \mathrm{~nm}$ de ouro é maximizado quando o ângulo de incidência é $46^{\circ}$ como visto nas simulações. Já para o laser violeta não existe um ponto onde se minimiza a refletividade em função do ângulo de incidência ou espessura do ouro. Isto por que a ressonância do ouro é acima do comprimento de onda do violeta, isto porque a parte imaginária da constante dielétrica do ouro para o comprimento de onda do violeta já não é pequena, portanto não correspondendo a condição de ressonância do 
plasmon de superfície. Logo o acoplamento plasmônico do ouro com laser violeta deveria ser muito ruim.

Exatamente isto que podemos ver na figura 4.2.5. Enquanto para o laser vermelho vemos um sinal de $5 \mathrm{mV}$ e uma propagação luminosa de $50 \mu \mathrm{m}$. Para o laser violeta vemos um sinal de $20 \mu \mathrm{V}$ sendo somente possível ver o centro de incidência luminosa e uma pequena propagação luminosa de não mais que uma dezena de micrometros.

Pelos acoplamentos no ouro e na prata serem muito parecidos, resolvemos continuar as medidas somente com a prata. Primeiramente pela prata acoplar melhor com laser violeta e pelo fato da propagação na prata se mostra mais proeminente.

\subsubsection{Amostra de prata com cobalto}

Como visto na figura 4.2.6 as amostras de prata com cobalto foram feitas da seguinte maneira: sobre o substrato de vidro foi depositado $5 \mathrm{~nm}$ de prata, depois depositamos alguns nanômetros de cobalto, e por fim recobrimos com $50 \mathrm{~nm}$ de prata.

A idéia do estudo do SP em amostras de metais nobres com filmes finos de material magnético era de através do SP aumentar o sinal magnético da amostra. O estudo não apresentou resultados interessantes por motivos já mencionados no capítulo anterior. Porém isto rendeu um ótimo estudo do acoplamento do SP com amostras de multicamadas.

A primeira amostra estudada por nós foi a com $55 \mathrm{~nm}$ de prata e $1 \mathrm{~nm}$ de cobalto. Na figura 4.2.7 vemos a propagação do SP nesta amostra. É importante notar que conforme adicionamos, e aumentamos a camada de cobalto, a distância de propagação do SP diminui. Nesta amostra vemos que a propagação passa dos $40 \mu \mathrm{m}$. Porém o sinal ótico já é pelo menos duas vezes menor que o sinal da prata pura. 
Na figura 4.2.7(b) vemos perfeitamente o decaimento exponencial do SP e ainda a interferência ótica de largo período. Este decaimento exponencial demonstra que mesmo com o filme fino de cobalto o SP ainda existe.

$\mathrm{Na}$ amostra de $55 \mathrm{~nm}$ de prata com $3 \mathrm{~nm}$ de cobalto vemos que o sinal ótico novamente caiu pelo menos um fator dois em relação a amostra de $1 \mathrm{~nm}$ de cobalto. Vemos isto na figura 4.2.8(b), porém ainda é possível ver a propagação do SP na vertical. Esta propagação também passa dos $40 \mu \mathrm{m}$ reiterando a análise de que o SP acopla na prata mesmo com o cobalto no meio.

$\mathrm{Na}$ amostra de $55 \mathrm{~nm}$ de prata com $10 \mathrm{~nm}$ de cobalto foi feito um estudo mais detalhado da propagação para os dois tipos de laser. $O$ que fica evidente na figura 4.2.9 é o fato do laser violeta acoplar pior o SP na prata. Vemos na imagem (a) a ótica com laser violeta para esta amostra, além do sinal ser baixo a propagação do SP não passa da metade da imagem, ou seja, cerca de $20 \mu \mathrm{m}$. Já na imagem (b) o sinal é mais alto e o SP se propaga até o fim da varredura. Nestas duas imagens é possível ver também a interferência de período longo.

Em relação a esta amostra podemos notar ainda que o sinal ótico com o laser vermelho diminuiu de um fator dois em relação ao da amostra com $3 \mathrm{~nm}$ de cobalto. Isto só deixa mais evidente que conforme adicionamos cobalto o sinal ótico diminui. Isto por duas razões: primeiro por que a amostra fica mais espessa, além dos $55 \mathrm{~nm}$ de prata ainda existe alguns nanômetros de cobalto; e segundo, porque a permissividade do cobalto é diferente da prata, então alterando o acoplamento do SP e promovendo a sua dissipação.

Apesar da diminuição do sinal fica claro que mesmo com cobalto, as amostras de prata com cobalto ainda possibilitam o acoplamento do SP. E isto é um resultado não encontrado na literatura. 


\subsection{Análise dos defeitos}

Nesta parte da análise vamos discutir os efeitos dos defeitos que espalham o SP. As amostras utilizadas para este estudo são aquelas com o substrato sujo. Portanto quando foram depositados a prata e o cobalto, os filmes recobriram as sujeiras e apresentaram protuberâncias. Um estudo pode ser visto também nos artigos do Zayats (Zayats, et al., 2003) (Zayats, et al., 2005), e isto reforça os resultados obtidos para nossas amostras.

Na figura 4.2.10 vemos uma amostra de prata com $55 \mathrm{~nm}$ de espessura para o laser vermelho. $\mathrm{Na}$ imagem topográfica (a) ficam visíveis dois defeitos: um bem no topo da imagem e um perto do meio da amostra. Estes mesmo defeitos podem ser vistos na imagem ótica(b). $O$ interessante é notar que um defeito no filme causa uma perturbação na propagação do SP. E a partir deste defeito surge um sinal luminoso mais intenso na direção da propagação do SP. Este mesmo tipo de resultado é visto nos artigos do Zayats. Porém nestes artigos a propagação destes feixes é de alguns micrometros, já no nosso trabalho vemos que este feixe segue por dezenas de micrometros, isto porque otimizamos a espessura da amostra e ângulo de incidência. Este feixe pode ser visto nos dois defeitos e esta é uma característica da interação do SP com um centro espalhador.

Com as amostras contendo cobalto também podemos ver o mesmo comportamento. Como no caso da figura 4.2.11(a) com a amostra de $10 \mathrm{~nm}$ de cobalto, onde não conseguimos ver exatamente onde está o defeito na ótica, porém existe uma serie de feixes que saem do centro de incidência da luz. Isto deixa caracterizado que em alguns pontos neste centro de incidência existem defeitos que espalharam o SP.

O mesmo é constatado na figura 4.2.11(b), na amostra de $3 \mathrm{~nm}$ de cobalto existe um defeito no final do centro de incidência. Neste caso o defeito fica mais visível e a partir dele saem os feixes de luz na direção de propagação do SP. É interessante notar que estes feixes são muito bem definidos, não existindo desvios de suas direções nem interrupções durante seu percurso. 
Para todos os casos de análises de defeitos foi usado o laser vermelho, pois como já dito anteriormente o SP com ele aparenta ter uma distância de propagação maior. Isto pois a distância de propagação teórica do SP para a incidência do laser vermelho é maior que para o laser violeta como veremos em um próximo tópico.

Em casos extremos onde podemos ver inúmeros defeitos na imagem topográfica fica mais evidente o que eles causam na propagação do SP. É o caso da figura 4.2.12, com a amostra de $55 \mathrm{~nm}$ de prata com $1 \mathrm{~nm}$ de cobalto, onde vemos na imagem topográfica (a) inúmeros defeitos que chegam a quase $100 \mathrm{~nm}$ de altura e 3micrometros de comprimento. Na imagem ótica (b) vemos o mesmo padrão encontrado nas outras imagens, com o feixe se propagação após o SP encontrar um defeito. Porém o interessante nesta amostra em especial é que podemos relacionar o local dos defeitos na topográfica com o local dos defeitos na ótica. Existe uma fileira de defeitos embaixo do centro de incidência do laser, na imagem ótica, que pode ser visto exatamente igual na imagem topográfica. Isto demonstra a eficiência da propagação do SP nas amostras produzidas. Pois mesmo com defeitos grandes o SP continua a se propagar.

Também através destes defeitos pudemos visualizar o efeito da polarização da luz incidente no acoplamento plasmônico. Na figura 4.2.13 temos duas situações de imagens. $\mathrm{Na}$ imagem (a) vemos o acoplamento do $\mathrm{SP}$ quando a luz está com polarização $\mathrm{p}$ e em (b) vemos a polarização $\mathrm{s}$. Com a polarização $p$ vemos o mesmo tipo de propagação descrita anteriormente, ou seja, existe um acoplamento plasmônico bom e quando o $\mathrm{SP}$ encontra os defeitos se espalha em feixes luminosos. Já quando a polarização é s os feixes praticamente são inexistentes, o que é possível ver é o centro de incidência luminosa e alguns defeitos. Pois mesmo maximizando a polarização $s$, sempre sobra um pouco de polarização em $p$.

Pelas imagens óticas obtidas podemos saber se existem defeitos na amostra que muitas vezes não são perceptíveis na imagem topográfica. Mais sobre este assunto iremos discutir nas imagens com retrace. 


\subsection{Grãos de prata e ouro}

O estudo dos grãos de prata e ouro começou quando começamos a encontrar as primeiras interferências óticas. Para se observar a interferência ótica é necessário fazer uma varredura reduzida $\left(6 \times 6 \mu \mathrm{m}^{2}\right)$, e devido a esta redução pudemos constatar que o SNOM conseguia observar os grãos de prata. Prosseguindo com o estudo de grãos fizemos o mesmo para os grãos de ouro, e apesar de na imagem topográfica não ser possível ver os grãos, na imagem de fase eles aparecem com certa clareza.

Vale ressaltar que a imagem de fase não é a mesma coisa que uma imagem topográfica, pois ela leva em conta inclusive as forças de cisalhamento entre a ponta e a amostra. Por esta razão a imagem de fase na maioria das vezes tem um contraste maior que a imagem topográfica.

Na figura 4.3.1 vemos os grãos de prata na imagem de fase (b), e se observarmos com cuidado na imagem topográfica (a), veremos os grãos maiores. Fizemos um perfil do grão central que é mais visível. O valor encontrado para ele é $1,2 \mathrm{~nm}$ de altura, $600 \mathrm{~nm}$ de comprimento e 1 micrometro de largura. Fazendo um perfil por toda a amostra vemos variações de altura de $0,5 \mathrm{~nm}$ a $1,2 \mathrm{~nm}$. Também encontramos grãos de $300 \mathrm{~nm}$ a 1 micrometro de comprimento e largura.

Se compararmos estas imagens com as da figura 4.3.2 podemos ver que o filme de ouro é bem mais homogêneo. Por isto ficou muito mais difícil caracterizar as alturas dos grãos de ouro. Com a imagem de fase conseguimos medir que o comprimento e a largura os grãos tinham de $600 \mathrm{~nm}$ a 2microns de tamanho. Porém como dito esta imagem não nos dá a informação da altura destes grãos, assim não podendo os caracterizar.

Os resultados obtidos são muito animadores, pois mostram que a sensibilidade em altura do SNOM é realmente muito boa e mostra que a resolução lateral pode ser melhor que os 100nm que estimávamos antigamente. 


\subsection{Padrão de interferência ótica}

Ao conseguir observar os grãos surgiu a hipótese de que a interferência ótica, observada na escala reduzida, poderia ser causada por estes grãos. Por que em alguns estudos anteriores vemos que a rugosidade do material pode causar algum tipo de perturbação. Em seu artigo Anatoly Zayats afirma que a rugosidade de seus filmes causa este mesmo tipo de interferência.

Para a análise destas interferências usamos o método de imagens de FFT. Pois com este método podemos extrair mais facilmente o comprimento da interferência ótica.

Podemos obter algumas informações destas interferências. Na figura 4.4.1 vemos quatro imagens. Em (a) temos a imagem topográfica de fase para a amostra de $55 \mathrm{~nm}$ e em (b) a imagem ótica com laser vermelho. $O$ valor da oscilação na imagem ótica é de $344 \mathrm{~nm}$. Já para o laser violeta temos a imagem ótica(d) e topográfica de fase(c). A oscilação obtida da imagem ótica é de $312 \mathrm{~nm}$. O que podemos notar é que para o laser violeta o comprimento da oscilação é menor que para o laser vermelho.

Na figura 4.4.2 podemos ver a FFT da imagem ótica para a amostra de prata com 55nm com os dois lasers (a) vermelho e (b) violeta. Encontramos nesta imagem os pontos vermelhos e azuis que representam o período de oscilação que aparece com maior freqüência. $E$ através desta imagem que conseguimos obter os valores dos períodos de oscilação ótica para cada uma das amostras.

Isto é confirmado na figura 4.4.3, para o ouro com 55nm em (a) temos a ótica com laser vermelho e em (b) a ótica com laser violeta. Para o laser vermelho a oscilação é de $305 \mathrm{~nm}$ e para o violeta $275 \mathrm{~nm}$. Que está de acordo com o resultado observado na figura 4.4.1. Esta oscilação não deve ser somente um efeito do comprimento de onda do SP, pois estes valores foram calculados por nós. Para a prata com laser vermelho o valor de $\lambda_{\mathrm{sp}}$ é de $642 \mathrm{~nm}$, enquanto com laser violeta o $\lambda_{\mathrm{sp}}$ é de $360 \mathrm{~nm}$ e para o ouro com laser vermelho é de $633 \mathrm{~nm}$. Como não vemos experimentalmente uma diminuição de um fator de dois do comprimento desta interferência do laser 
vermelho para o laser violeta, então chegamos a conclusão que esta não é a única causa desta interferência. Ainda não temos uma explicação definitiva para este tipo de interferência. Mas sua relação com a rugosidade do material e com o comprimento de onda do SP deve ser considerada. Além de uma relação com o fato da incidência não ser plana. Na análise para as amostras contendo cobalto o resultado também é muito interessante. $\mathrm{Na}$ figura 4.4.4 temos duas amostras: (a) $55 \mathrm{~nm}$ de prata com $0,5 \mathrm{~nm}$ de cobalto e (b) $55 \mathrm{~nm}$ de prata com $3 \mathrm{~nm}$ de cobalto. $O$ que pode ser notado em relação a interferência ótica é que para o caso (a) encontramos $404 \mathrm{~nm}$ e para (b) $420 \mathrm{~nm}$. Então se nota uma dependência com a espessura do filme de cobalto, quanto mais espesso o filme de cobalto maior o comprimento desta oscilação. Nestes casos não obtivemos os valores dos grãos de prata para notar se ao colocar o cobalto existia alguma diferença nos tamanhos dos grãos formados. O valor do comprimento de onda do SP neste caso não difere do valor para a prata com $55 \mathrm{~nm}$ de espessura.

Zayats diz que o efeito de interferência é causado pela rugosidade no filme, que trabalha como um defeito na amostra. Esta rugosidade mesmo que não seja visível na topográfica pode causar este tipo de interferência ótica. Segundo Zayats a rugosidade pode causar uma diminuição na distância de propagação do SP na superfície da amostra, que também foi constatado por nós e iremos mostrar em um próximo tópico.

\subsection{Análise com o Retrace}

Nesta parte da análise podemos comparar um pouco da previsão teórica para o decaimento exponencial do SP, com comportamento de uma onda evanescente perpendicularmente a superfície da amostra, com os dados experimentais. Como mostrado anteriormente podemos calcular até que distância o SP deveria ser observado pelo SNOM, no modo PSTM. Primeiramente vamos colocar os valores esperados para cada caso para depois analisar em qual deles o experimento concorda com a teoria. 
A distância sonda-amostra para qual a intensidade do SP deve decair para 1/e pode ser calculado pelo valor de $L_{z i}$, como descrevemos no capítulo teórico. Estes valores são encontrados na tabela 5.5.1. Os valores não são muito diferentes entre si.

\begin{tabular}{|c|c|}
\hline Amostra & $\mathrm{L}_{\text {zi }}(\mathrm{nm})$ \\
\hline $55 \mathrm{~nm} \mathrm{Ag}$ & 458 \\
\hline $55 \mathrm{~nm} \mathrm{Ag}+0,5 \mathrm{~nm}$ Co & 456 \\
\hline $55 \mathrm{~nm} \mathrm{Ag}+3 \mathrm{~nm} \mathrm{Co}$ & 453 \\
\hline
\end{tabular}

Tabela 5.5. 1 distância de decaimento evanescente $\left(L_{z i}\right)$ do campo perpendicular a interface para diferentes amostras.

$\mathrm{Na}$ figura 4.5.1 temos uma amostra de prata de $55 \mathrm{~nm}$. A varredura foi interrompida na direção perpendicular à propagação do SP, assim permanecendo estável no tempo o perfil do sinal ótico do SP. Em 4.5.1(2) vemos a propagação do SP com a ponta em regulação, e em (1) a imagem com o modo retrace. Podemos considerar que a distância sonda-amostra em regulação não deve passar de $20 \mathrm{~nm}$. Como pode ser observado na imagem de retrace o SP é observado muito bem até a imagem (f) que é obtida a $320 \mathrm{~nm}$ da amostra. Na imagem (g) com a sonda a 400nm da amostra vemos somente o centro de incidência. E em (h), (i) e (j) o SP fica imperceptível. Como (h) está em $480 \mathrm{~nm}$ e os outros dois acima disto, podemos dizer que este resultado está de acordo com o modelo teórico. Pois para distâncias acima de 450nm, o SP deveria decair para 1le. E em (k) a 20nm da amostra voltamos a observar a propagação do SP. 


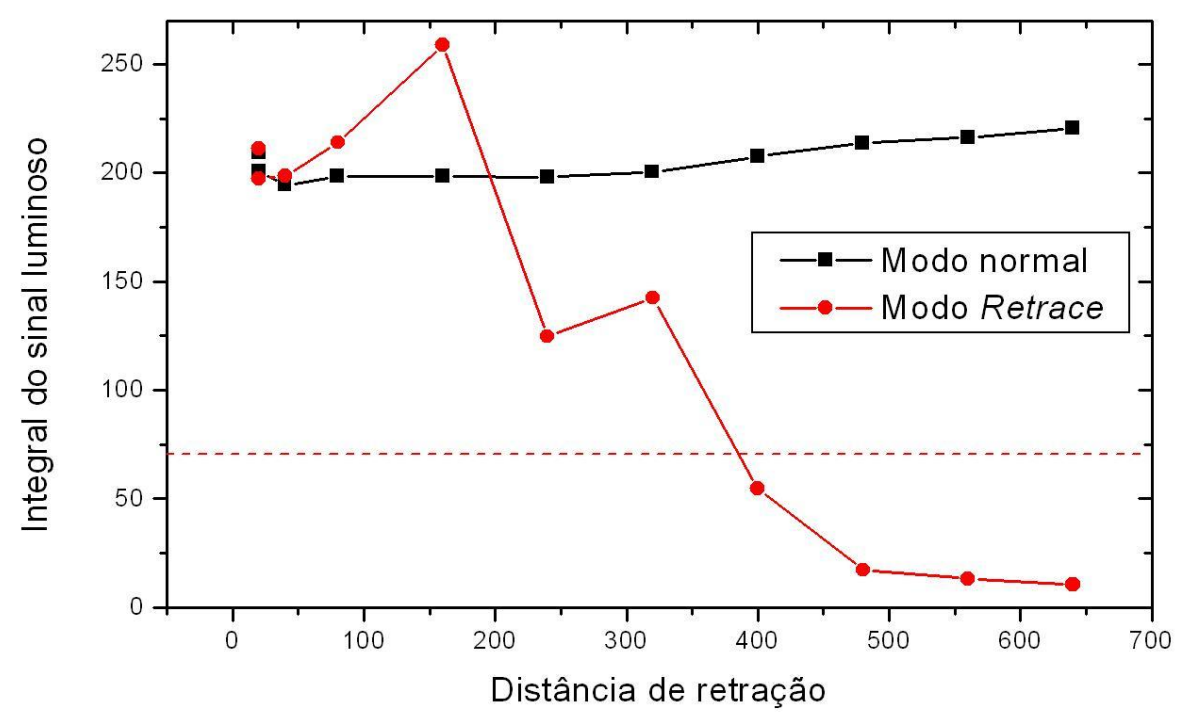

Figura 5.5.1 Sinal luminoso pela distância do retrace.

Na figura 5.5.1 temos um gráfico que ilustra melhor a discussão acima. O que denominamos "Sinal luminoso" é a área do perfil do sinal ótico para cada uma das retrações feitas na figura 4.5.1. Os pontos experimentais em preto são aqueles que a ponta está em regulação, já em vermelho vemos os pontos experimentais que a ponta está retraída. Pelos pontos em regulação vemos que existe um aumento de não mais que $5 \%$ do valor inicial. Isto é visto, pois com a retração da ponta para a segunda imagem, não se pode garantir que a ponta volte a mesma distância da imagem anterior. Porém como podemos ver a variação é muito pequena. Pela imagem em retração podemos ver um decaimento do sinal luminoso conforme mais afastada a sonda esteja da amostra. A linha vermelha tracejada é o sinal luminoso com amplitude de 1/e. A distância com a qual experimentalmente o sinal decai para 1/e é de $380 \mathrm{~nm}$, vemos isto com a interceptação da linha tracejada com os dados experimentais. Isto demonstra que os dados experimentais se comportam muito bem com a teoria, como vimos anteriormente o valor teórico desta distância deveria ser $450 \mathrm{~nm}$. Um ponto interessante desta figura é ver que existe uma oscilação do sinal luminoso nos dados de retração. Isto fica evidente no intervalo entre $80 \mathrm{~nm}$ e $320 \mathrm{~nm}$. De $80 \mathrm{~nm}$ para 
$160 \mathrm{~nm}$ existe um aumento do sinal luminoso que também pode ser visto na imagem 4.5.1. Em 240nm existe uma diminuição do sinal e depois em 320 existe novamente um aumento. Não temos ainda uma explicação concreta para este fato, porém este pode ser mais um dos efeitos da onda incidente não ser plana.

Os defeitos nas amostras também podem ser analisados melhor com 0 modo retrace. Na figura 4.5.2(a) vemos a imagem ótica em regulação e em (b) o retrace a 700nm de distância. Duas coisas podem ser analisadas nesta figura: primeiro que os defeitos que espalham a luz podem ser notados em campo distante, e segundo que os feixes de luz que se formam após o defeito são efeitos da propagação do SP. Isto pode ser notado no modo retrace com 700nm de distância, onde o SP propagando desaparece. No entanto, os pontos de espalhamento (defeitos) continuam visíveis na imagem obtida com o modo retrace.

Ainda sobre este mesmo assunto podemos analisar a figura 4.5.3. $\mathrm{Na}$ imagem topográfica(c) vemos que existem alguns defeitos que foram circulados em preto. A imagem ótica normal (a) apresenta a propagação do SP e na imagem com retrace (b) podemos ver os mesmos defeitos da topográfica circulados em branco.

O começo da imagem de retrace foi feito com 50nm de distância pontaamostra, vemos que o centro de incidência do SP está como observado nas imagens normais. Na segunda faixa da imagem temos uma retração de 300nm, nesta parte já notamos que o centro de incidência fica bem menos claro que na imagem normal. Por fim com a retração em 700nm as análises feitas acima podem ser novamente vistas. O fato da retração estar a 700nm de distância e na sua imagem não ser possível mais ver o feixe de luz se propagando, confirma que esta propagação tem o caráter de onda evanescente, como o SP na superfície da amostra. Um segundo ponto importante é a possibilidade de encontrar defeitos na amostra por esta técnica. Logo no começo da imagem com retração a 700nm vemos um ponto que espalha luz, que está circulado em branco, ele corresponde exatamente a um dos defeitos visto na imagem topográfica, que está circulado em preto. Mais ao fim da varredura vemos outro ponto mais 
escuro, que também se relaciona a outro defeito na amostra. Portanto comprovando que o SP só pode ser visto em campo próximo, porém a luz espalhada pode ser vista em campo distante. Mais uma vez comprovando a eficiência do nosso método em acoplar SP nas amostras.

Destas últimas figuras analisadas vale ressaltar que eram amostras de prata com cobalto. Demonstrando que mesmo com uma camada de cobalto o filme de prata não perde a característica de acoplar SP.

Por último vamos analisar a imagem com interferência ótica através do modo retrace. Queremos tentar concluir se esta interferência tem alguma relação com o acoplamento do SP. Na figura 4.5.4 para o filme de $55 \mathrm{~nm}$ de prata com $0,5 \mathrm{~nm}$ de cobalto vemos em (1) a imagem ótica com retrace e em (2) a ótica em regulação.

A imagem de retrace começa em (a) com $800 \mathrm{~nm}$, na comparação das duas imagens podemos ver que na ótica normal existe a interferência, já no retrace ela não aparece. De (b) a (f) vemos o padrão de interferência em ambas as imagens. Em (g) a 300nm já vemos que o padrão começa a perder a definição. Em (h) o padrão é quase imperceptível, e após isto o padrão já não é mais visto. Como (i) está a 420nm, (j) a 500 e (k) a 700nm era esperado que se este padrão fosse uma conseqüência do SP ele sumiria. E foi exatamente isto que constatamos, que a partir de $420 \mathrm{~nm} o$ padrão não pode ser visto. Este resultado é muito importante porque pode indicar que este padrão de interferência tem como uma de suas causas o próprio SP. Isto nos leva a crer que é uma conjunção entre a rugosidade do material e o próprio comprimento de onda do SP.

Portanto devido a este estudo com retrace pudemos esclarecer alguns pontos quanto as características do SP e também a confirmação de que nas imagens obtidas temos uma propagação plasmônica. 


\subsection{Distância de propagação}

Para finalizar esta análise vamos discutir sobre a distância de propagação $\left(\mathrm{L}_{\mathrm{i}}\right)$ do SP na superfície da amostra. Iremos comparar os valores teóricos e experimentais e discorrer sobre possíveis problemas encontrados.

Tipicamente é de se esperar que a propagação do SP respeite uma lei exponencial. Para extrair o valor experimental da distância de propagação (Lexp) utilizamos de dois métodos de ajustes exponenciais. No primeiro método consideramos que a propagação do SP e a luz espalhada no ponto de incidência luminosa podem ser descritas por uma única exponencial do tipo:

$$
I=I_{0} e^{-\frac{x}{L}}
$$

5.61

O valor de L é a distância de propagação experimental.

No segundo método consideramos que existem duas exponenciais, uma que representa o espalhamento luminoso no ponto de incidência luminosa e outra que representa a propagação do SP. A expressão para este caso é:

$$
I=I_{1} e^{-\frac{x}{L_{1}}}+I_{2} e^{-\frac{x}{L_{2}}}
$$

5.62

Onde $L_{1}$ é a distância de propagação do centro de incidência e $L_{2}$ é a distância de propagação do SP. Após ajustar os dois modelos aos nossos dados notamos que o segundo ajuste tem melhor qualidade que o primeiro ajuste. Nos gráficos a seguir mostraremos os dados experimentais (pontos pretos), o primeiro método de ajuste (linha contínua azul), o segundo método de ajuste (linha contínua vermelha) e também as duas exponenciais do segundo ajuste separadas. A exponencial referente ao centro de incidência 
(linha tracejada laranja) e a exponencial referente ao SP (linha tracejada verde).

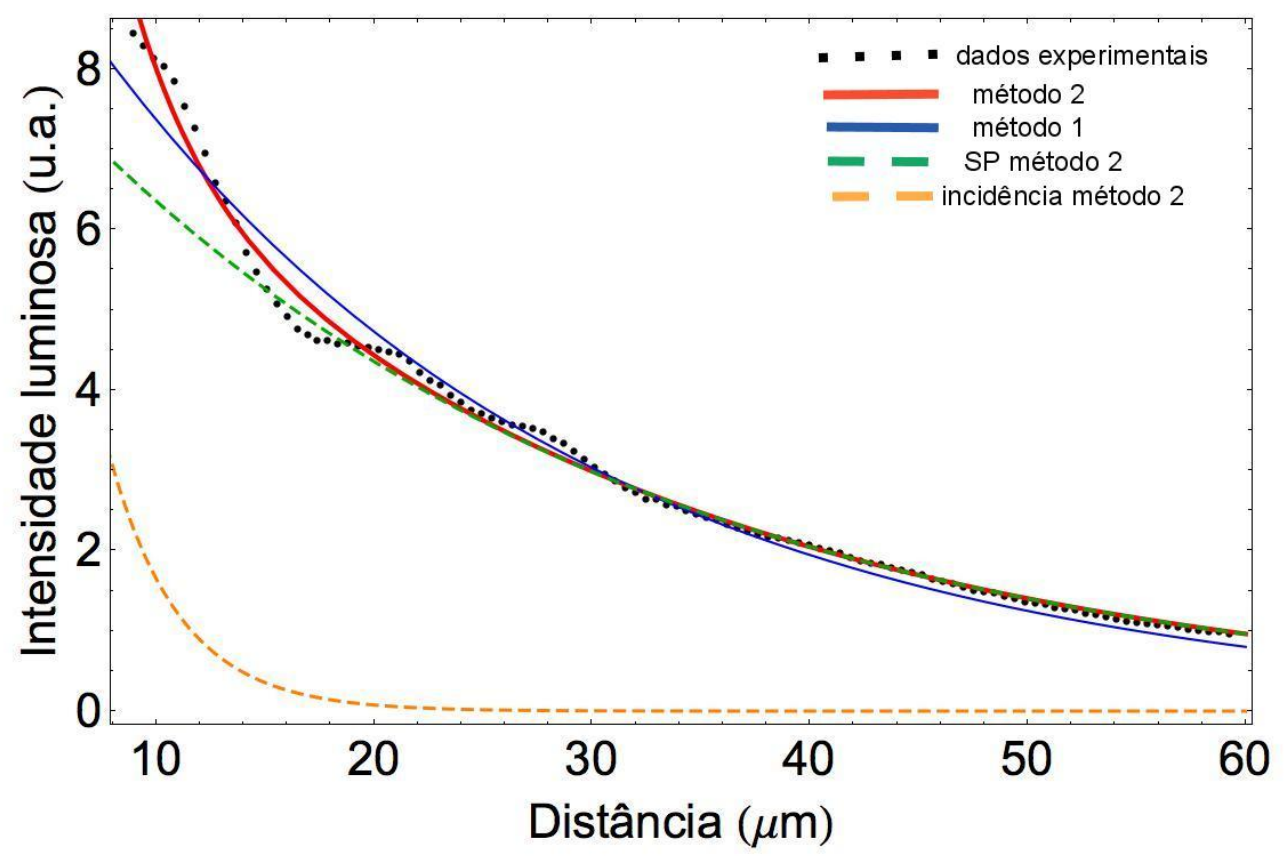

Figura 5.6.1 Distância de propagação para a amostra de $55 \mathrm{~nm}$ de prata.

Começaremos com o estudo do caso da prata com 55nm com laser vermelho. No gráfico 5.6.1 temos a queda de intensidade luminosa com a distância em y. Como pode ser visto no gráfico o ajuste pelo primeiro método (linha azul) não descreve corretamente os dados experimentais, não convergindo no começo dos dados, que representam a incidência luminosa, nem o final dos dados, que representa a propagação do SP. Já o ajuste pelo segundo método (vermelho) descreve muito bem os pontos experimentais, dando conta da incidência luminosa e também do final da propagação do SP. Pelo ajuste em laranja fica evidente que o centro de incidência rapidamente vai a zero e depois disto o que prevalece é a propagação do $\mathrm{SP}$, que pode ser vista pelo ajuste em verde. Portanto este segundo método ajusta melhor aos nossos dados.

Para o primeiro método de ajuste o valor da distância de propagação experimental ( $L_{\text {exp1 }}$ ) encontrada é de $22,5 \mu \mathrm{m}$. E para o segundo ajuste os valores encontrados para a distância de propagação do centro luminoso $\left(L_{1}\right)$ e do SP $\left(L_{2}\right)$ são respectivamente $3,3 \mu \mathrm{m}$ e $26,5 \mu \mathrm{m}$. O valor calculado pelo 
modelo do Raether (Raether, 1988) nos fornece um valor de $L_{i}=46,3 \mu \mathrm{m}$. O valor teórico e experimental não são compatíveis e uma das razões para isto é o fato da amostra não ser completamente lisa, pois existem grãos. Estes grãos que possivelmente causam a interferência ótica também fazem com que a distância de propagação diminua consideravelmente, neste caso de um fator de 1,75. Este mesmo tipo de resultado pode ser encontrado no artigo do Zayats. Este efeito pode ser correlacionado com a perda devida ao espalhamento luminoso nos defeitos.

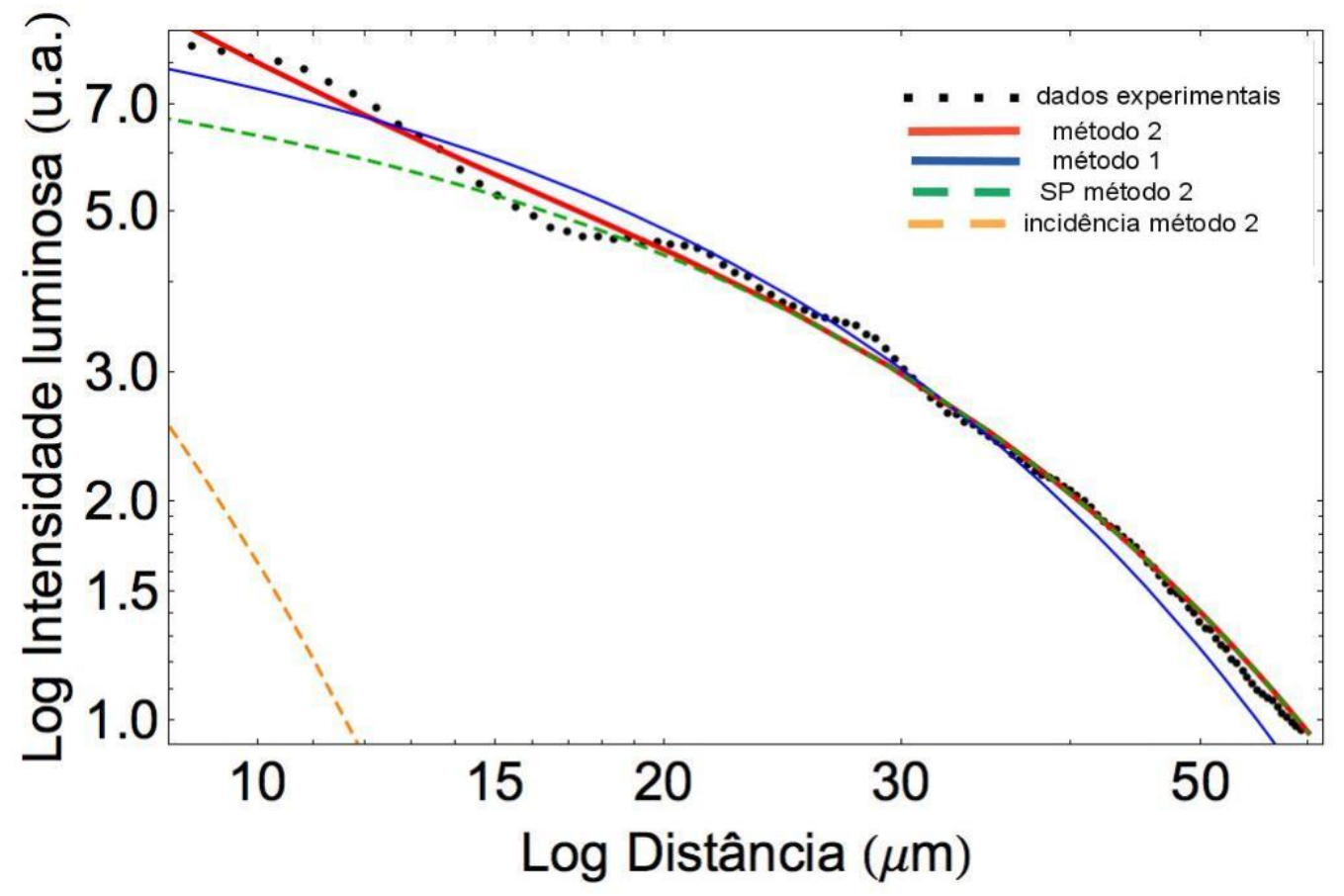

Figura 5.6.2 Distância de propagação para a amostra de $55 \mathrm{~nm}$ em escala log.

Apesar dos valores experimentais para os dois métodos não serem tão diferentes, se analisarmos em escala logarítmica os dois ajustes as diferenças entre os dados experimentais e os ajustes ficam mais evidentes. Isto pode ser visto no gráfico da figura 5.6.2 em que o ajuste em vermelho descreve perfeitamente os dados experimentais, e o ajuste em azul não descreve adequadamente nem o começo e nem o final dos dados.

No gráfico 5.6.3 vemos os decaimentos exponenciais para diversas amostras. Vemos o decaimento para amostra de $55 \mathrm{~nm}$ de prata (azul claro), 
$55 \mathrm{~nm}$ de prata com $1 \mathrm{~nm}$ de cobalto (verde clara); $55 \mathrm{~nm}$ de prata com $3 \mathrm{~nm}$ de cobalto (curva verde escura); $55 \mathrm{~nm}$ de prata com $10 \mathrm{~nm}$ de cobalto (curva amarela); e $55 \mathrm{~nm}$ de ouro (curva azul escura) todas essas com o laser vermelho. Também vemos para o laser violeta as amostras: $55 \mathrm{~nm}$ de prata (curva preta) e $55 \mathrm{~nm}$ de prata com $10 \mathrm{~nm}$ de cobalto (curva laranja).

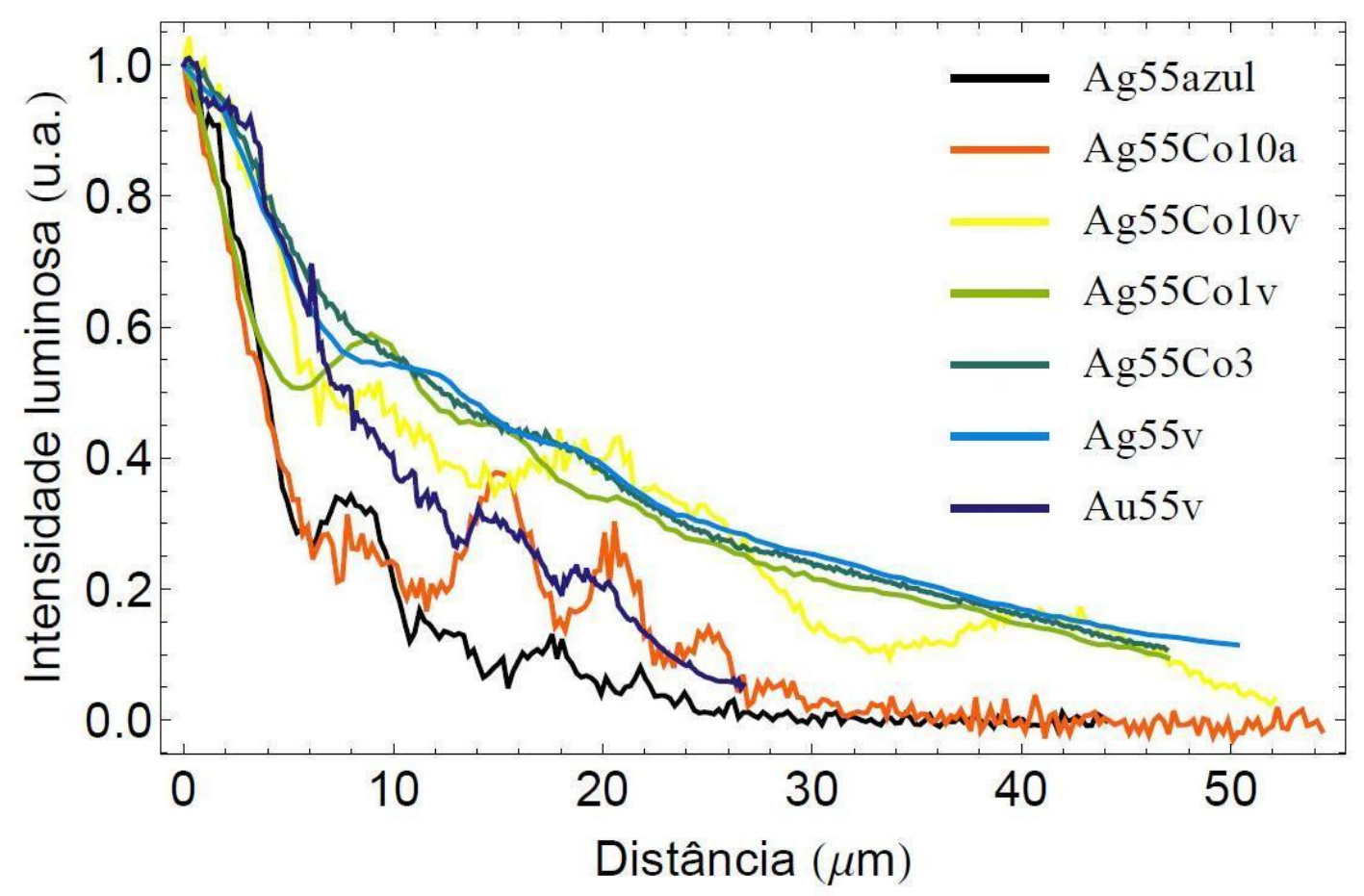

Figura 5.6.3 Distância de propagação experimental.

Para todas as amostras foi feito o mesmo ajuste que para a prata com $55 \mathrm{~nm}$, no gráfico 5.6 .4 vemos os dados experimentais juntamente com os ajustes pelos dois métodos. 


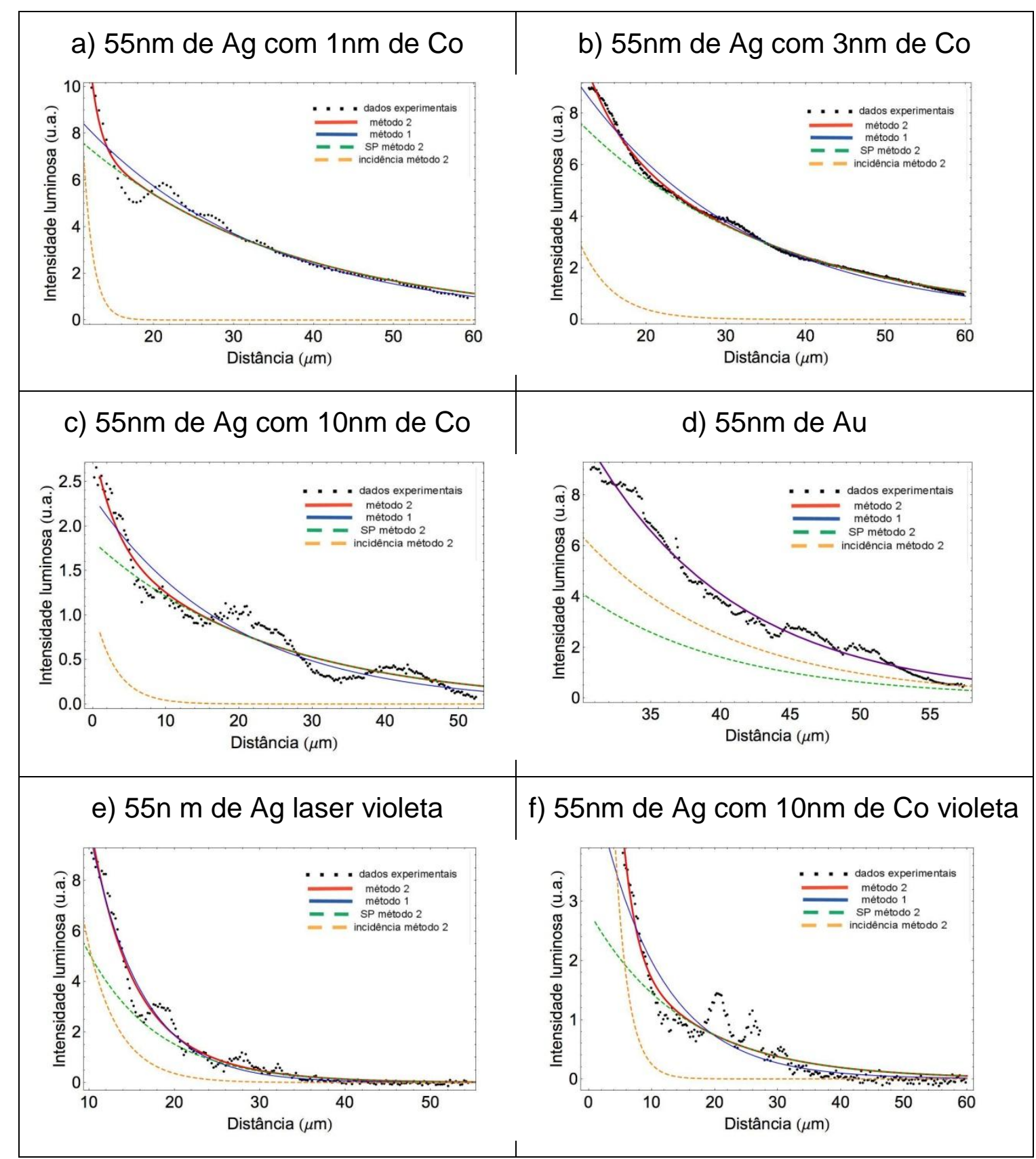

Figura 5.6.4 Distância de propagação do plasmon de superfície para diversas amostras.

Foi obtido também para cada curva o valor da sua distância de propagação experimental. Os valores encontrados para cada uma das exponenciais estão listados na tabela 5.6.1, juntamente com os valores teóricos calculados pelo modelo de Raether. 


\begin{tabular}{|c|c|c|c|c|}
\hline Amostra & $\mathrm{L}_{\text {exp1 }}(\mu \mathrm{m})$ & $\mathrm{L}_{1}(\mu \mathrm{m})$ & $\mathrm{L}_{2}(\mu \mathrm{m})$ & $\mathrm{L}_{i}(\mu \mathrm{m})$ \\
\hline Ag55 vermelho & 22,5 & 3,2 & 26,5 & 46,3 \\
\hline Ag55Co1 vermelho & 22,9 & 1,2 & 25,7 & 32,6 \\
\hline Ag55Co3 vermelho & 20,9 & 4,1 & 24,6 & 22,7 \\
\hline Ag55Co10 vermelho & 19,1 & 3,1 & 24,1 & 10,4 \\
\hline Au55 vermelho & 10,5 & 10,5 & 10,5 & 9,4 \\
\hline Ag55 violeta & 6,0 & 3,7 & 8,2 & 2,5 \\
\hline Ag55Co10 violeta & 10,0 & 2,1 & 14,8 & 0,8 \\
\hline
\end{tabular}

Tabela 5.61 Distância de propagação experimental pelo método $1\left(L_{\exp 1}\right)$, Distancia de propagação experimental pelo método 2: centro de incidência $\left(L_{1}\right)$ e do $\operatorname{SP}\left(L_{2}\right)$ e teórica $\left(L_{i}\right)$.

Como vemos os valores teóricos e experimentais não são condizentes, isto reforça ainda mais o proposto anteriormente de que esta diminuição na distância de propagação experimental está relacionado com a rugosidade do material. O que corrobora para este fato é que a amostra de ouro é bem mais lisa que as amostras de prata e a diferença entre a distância de propagação experimental e teórica do ouro é muito menor que as de prata. Para o ouro temos $L_{\text {exp }}=10,5 \mu \mathrm{m}$ que é igual para os dois métodos e $\circ \mathrm{L}_{\mathrm{i}}=$ $9,4 \mu \mathrm{m}$. Enquanto para a prata os valores são mais discrepantes. O mesmo foi visto no artigo do Zayats e isso reafirma nossos resultados.

Outro ponto importante para se notar é o fato da distância de propagação do centro de incidência ser da ordem de alguns micrometros. Portanto mostrando que o decaimento do centro de incidência fazia diferença quando ajustada a distância de propagação pelo modelo 1.

O que pode ser visto nestes dados é que existe um decréscimo na distância de propagação com o aumento da camada de cobalto, porém este decréscimo é menor que $10 \%$ do valor da distância de propagação. Isto mostra um caráter importante, que apesar de depender da espessura da camada de cobalto, quem realmente interfere nesta distância é a camada de 
prata. Este tipo de resultado não é encontrado na literatura para comparação.

Para o cálculo teórico dos filmes de prata com cobalto foi usado um método de aproximação. Para isto se usou uma média ponderada entre a espessura da prata e sua permissividade e a espessura do cobalto e sua permissividade (Johnson, et al., 1974), para se obter a permissividade da amostra de prata com cobalto. Apesar de aparentar ser uma boa aproximação para o cálculo teórico, vemos que o decréscimo da distância de propagação teórica é muito maior que o decréscimo da distância de propagação experimental. Chegando ao caso extremo na amostra de $55 \mathrm{~nm}$ de prata com $10 \mathrm{~nm}$ de cobalto, onde a distância teórica é muito menor que a distância experimental.

Para o laser violeta vemos que os dados experimentais estão acima dos dados teóricos. Podemos dizer que esperávamos que o acoplamento com ele fosse pior que com o vermelho, como efetivamente acontece. Porém não temos uma explicação razoável pelas discrepâncias nos resultados.

Finalizamos assim as análises experimentais desta dissertação. No próximo capítulo falaremos sobre as conclusões deste trabalho e por fim as perspectivas futuras para o doutorado. 


\section{Conclusões}

As conclusões que podemos chegar ao fim deste trabalho são:

- Após os melhoramentos do SNOM além de ser possível varredura em maior escala, o equipamento também se tornou mais estável. Assim conseguindo imagens topográficas e óticas com menos ruído e de melhor qualidade.

- O desenvolvimento do modo PSTM para o nosso equipamento nos permitiu imagens óticas, na configuração Krestchmann, da propagação do SP para diversas amostras.

- A inclusão de um segundo laser $(405 \mathrm{~nm})$ permitiu para o SNOM uma maior versatilidade. Através deste novo laser pudemos averiguar a qualidade dos SPs com dois comprimentos de ondas diferentes. Alem disto, o equipamento agora permite fazer litografia ótica de escrita direta por causa desta inclusão.

- O SNOM demonstrou ser o equipamento ideal para a visualização do SP em campo próximo. Obtivemos resultados impressionantes para a propagação do SP em diferentes materiais. Isto abre uma grande quantidade de possibilidades de experimentos para 0 equipamento.

- Os resultados do SP mostraram uma grande eficiência em encontrar defeitos em amostras. Isso é muito interessante quando se precisa saber se a amostra é lisa e sem defeitos.

- Usar o SP para amplificar o sinal magnético pode ser uma ótima idéia para refinar a caracterização magnética de uma amostra. Portanto precisamos melhorar o equipamento para termos confiança nos resultados obtidos.

- O SNOM demonstrou ter uma resolução ótica muito melhor do que esperávamos. Nas imagens óticas de interferência podemos ver que sua resolução ótica deve ser menor que 100nm.

- Por fim concluímos que após a análise da propagação do SP podemos ver que a sua estrutura é muito mais complexa do que imaginávamos. Podemos ver a propagação de longo alcance 
(maior que $70 \mu \mathrm{m}$ ), podemos ver as interferências óticas de grande e pequena escala e ainda podemos ver o efeito do SP quando encontra um defeito na amostra. Isto tudo foi muito enriquecedor para o aprendizado sobre a propagação do SP na superfície de um material. 


\section{Perspectivas futuras}

Devido aos resultados obtidos neste mestrado abriram-se novas áreas de aplicação para o SNOM. Abaixo irei listar as expectativas futuras para o doutorado.

- A qualidade dos resultados plasmônicos levantou a possibilidade de refinar ainda mais este tipo de medida. Como primeira perspectiva, temos a continuação deste tipo de pesquisa. Investindo agora em guias de ondas plasmônicos.

- Para tentarmos refinar os resultados obtidos para a propagação do SP existe a possibilidade de produzir amostras de prata ou ouro com baixa taxa de deposição e submetendo a amostra a um tratamento térmico. Visamos a partir disto conseguir uma amostra mais lisa, sem a rugosidade que apresentou neste trabalho.

- Vem sendo desenvolvido em paralelo um estudo de fluorescência ótica com o SNOM. E temos a idéia de usar o SP para aumentar o sinal de fluorescência medido com o SNOM.

- Como dito anteriormente usando um FIB para perfurar a abertura da sonda, podemos melhorar as imagens óticas obtidas, porque as sondas terão menor abertura. Esta é uma pesquisa que temos muito interesse em começar para poder refinar os resultados obtidos.

- Nos resultados magnéticos temos a necessidade de melhorar o arranjo experimental. Portanto pretendemos para um próximo passo construir estruturas magnéticas dentro do filme de prata. Podendo assim encontrar paredes de domínios magnéticos com maior facilidade. Resolvendo o problema das medidas magnetoóticas no SNOM que ficou em aberto. Também procuraremos por uma solução para a incidência da luz, visando obter homogeneidade na iluminação da amostra.

- Por fim, usar o SNOM para medidas do tipo SERS (Surface enhanced Raman spectroscopy) onde os SPs podem melhorar os sinais de espectroscopia Raman. 


\section{Referências}

Bouhelier A., Wiederrecht G. P. Excitation of broadband surface plasmon polaritons:

Plasmonic continuum spectroscopy // Phys. Rev. B. - 2005. - Vol. 71. - p. 195406.

Bouhelier A., Wiederrecht G.P. Surface plasmon rainbow jets // Opt. Lett.. - 2005. - Vol. 30. pp. 884-886.

Dawson P., Fornel F. , Goudonnet J.P. Imaging of Surface Plasmon Propagation and Edge Interaction Using a Photon Scanning Tunneling Microscope // Phys. Rev. Let.. - 1994. - Vol. 72. pp. 2927-2930.

Devaux E. [et al.] Lauching and decoupling surface plasmons via micro-gratings // Appl. Phys. Lett.. - 2003. - Vol. 83. - p. 4936.

Johnson P. B., Christy R. W. Optical Constants of the Noble Metals // Phys. Rev. B. - 1972. Vol. 6. - pp. 4370-4379.

Johnson P.B., Christy R.W. Opitcal constants of transition metals: Ti, V, Cr, Mn, Fe, Co, Ni and Pd // Phys. Rev. B. - 1974. - Vol. 9. - pp. 5056-5070.

Krestchmann E. , Raether H. Radiative decay of non-radiative surface plasmons excited by light // Z. Naturforschung. - 1968. - Vol. 23A. - pp. 2135-2136.

Maier S. A. Plasmonics Fundamentals and Applications [Livro]. - [s.l.] : Springer, 2007.

Mayer K. M. , Hafne J. H. Localized Surface Plasmon Resonance Sensors // Chem. Rev. - 2011. Vol. 111. - pp. 3828-3857.

Nanotec [Online]. - http://www.nanotec.es/.

NC STATE University [Online]. - 2000. -

http://www.physics.ncsu.edu/optics/nsom/NSOMintro.html.

Otto A. Excitation of nonradiative surface plasma waves in silver by the method of frustrated total reflection // Z. Physik. - 1968. - Vol. 216. - pp. 398-410.

Pojar, M. Estudo das Propriedades Magnéticas de um objeto microestruturado através do SNOM-MO // Tese de Doutorado. - 2008.

Raether H. Surface Plasmons on Smooth and Rough Surfaces and on Gratings. - [s.l.] : SpringerVerlag, 1988.

Rayleigh L. On the theory of optical images, with special reference to the microscope. - [s.I.] : Philos. Mag., 1896. - Vol. 5. - pp. 167-195.

Ritchie R.H. Plasma losses by fast electrons in thin films [Artigo] // Phys. Rev.. - 1957. - 106. pp. 874-881.

Rycenga M. [et al.] Controlling the Synthesis and Assembly of Silver Nanostructures for Plasmonic Applications // Chem. Rev.. - 2011. - Vol. 111. - pp. 3669-3712. 
Schoenmaker J., Lancarotte M. S., Seabra A. C., Souche Y., Santos A. D. Magnetic Characterization of Microscopic Particles by Mo-SNOM // J. Microscopy. - 2004. - Vols. 214-1. pp. 22-26.

Schoenmaker J., Lancarotte M. S., Seabra A.C., Sampaio L.C., Souche Y., Santos A.D. Local magnetic study through magneto-optics and scanning near-field optical microscopy // Acta Microscopica. - 2003. - Vols. 12-A.

Schoenmaker J. Desenvolvimento de um Microscópio Óptico e Magnetoóptico de Varredura em Campo Próximo // Tese de Doutorado. - 2005.

Verhagen E., Spasenovic M., Polman A., Kuipers L. Nanowire Plasmon Excitation by Adiabatic Mode Transformation // Phys. Rev. Let. 2009 -Vol. 102- pp. 203904-1- 203904-4

Zayats A V.,Smolyaninov I. I Near-field photonics: surface plasmon polaritons and localized surface plasmons // J. Opt. A: Pure Appl. Opt.. - 2003. - Vol. 5. - pp. S16-S50. - S16-S50.

Zayats A. V., Smolyaninov I. I. e and Maradudinc A. A. Nano-optics of surface plasmon polaritons // Phys. Reports. - 2005. - pp. 131-314. 


\section{Apêndice I}

Resultados acadêmicos deste trabalho de mestrado:

\section{Participações em eventos científicos}

- Apresentei um pôster intitulado: "SNOM: from lithography process to Magnetic characterization" em 2010 no "IX ENCONTRO DA SBPMAT".

- Apresentei um pôster intitulado: "Magneto-Optical Scanning NearField Optical Microscopy" em 2009 no "Workshop e Escola Avançada em Nanoplasmônica".

- Apresentei um pôster intitulado: "Magnetic characterization and lithography process using MO-SNOM" em 2010 no "XXXIII ENCONTRO NACIONAL DE FÍSICA DA MATÉRIA CONDENSADA".

\section{Publicações científicas}

Os próximos dois meses serão dedicados à redação e submissão de artigos científicos com os resultados apresentados nesta dissertação de mestrado. 